\title{
Factor Based Commodity Investing ${ }^{1}$
}

\author{
Athanasios Sakkas ${ }^{2}$, Nikolaos Tessaromatis ${ }^{3}$
}

March 2020

Journal of Banking and Finance, forthcoming

\begin{abstract}
A multi-factor commodity portfolio combining the momentum, basis, basis-momentum, hedging pressure and value commodity factor portfolios outperforms significantly, economically and statistically, widely used commodity benchmarks. We find evidence that a variance timing strategy applied to commodity factor portfolios generates timing gains for the commodity momentum factor but not the other commodity factors. Dynamic commodities strategies based on commodity factor return prediction models provide little value added.
\end{abstract}

JEL Classification: G11, G12

Keywords: Commodities, Factor Premia, Momentum; Basis, Basis-Momentum, Variance Timing, Commodity Return Predictability

\footnotetext{
${ }^{1}$ The authors are grateful to the Editor, an Associate Editor, and two anonymous referees for their constructive comments. Furthermore, the paper has benefited from comments by participants at the Financial Management Association, San Diego, US 2018, European Financial Management Association, Milan, Italy 2018 and Commodity and Energy Markets Association Annual Meeting, Rome, Italy 2018. Any remaining errors are the responsibility of the authors.

${ }^{2}$ Contact address: Nottingham University Business School, University of Nottingham, Nottingham, UK. Tel: $+44(0)$ 115 9515264. Email: athanasios.sakkas@nottingham.ac.uk

${ }^{3}$ Contact address: EDHEC Business School and EDHEC Risk Institute, Nice, France. Tel: +44(0) 2073325605. Email: nikolaos.tessaromatis@edhec.edu
} 


\section{Introduction}

There is growing evidence that commodity investment strategies based on exposures to commodity fundamental characteristics earn significant risk premiums, in addition to the premium offered by a broadly diversified commodity index. Choosing among the proposed commodity factors those that are priced is important for both commodity pricing and commodity portfolio management. Building on existing research on the pricing of commodity factors we identify priced commodity factors, use them to create an optimal passive multifactor commodity portfolio and examine the efficiency gains achieved compared to widely used commodity benchmarks. Assuming that commodity risk premiums are time varying, we also explore the possible benefits from dynamic strategies that rotate between commodity factors based on commodity variance timing and commodity return forecasting models.

Research shows that commodity investment strategies based on exposures to commodity fundamental characteristics such as the basis, momentum, basis-momentum, value, inflation, hedging pressure, volatility, speculative pressure, skewness, dollar beta and liquidity outperform commercially available commodity indices such as the S\&P GSCI or a passive equally weighted index of all commodities. ${ }^{4}$ A number of recent studies provide evidence on pricing of the basis (Szymanowska et al. 2014), the basis and the average commodity (an equally weighted portfolio of all commodities) factor (Yang, 2013), the basis ${ }^{5}$, commodity momentum and the average commodity factor (Bakshi, Gao and Rossi, 2019), and the average commodity factor and basis-

\footnotetext{
${ }^{4}$ Miffre (2016), provides a comprehensive review of the literature of the performance of various investment strategies in commodity futures markets. Fernandez-Perez, Fuertes and Miffre (2019), examine the performance of the combination of five long/short strategies in equity index, fixed income, currency, and commodity futures markets.

${ }^{5}$ Bakshi, Gao and Rossi (2019) argue that the basis factor provides to investors compensation for the low returns of the factor during periods of high global equity volatility while the momentum factor tends to do well when aggregate activity increases.
} 
momentum ${ }^{6}$ (defined as the difference in momentum signals of first and second nearby futures contracts) factor (Boon and Prado, 2019) in the cross section of commodity returns. In contrast, Daskalaki, Kostakis and Skiadopoulos (2014), in a comprehensive study of the pricing of commodity futures, find that neither macro-economic nor equity nor commodity factors price commodity futures. They attribute the difference in results obtained compared with other studies to the use as test assets commodity portfolios rather than individual commodities. Identifying a small number of priced commodity factors from many possible factor candidates remains a challenge (see also Skiadopoulos, 2013).

While capturing commodity risk premia requires the construction of passive portfolios with the desired exposure to commodity factors, timing commodity returns presupposes the ability to predict commodity returns and risk and calls for the design of dynamic trading strategies that rotate between the factors. Hong and Yogo (2012) provide evidence on the predictability of individual commodity futures using the short-term interest rate and the term premium, financial variables used in the stock and bond forecasting literature. ${ }^{7}$ In an out-of-sample study of individual commodity and a basis-based commodity portfolio predictability, Ahmed and Tsvetanov (2016) find weak evidence that conditional and unconditional forecasts of the average commodity portfolio and the basis factor, predict future commodity returns. Commodity return forecasts generate no economic gain to investors who use the predictions to build commodity timing strategies. Daskalaki, Skiadopoulos and Topaloglou (2017) test the predictive ability of the dividend yield, Treasury bill yield, default spread, term spread, industrial production, money

\footnotetext{
${ }^{6}$ The basis-momentum factor proposed by Boons and Prado (2019) cannot be explained by the classical theories of storage (Kaldor, 1939), backwardation (Keynes, 1930) or hedging pressure (Cootner, 1960, 1967) but represents compensation for commodity volatility risk.

${ }^{7}$ Chen, Rogoff and Rossi (2010) show that "commodity currencies" predict the price of the commodity produced by the countries of these currencies. Bork, Kaltwasser and Sercu (2014) argue that the results are not robust to variations in the test design and the use of average rather than end of period prices of the commodity indexes used.
} 
supply growth and the growth in the Baltic Dry Index for equities, bonds and commodity indices. They find that equities and bonds can be predicted by some of the predictors but no evidence of commodity index return predictability. Gao and Nardari (2018) in contrast, using a forecast combination approach to predict equity, bond and commodity returns and the dynamic conditional correlation model of Engle (2002) to predict risk, find that the addition of commodities to the traditional stock-bond-cash asset mix improves utility. The evidence on the predictability of commodity returns is as controversial as the evidence on the predictability in equity markets.

Our study focuses on four questions. First, which commodity factors are priced? Existing evidence on commodity pricing supports a four-factor model that includes the average commodity factor and the basis, momentum and the basis-momentum factors. Whether the other proposed factors are priced or are redundant in the presence of the factors from the four-factor model is an open question. The question is particularly important when considering the implications of multiple priced factors in the creation of optimal multifactor portfolios. We use the testing methodology proposed by Barillas and Shanken (2017) and applied in Fama and French (2018), and the methodology developed by Harvey and Liu (2019) to test whether four or more commodity factors are priced in commodity markets. Based on the evidence and theoretical justification provided by Yang (2013), Szymanowska et al. (2014), Bakshi, Gao and Rossi (2019) and Boons and Prado (2019) we (a) use as baseline a four-factor model to confirm the pricing of the average commodity portfolio, the basis, momentum and basis-momentum factors and (b) test the pricing of commodity factor portfolios exposed to value, inflation, open interest, hedging pressure, volatility and skewness.

Second, what is the optimal commodity portfolio when commodity returns are driven by multiple commodity factors? In the presence of multiple priced commodity factors the investor 
should hold a multi-factor portfolio (Fama, 1996, Cochrane, 1999). The task of the paper is to use the commodity priced factors to build a well-diversified commodity portfolio. To address the issue of estimation risk, we use alternative portfolio construction methodologies in the factor combination. Consistent with the current practice in benchmark creation, we create portfolios without short positions in individual commodities but we also consider long-short versions that allow for short positions especially since shorting is inexpensive and straight forward in the commodities futures market.

Third, how does the performance of a multi-factor commodity portfolio compare with the performance of existing commodity indices? To address this question, we compare the performance of the multifactor commodity portfolio to existing commodity benchmarks and in particular the S\&P GSCI which represents the leading fully collateralized investable index and is the preferred benchmark for the majority of professionally managed portfolios. We also test whether second and third generation commodity indices used by practitioners as passive commodity investment strategies are spanned by the commodity priced factor portfolios identified in this study.

Fourth, are commodity factor portfolio returns predictable and if so, is it possible to create dynamic factor strategies that outperform passive commodity factor strategies? To assess the economic benefits of risk and returns predictability we create dynamic investment strategies based on risk or return prediction signals and measure the improvement in performance compared to passive investment strategies.

Our study supports the following conclusions. First, the spanning regressions of Barillas and Shanken (2017) and Fama and French (2018) and the methodology developed by Harvey and Liu (2019) confirm the pricing of the equally weighted portfolio of all commodities, and portfolios 
based on the basis, momentum and basis-momentum commodity factors. The evidence is consistent with a four-factor pricing model for commodities which nests the one-factor model of Szymanowska et al. (2014), the two-factor models of Yang (2013) and Boons and Prado (2019), and the three-factor model of Bakshi, Gao and Rossi (2019). Boons and Prado (2019) also test the pricing performance of a four-factor model that includes, in addition to the average and basismomentum factors, the basis and momentum. Our paper is the first to study whether commodity factors such as value, inflation, hedging pressure, volatility, open interest and skewness are priced against the four-factor model. Spanning tests suggest that from the six additional factors we consider, only value and hedging pressure provide marginal information about commodity average returns and are therefore also priced commodity factors. In the spirit of Huberman and Kandel (1987) we interpret the evidence as suggesting that the mean-variance efficient tangency commodity portfolio is a combination of the average commodity factor and the basis, basismomentum, momentum, value and hedging pressure long/short commodity factor portfolios.

Second, an equally weighted commodity factor portfolio combining the low basis, high momentum, high basis-momentum, high value and high hedging pressure factor portfolios, achieves over the period 1970-2018 a Sharpe ratio of 0.716 that represents a major improvement compared with the return to risk offered by the S\&P GSCI (0.198) and an equally weighted portfolio of all commodities (0.377). The improvement in return-to-risk is significantly better when short positions are allowed in the construction of the commodity factor portfolios (Sharpe ratio 1.253). The multifactor commodity portfolio is superior whether we use portfolio construction methodologies that combine stand-alone commodity factor portfolios (mean-variance, minimum variance, maximum diversification or risk parity) or combine individual commodity characteristics following the cross-sectional regression methodology of Lewellen (2015), to 
construct the multifactor portfolio. Combining individual characteristics into a composite valuation signal enables netting out of trades in individual commodities associated with the rebalancing of different characteristics. DeMiguel, Martin-Utrera, Nogales and Uppal (2019) find significant reductions in turnover and transaction costs when considering all characteristics simultaneously rather than combining standalone factors in the context of stock portfolios.

Third, the factor-based portfolio represents a dramatic improvement compared with the S\&P GSCI, the benchmark used by most institutional investors, ETFs, ETNs and mutual funds. In particular, over the 1970 - 2018 period the S\&P GSCI achieved an annual excess return of 3.90\% compared with an annual excess return of $10.62 \%$ of an equally weighted long-only commodity factor portfolio. The significant outperformance has been achieved with much lower volatility (14.82\% vs. $19.64 \%)$ and is robust across sub-periods, the business cycle and volatility states. The evidence suggests that the S\&P GSCI is unlikely to be on the mean-variance efficient frontier and that switching to the factor-based commodity benchmark increases the return to risk from investing in commodities significantly. The long-only commodity multifactor portfolio offers a better return to risk trade-off than the Dow-Jones-UBS Commodity Index, the Deutsche Bank Liquid Commodity Index (DBLCI), the DBLCI-Optimum Yield, and the Morningstar Long-only Commodity Index.

Finally, we build dynamic factor portfolio timing strategies based on predictions of factor returns and volatility. We find strong evidence suggesting that variance timing works out-ofsample for the long-short commodity momentum premium, consistent with the findings of the success of variance-based timing for equity momentum reported in Barroso and Santa-Clara (2015) but adds little value to passive investments in the long-short basis, basis-momentum, hedging pressure or value factor premiums. Variance timing is profitable for all long-only versions of the 
commodity factors but alphas are marginally statistically significant only for the low basis and high value factors.

We use different approaches to predict commodity factor portfolio returns and find little evidence to suggest that return forecasting adds value once variance timing has been implemented. The failure of return forecasting to add value, consistent with the results reported in Ahmed and Tsvetanov (2016), applies to both long-short and long-only versions of the commodity factor portfolios.

Our findings have important implications for commodity portfolio management. A multifactor commodity portfolio combining the high momentum, the low basis, the high basismomentum, the value and the high hedging pressure commodity portfolios is significantly better than the widely used S\&P GSCI benchmark. The commodity factor portfolio outperforms the S\&P GSCI consistently across sub-periods. The difference in performance is statistically significant and unlikely to be the result of chance. The Harvey and Liu (2019) testing methodology suggests that the S\&P GSCI is not a risk factor. The implication from this finding is that investors should replace the S\&P GSCI with the better diversified and performing portfolio of commodity factors.

The rest of the paper is organized as follows. In Section 2 we describe the data. In Section 3 we discuss the return and risk characteristics of commodities. Section 4 presents the methodologies and results on the question of which commodity factors are priced. Section 5 presents evidence on the optimal commodity portfolio when commodity returns are driven by factors. Section 6 provides evidence on whether commercially available commodity indices are spanned by commodity factor portfolios. Section 7 examines the performance of dynamic tactical commodity 
allocation based on the predictability of commodity return and variance timing. Section 8 concludes.

\section{Data and Variables}

\subsection{Commodity futures data}

We base our analysis on monthly data covering the period January 1970 to August 2018. Our sample starts from January 1970 in order to have a common sample period of our commodity factor with the industry-standard benchmark for commodities investing S\&P GSCI. The commodity monthly futures returns are constructed from end-of-day settlement prices sourced from Commodity Research Bureau (CRB) for commodities traded at the four North American Exchanges (NYMEX, NYBOT, CBOT, and CME) and the Tokyo Commodity Exchange (TOCOM), and Bloomberg for commodities on the London Metals Exchange (LME). Our dataset consists of 38 commodities covering five major sectors, namely, energy, grains \& oilseeds, livestock, metals and softs. Table 1 tabulates the 38 commodities grouped by category, the exchange on which they are traded, the corresponding Bloomberg/CRB ticker symbol, the year of the first recorded observation, the delivery months and the Commodity Futures Trading Commission (CTFC) code. The dataset is comparable with the dataset used by Gorton, Hayashi and Rouwenhorst (2013), Hong and Yogo (2012), Szymanowska et al. (2014) and Bakshi, Gao and Rossi (2019).

Following Gorton, Hayashi and Rouwenhorst (2013) and Yang (2013) we calculate futures monthly excess (of the risk-free rate) returns on a fully collateralized futures position, for each commodity $j$ as $R_{j, t+1}^{T_{n}}=\frac{F_{j, t+1}^{T_{n}}-F_{j, t}^{T_{n}}}{F_{j, t}^{T_{n}}}$, where $F_{j, t}^{T_{n}}$ is the futures price at the end of month $t$ for the $n^{\text {th }}$ nearby contract of commodity $j$ with expiration month $T_{n}$ and $F_{j, t+1}^{T_{n}}$ is the futures price of the same 
contract at the end of month $t+1$. We consider the first nearby (nearest to maturity) futures contracts $(n=1)$ and second nearby (second nearest to maturity) futures contracts $(n=2)$ and exclude future contracts with less than one month to maturity, in which case futures traders need to take a physical delivery of the underlying commodity (Hong and Yogo, 2012). Hence, the monthly futures returns are calculated based on a roll-over strategy where an investor maintains a long position in the first nearby (nearest to maturity) futures contract on commodity $j$ until the beginning of the delivery month and rolls-over to the second nearby (second nearest to maturity) contract with the following delivery month. Note that on the rollover day we close the position in the first nearby futures contract, and at the same time we open a position in the second nearby contract which then becomes the nearest to maturity contract.

Table 2 reports the summary statistics of the 38 commodities over the period January 1970 to August 2018. Table 2 shows that investment in most individual commodities is unattractive; 26 out of 38 commodities have Sharpe ratios below 0.25 , consistent with findings by Bakshi, Gao and Rossi (2019, Table Internet-II). The absolute first-order autocorrelation for 29 out of 38 commodities is below 0.1 , indicating that most commodity future returns are serially uncorrelated. Most of the commodities have a positive skewness. Finally, 27 of 38 commodities are in contango on average. In general, the magnitudes shown in Table 2 are consistent with the evidence reported in Erb and Harvey (2006, Table 4), Gorton, Hayashi, and Rouwenhorst (2013, Table I) and Bakshi, Gao and Rossi (2019, Table Internet-II).

\subsection{Commodity factor portfolios}

We construct long-only and long-short commodity factor portfolios. We focus on nine commodity sorting characteristics, i.e. (a) Momentum (Miffre and Rallis, 2007, Fuertes, Miffre and Fernandez-Perez, 2015, Bakshi, Gao and Rossi, 2019, Boons and Prado, 2019), (b) Basis 
(Szymanowska et al., 2014, Gorton, Hayashi and Rouwenhorst, 2013, Yang, 2013, Fuertes, Miffre and Fernandez-Perez, 2015, Bakshi, Gao and Rossi, 2019, Boons and Prado, 2019), (c) BasisMomentum (Boons and Prado, 2019), (d) Skewness (Fernandez-Perez et al., 2018), (e) Inflation beta (Bodie and Rosansky, 1980, Erb and Harvey, 2006, Gorton and Rouwenhorst, 2006, Szymanowska et al., 2014), (f) Volatility (Dhume, 2011, Gorton, Hayashi, and Rouwenhorst, 2013, Szymanowska et al., 2014), (g) Hedging Pressure (Cootner, 1960, Hirshleifer, 1988, De Roon, Nijman and Veld, 2000, Basu and Miffre, 2013, Dewally, Ederington, and Fernando, 2013), (i) Open Interest (Hong and Yogo, 2012, Szymanowska et al., 2014) and (g) Value (Asness, Moskowitz and Pedersen, 2013). For a full description of the commodity factors see Section B of the Internet Appendix. ${ }^{8}$

To construct the commodity factor portfolios, we sort at the end of each month the future returns of the 38 commodities based on their sorting characteristics and then calculate the equally weighted return of the top 30 percent and bottom 30 percent of the commodities. We also calculate the return of the average commodity (AVG) portfolio as the equally weighted return of the 38 commodity future contracts, rebalanced monthly. Note that at the beginning of our sample (January 1970) 17 commodity futures are available. The complete set of 38 commodity futures is available from January 2006 until the end of our sample.

\section{The performance of commodity portfolios}

\subsection{The return and risk of commodity portfolios}

\footnotetext{
${ }^{8}$ We exclude from our analysis commodity factors based on the speculative pressure (Cootner, 1960, Hirshleifer, 1988, Basu and Miffre, 2013, Dewally et al., 2013), dollar beta (Erb and Harvey, 2006, Szymanowska et al., 2014) and liquidity (Marshall, Nhut, and Visaltanachoti, 2012, Szymanowska et al., 2014) because data were not available in 1970 .
} 
In Panel A of Table 3 we show the performance of the Standard and Poor's Goldman Sachs Commodity Index (S\&P GSCI), a widely used benchmark in professional asset management and the average commodity portfolio (AVG). In Panels B to $\mathrm{J}$ we present descriptive statistics of the performance of high, medium, low and long-short commodity factor portfolios based on momentum, basis, basis-momentum, skewness, inflation beta, volatility, hedging pressure, open interest and value, over the full sample period January 1970 - August 2018. Mean, standard deviation, skewness and kurtosis are annualised (Cumming et al., 2014). The Goldman Sachs Commodity Index (S\&P GSCI) and the average commodity market factor (AVG) had average excess returns of $3.90 \%$ and $5.13 \%$ per annum, respectively. The volatility of the S\&P GSCI $(19.64 \%)$ is significantly higher than the volatility of the average commodity market factor (13.61\%) reflecting the overweighting of energy in the S\&P GSCI (the standard deviation of the S\&P GSCI Light Energy, which invests less in energy is $14 \%$ per annum over the same period).

The high basis-momentum commodity portfolio exhibits the highest realized excess return (14.68\%) followed by the high momentum (13.13\%) and low basis (12.25\%) commodity portfolios. The high open interest (4.09\%), high inflation beta (6.12\%), low skewness $(6.29 \%)$ and high value (6.41\%) commodity portfolios achieved the lowest excess returns. The inflation beta portfolio exhibits the highest volatility $(20.45 \%)$, followed by the high momentum commodity portfolio (20.09\%), high open interest (18.81\%) and high hedging pressure (18.16\%). The long-short commodity basis-momentum, momentum and basis achieved premia in excess of $10 \%$ per annum, $16.36 \%, 14.93 \%$, and $13.76 \%$ respectively. The value $(21.15 \%)$, momentum $(20.80 \%)$ and hedging pressure $(20.37 \%)$ commodity premia have the highest volatilities. Both long and short portfolios contribute to the profitability of most commodity factor premia. 
Sharpe ratio comparisons show that the S\&P GSCI offers a less attractive return to risk tradeoff (0.198) than the average commodity portfolio (0.377). The long components of all commodity factor premia exhibit higher Sharpe ratios than the S\&P GSCI. Six out of nine long commodity factor portfolios that make the long-leg of the premia exhibit higher Sharpe ratios than the average commodity portfolio (AVG); the exceptions are the high inflation beta, high hedging pressure and high open interest commodity portfolios. The basis-momentum, basis and momentum commodity premia had the highest return to risk ratios $(0.930,0.811$ and 0.718 respectively) and the open interest (-0.027), value (0.136) and inflation beta (0.159) the lowest. ${ }^{9,10}$

\subsection{Transaction costs}

The excess returns reported in Table 3 assume no transactions costs. The creation and maintenance of commodity factor portfolios generates turnover which depending on the cost of trading will reduce the return of commodity factor portfolios. Investing in commodity factor portfolios implemented using commodity futures generates two kinds of costs: (a) roll-over costs associated with the cost of rolling over the maturing contract to the second nearby futures contract and (b) rebalancing costs associated with the rebalancing of portfolio weights required to maintain factor exposure. The turnover associated with monthly roll-over is $12 \times 2 \times 100 \%$ for long-only portfolios and 12x4x100\% for long-short portfolios. A monthly roll-over futures strategy does not

\footnotetext{
${ }^{9}$ In the Internet Appendix, section A.1, we investigate the performance of the commodity benchmarks and the longshort commodity factors before and after the financialization of commodity futures, i.e. January 1970 to December 2004 and January 2005 to August 2018, respectively. On average, across commodity portfolios returns and risks are higher in the pre-financialization period. We also examine the performance of commodity portfolios for the period spanning from January 1990 to August 2018, a period which coincides with the advent of commercial commodity indices. Performance statistics are similar to the full sample period.

${ }^{10}$ The commodity factor portfolios presented in Table 3 are constructed by equally weighting individual commodities. In the Internet Appendix, section A.2, we employ alternative portfolio construction methodologies (inverse volatility, maximum diversification, minimum variance and mean-variance). Our results suggest that equally weighted commodity portfolios have similar performance to portfolios based on alternative weighting schemes. Hence from this point on we report only results based on the EW weighting scheme.
} 
generate additional rebalancing turnover since the roll-over transactions could be used to implement rebalancing trades. We assume monthly roll-over for all futures contracts ${ }^{11}$ and estimate transaction costs by multiplying roll-over generated turnover with the cost of trading.

Marshall, Nhut, and Visaltanachoti (2012) estimate, depending on different dollar value trade size buckets, half spreads between 3.1 to 4.4 basis points. ${ }^{12}$ If we conservatively assume that the half-spread is 4.4 basis points, the total annual roll-over transaction cost of a long-only commodity portfolio is $12 \times 2 \times 4.4=105.6$ basis points. For a long-short commodity portfolio, transaction costs will be double i.e. 211.2 basis points. In the last column in Table 3 we show Sharpe ratios adjusted for transaction costs. Transaction costs adjusted Sharpe ratios for most commodity factor portfolios and premia are marginally lower than Sharpe ratios that ignore transaction costs and remain economically significant. However, taking into account transaction costs weakens considerably the profitability of the skewness, inflation beta, open interest and value commodity factor premia.

\section{Choosing priced commodity factors}

The results in Table 3 confirm evidence in the literature suggesting that commodity factorbased portfolios offer a superior risk-return trade-off compared to the widely used in practice S\&P GSCI benchmark. Six out of nine long-only factor-based portfolios outperform an equally weighted portfolio of the 38 commodities we examine in this study. The average commodity portfolio ${ }^{13}$ has been used in many academic studies as a proxy of the "market" portfolio for

\footnotetext{
${ }^{11}$ Twenty out of the thirty-eight futures contracts have seven or more roll-over months per year. Assuming a onemonth roll-over schedule results in maximum turnover and transaction costs estimates.

${ }^{12}$ Bollerslev et al. (2018) estimate the average bid-ask spread of twenty commodities to be equal to 3.5 basis points (see Table A1, p.2765).

${ }^{13}$ Erb and Harvey (2006) caution against using an equally weighted portfolio of commodities as a proxy for the return of the commodities market, arguing that a monthly rebalanced equally weighted index will be distorted by a rebalancing premium and is not investable in large scale. We calculate the average portfolio using quarterly and
} 
commodities and as a superior alternative to the S\&P GSCI. In this Section we apply the recent methodologies of Harvey and Liu (2019) and Barillas and Shanken (2017) and Fama and French (2018) to test whether the S\&P GSCI, the average commodity portfolio (AVG) and the basis, momentum and basis-momentum, skewness, inflation beta, volatility, hedging pressure, open interest and value commodity factors are priced in the cross-section of commodity returns. In the presence of multiple priced commodity risk premia an investor in addition to the commodity "market" portfolio should also consider exposure to non-market risk premia. If commodity factor premia are uncorrelated, investing in a portfolio of commodity risk premia should provide considerable efficiency gains compared to the benchmark commodity market portfolio.

The methodology developed in Harvey and Liu (2019) identifies from among a number of candidate factors those that are priced, addresses data mining directly, takes into account the crosscorrelation between factors and allows for general distributional assumptions and more specifically non-normality. The methodology, applied to either portfolios or individual securities as test assets, has been designed to answer the following question: given a benchmark and an alternative factor model, what is the incremental contribution of the alternative model? Barillas and Shanken (2017) and Fama and French (2018) use an alternative testing methodology to assess the benefits from adding a factor to a factor model. The methodology involves running a spanning regression of a candidate factor on a model's other factors. A non-zero intercept indicates that the factor makes a marginal contribution to the factor model and helps explain average returns. The GRS (Gibbons,

annual rebalancing and, like Bhardwaj, Gorton and Rouwenhorst (2015), we find that average returns are marginally higher to returns based on monthly rebalancing (results available upon request). Investability is more of an issue but as observed by Levine et al. (2018) there is little evidence to suggest that including less liquid commodities inflates the return of the average portfolio. When we create an equally weighted portfolio consisting of the futures contracts that make-up the S\&P GSCI, we find no difference in performance compared with the 38 equally weighted commodity index (results available upon request). 
Ross and Shanken, 1989) test of competing models tests whether a new factor improves the meanvariance efficiency of a portfolio constructed from existing factors.

\subsection{The Harvey and Liu (2019) Method}

Harvey and Liu (2019) utilize multiple hypothesis testing and a bootstrapping technique to identify the factors that can explain the cross-section of expected equity returns. The test consists of estimating two factor models: the baseline model and an augmented model that includes an additional factor relative to the baseline model. According to Harvey and Liu (2019) p. 18 "a risk factor is considered useful if, relative to the baseline model, the inclusion of the risk factor in the baseline model helps reduce the magnitude of the cross section of intercepts under the baseline model". We employ the two test statistics $S I_{e w}^{m}$ and $S I_{e w}^{m e d}$ in Harvey and Liu (2019) to evaluate the statistical significance in explaining the cross-section of commodity expected returns between the baseline and the augmented regression model. $S I_{e w}^{m}$ and $S I_{e w}^{m e d}$ measure the difference in equally weighted scaled mean and median absolute regression intercepts between the baseline model and the augmented model, respectively. More details on the two statistics can be found in Harvey and Liu (2019).

Table 4 presents (i) $S I_{e w}^{m}$ and $S I_{e w}^{m e d}$, (ii) the bootstrapped $5^{\text {th }}$ percentile on the distribution of $S I_{e w}^{m}$ and $S I_{e w}^{m e d}$ for each individual commodity risk factor with the corresponding p-values under the null hypothesis that the commodity risk factor individually has no ability to explain the crosssection of test assets returns (single hypothesis testing) and (iii) the bootstrapped $5^{\text {th }}$ percentile on the distribution of the minimum $S I_{e w}^{m}$ and $S I_{e w}^{m e d}$ amongst the commodity risk factors with the corresponding p-values under the null hypothesis that the commodity risk factor individually has no ability to explain the cross-section of test assets returns (multiple hypothesis testing). 
Panel A of Table 4 tabulates the results when the 38 individual commodities of Table 1 are the test assets. We start our analysis by testing whether any of the eleven commodity risk factors, namely the S\&P GSCI and the average commodity factor, as well as the long-short momentum, long-short basis, long-short basis-momentum, long-short skewness, long-short inflation beta, longshort volatility, long-short hedging pressure, long-short open interest and long-short value, can explain the cross-section of expected individual commodity returns. We find that the average commodity factor is the best among the factors, since it reduces the mean (median) scaled absolute intercept by $30.7 \%(35.6 \%)$, the highest reduction among the remaining factors. The bootstrapped $5^{\text {th }}$ percentile of $S I_{e w}^{m}\left(S I_{e w}^{m e d}\right)$ for the average commodity factor is $-0.216(-0.285)$, a reduction in the mean (median) scaled intercept of $21.6 \%$ and $28.5 \%$ respectively. This factor reduces the mean (median) scaled intercept by more than the $5^{\text {th }}$ percentile with a p-value equal to $0.010(0.017)$ (see Panel A.1). For the multiple hypothesis test, the bootstrapped $5^{\text {th }}$ percentile of $S I_{e w}^{m}\left(S I_{e w}^{m e d}\right)$ is $0.226(-0.296)$ and statistically significant with a multiple testing p-value equal to $0.010(0.018)$.

Overall, the average commodity factor is the most important among the candidate factors and is statistically significant at the $5 \%$ or better level of significance. When we include the average commodity factor in the baseline model we find that the second most dominant factor is the longshort basis factor with a multiple testing p-value equal to 0.000 based on $S I_{e w}^{m}$ and $S I_{e w}^{m e d}$ (Panel A.2). When we include the long-short basis factor into the baseline model (see Panel A.3) we find that none of the remaining candidate commodity factors is significant under the multiple hypothesis testing on $S I_{e w}^{m}\left(\mathrm{p}\right.$-value=0.405) and $S I_{e w}^{m e d}(\mathrm{p}$-value=0.605).

Panel B of Table 4 tabulates the results when commodity portfolios are considered as test assets. In particular, we use the 27 low, medium and high commodity factor portfolios. The average commodity factor is the best among the factors, reducing the mean (median) scaled absolute 
intercept by $47.9 \%$ (60.4\%), the highest reduction among the remaining factors. The bootstrapped $5^{\text {th }}$ percentile of $S I_{e w}^{m}\left(S I_{e w}^{m e d}\right)$ for the average commodity factor shows that the reduction in the mean (median) scaled intercept is $35.0 \%(40.1 \%)$, at the $5^{\text {th }}$ percentile. This factor reduces the mean (median) scaled intercept by more than the $5^{\text {th }}$ percentile with p-values equal to $0.002(0.000)$ (see Panel B.1). With respect to the multiple hypothesis test, the bootstrapped $5^{\text {th }}$ percentile of $S I_{e w}^{m}\left(S I_{e w}^{m e d}\right)$ is $-0.362(-0.420)$ and statistically significant with a multiple testing p-value equal to $0.003(0.000)$. Overall, the average commodity factor is the most important among the candidate factors and is statistically significant at $1 \%$ level with respect to the single and multiple hypothesis tests.

We repeat our analysis by including the average commodity factor into the baseline model and we find that the second most dominant factor is the long-short basis-momentum commodity factor with a multiple testing p-value equal to 0.000 based on $S I_{e w}^{m}$ (Panel B.2). When we include the long-short basis-momentum factor into the baseline model we find that the third most dominant factor is the long-short momentum factor with a multiple testing p-value equal to 0.008 based on $S I_{e w}^{m}$ (Panel B.3). When we include the long-short momentum factor into the baseline model we find that the fourth most important factor is the long-short value with a multiple testing $p$-value equal to 0.009 based on $S I_{e w}^{m}$ (Panel B.4). Thereafter, we include the long-short value factor into the baseline model and find that the fifth most important factor is the long-short basis with a multiple testing p-value equal to 0.000 based on $S I_{e w}^{m}$ (Panel B.5).

Finally, we include the long-short basis into the baseline model and find that none of the remaining candidate factors is not significant under the multiple hypothesis testing on $S I_{e w}^{m}$ (pvalue $=0.558$, see Panel B.6). When employing the test-statistic $S I_{e w}^{m e d}$, only the average 
commodity factor followed by the long-short basis and long-short hedging pressure are able to explain the cross-section of commodities.

Our results are sensitive to the use of individual commodities or commodity portfolios as test assets. There is no consensus in the academic asset pricing literature on equities whether individual stocks or equity portfolios should be used as test assets. A number of academic studies argue that individual stocks are very noisy to be considered as test assets (Jensen, Black and Scholes, 1972, Fama and MacBeth, 1973). Other studies argue that portfolios might create bias and inefficiency when used as test assets (Avramov and Chordia, 2006, Lewellen, Nagel and Shanken, 2010 and Ang, Liu and Schwarz, 2019). Harvey and Liu (2019) argue that the use of individual stocks as test assets minimise the data snooping bias that arises from portfolio-based asset pricing tests (Lo and MacKinlay, 1990).

In summary, using individual commodities as testing assets we find that the average commodity portfolio is the most dominant commodity risk factor. The two-factor model comprised of the average commodity factor and the long-short basis can explain the cross section of individual commodities. Using commodity portfolios as test assets we find that a six-factor model comprised of the average commodity factor, the long-short momentum, the long-short basis, the long-short basis momentum, long-short hedging pressure and long-short value can explain the cross section of commodity portfolios. The average commodity factor is considered the best among the candidate commodity risk factors in explaining the cross-section of individual commodity returns and commodity portfolios, while on the other hand the commodity benchmark S\&P GSCI is found to be an insignificant factor.

\subsection{Spanning Tests}


Barillas and Shanken (2017) and Fama and French (2018) use spanning regressions to find which equity risk factors are significant in explaining the time variation of expected equity returns. A risk factor is considered useful if, when regressed on the other factors, produces intercepts which are non-zero. The GRS statistic of Gibbons, Ross and Shanken (1989) is used to test whether a factor or factors enhance a model's ability to explain expected returns. Table 5 presents results from a time-series regression over the period January 1970 - August 2018 in which the dependent variable is the return of the candidate commodity risk factor and the independent variables are the returns of the competing model commodity risk factors.

To run the spanning regressions, we need a baseline model. In this respect we include in the baseline model those factors for which there is a theoretical motivation and have been found to be priced in the literature on commodity asset pricing. Hence, we restrict the choice of factors, to the factors proposed by Yang (2013, average commodity and basis factors), Szymanowska et al (2014, basis factor), Bakshi, Gao and Rossi (2019, average commodity, the basis and momentum factors) and Boons and Prado (2019, average commodity and the basis-momentum factors) to describe the baseline model. The commodity basis represents a reward for global equity volatility (Bakshi, Gao and Rossi, 2019), commodity momentum represents a reward to innovations in aggregate speculative activity (Bakshi, Gao and Rossi, 2019) and the commodity basis-momentum premium represents a reward to commodity market volatility risk (Boons and Prado, 2019).

Panel A of Table 5 shows that the intercept in the spanning regression for the long-short momentum is $0.50 \%$ per month $(\mathrm{t}$-stat $=1.979)$, for the long-short basis is $0.50 \%(\mathrm{t}-\mathrm{stat}=2.383)$, for the long-short basis-momentum is $0.80 \%$ ( $\mathrm{t}$-stat=4.612), for the long-short hedging pressure is $0.60 \%$ ( $\mathrm{t}-\mathrm{stat}=2.268)$ and for the long-short value is $0.90 \%$ ( $\mathrm{t}-\mathrm{stat}=4.432)$. On the contrary, the 
intercepts for the long-short skewness, inflation beta, volatility and open interest commodity factor portfolios are insignificant even at the $10 \%$ significance level.

Overall, we find that (a) the returns of the average commodity, long-short basis and long-short basis-momentum factors do not span the return of the long-short momentum factor, (b) the returns of the average commodity, long-short momentum and long-short basis-momentum factors do not span the return of the long-short basis factor, (c) the returns of the average commodity, long-short momentum and long-short basis factors do not span the long-short basis-momentum factors, (d) the returns of the average commodity, long-short momentum, long-short basis and long-short basis-momentum factors do not span the long-short hedging pressure factor and (e) the returns of the average commodity, long-short momentum, long-short basis and long-short basis-momentum factors do not span the long-short value factor.

In Panel B of Table 5, we repeat the spanning regression tests by considering the commodity factors that have been found to provide significant intercepts in the baseline model of Panel A. We examine whether these factors provide significant alpha (intercept) relative to an augmented model that comprises the average commodity factor and the long-short momentum, basis, basismomentum, hedging pressure and value commodity factors. Panel B of Table 5 shows that the intercept in the spanning regression for the long-short momentum is now $0.70 \%$ per month (t-stat $=3.479$ ), for the long-short basis is $0.70 \%$ ( $\mathrm{t}$-stat $=3.321)$, for the long-short basis-momentum is $0.60 \%$ ( $\mathrm{t}$-stat=3.439), for the long-short hedging pressure is $0.50 \%$ ( $\mathrm{t}-\mathrm{stat}=1.950)$ and for the longshort value is $0.90 \%$ (t-stat $=4.433)$.

Panel C of Table 5 tabulates the GRS statistic (Gibbons, Ross, and Shanken, 1989) which tests whether multiple factors jointly provide additional explanation to a baseline model. We choose between the following models: 
a) The three (AVG, basis and momentum), four (AVG, basis, momentum and basismomentum) and six (AVG, basis, momentum, basis-momentum, hedging pressure and value) factor models against the single market factor (the AVG) model,

b) The three (AVG, basis and momentum), four (AVG, basis, momentum and basismomentum) and six (AVG, basis, momentum, basis-momentum, hedging pressure and value) factor models against the single basis factor model of Szymanowska et al. (2014),

c) The four (AVG, basis, momentum, basis-momentum) and six (AVG, basis, momentum, basis-momentum, hedging pressure and value) factor models against the two (AVG and basis) factor model of Yang (2013),

d) The four (AVG, basis, momentum and basis-momentum) and six (AVG, basis, momentum, basis-momentum, hedging pressure and value) factor models against the two (AVG and basis-momentum) factor models of Boons and Prado (2019) and

e) The four (AVG, basis, momentum and basis-momentum) and six (AVG, basis, momentum, basis-momentum, hedging pressure and value) factor models against the three (AVG, basis and momentum) factor model of Bakshi, Gao and Rossi (2019).

The GRS test on the intercepts from the spanning regressions of long-short basis and longshort momentum on the average commodity factor rejects the null hypothesis that the intercepts are jointly zero with a p-value equal to zero (p-value=0.000). We find similar results when we jointly test the intercepts from the spanning regressions of long-short basis, long-short momentum and long-short basis-momentum on the average commodity factor and from the spanning regressions that include also the long-short hedging pressure and long-short value. GRS tests of a three, four and six factor models against the basis model of Szymanowska et al. (2014) suggest that the addition of the average commodity, momentum, basis-momentum, hedging pressure and 
value factors adds to the explanation of the baseline model. Based on the estimated GRS statistics the two factor models of Yang (2013) and Boons and Prado (2019) are inferior to models that add the momentum and basis-momentum and the basis and momentum factors respectively. These two factor models remain inferior to models that also include hedging pressure and value factors. Finally, the GRS tests of four and six factor models against the three-factor model of Bakshi, Gao and Rossi (2019) suggests that the addition of the basis-momentum, hedging pressure and value factors adds to the explanation of the base model.

In short, we find evidence that a six-factor model, comprised of the average commodity factor and the long-short momentum, basis, basis-momentum, hedging pressure and value commodity factors, contains all economically relevant pricing information.

\section{Multifactor commodity portfolios: the benefits from diversification}

Evidence of the cross-sectional and time series tests in Section 4 suggests that the five nonmarket commodity premia (i.e. momentum, basis, basis-momentum, hedging pressure and value) represent independent and non-redundant sources of return available to commodity investors. The correlation matrix of the commodity factors in Table IA4 in the Internet Appendix shows correlations between the commodity factor premia close to zero suggesting potential diversification benefits from creating a multifactor commodity portfolio. To create the combined factor commodity portfolio, we use mean-variance optimization with expected return and variance-covariance based on historical data. To assess the robustness of the mean-variance based portfolios to estimation error we also use equal (EW), inverse variance (IV), minimum variance (MinVar) and maximum diversification portfolio (MDP) weights. These portfolio construction methodologies combine stand-alone factor portfolios (top-down approach) and are widely used in 
equity multifactor portfolio construction. Top-down approaches involve a two-step portfolio construction process; first, individual factor portfolios are constructed and second the stand-alone factors are combined to create a multifactor portfolio.

An alternative portfolio construction methodology, used by Lewellen (2015) to create a multifactor equity portfolio, combines different commodity characteristics to estimate a commodity's expected return, based on Fama-MacBeth (FM) cross-sectional $\left(\mathrm{CS}^{14}\right)$ regressions and provides an alternative way to combine many characteristics into a composite trading strategy (bottom-up approach). A major advantage of Lewellen's (2015) methodology is that it takes into account all commodity characteristics simultaneously enabling netting out of trades in individual commodities and results in a substantial reduction in the turnover generated when rebalancing compared to combining standalone commodity factor portfolios. DeMiguel, Martin-Utrera, Nogales and Uppal (2019) discuss the trading-diversification benefits obtained by combining characteristics in the context of stock portfolios. The slopes of FM regression are estimates of commodity factor returns and are therefore an alternative to the time series approach (Fama, 1976, Fama and French, 2019) to create a multi-factor commodity portfolio. A detailed description of the portfolio construction (top-down and bottom up) methodologies can be found in the Internet Appendix, Section D.

Table 6, Panel A, presents the performance of the average commodity factor. Panels B and C show the performance of multifactor commodity portfolios based on long-only (Panel B) and longshort commodity factor portfolios based on the momentum, basis, basis-momentum, hedging pressure and value factors (Panel C). The multifactor commodity portfolios are created using the

\footnotetext{
${ }^{14}$ We thank the referee for suggesting Lewellen's (2015) methodology to create the multifactor commodity portfolio. We provide details of the cross-sectional (CS) methodology of Lewellen (2015) as applied to commodities in the Internet Appendix.
} 
six alternative portfolio construction rules. Average return (Mean), standard deviation (SD), Sharpe Ratio (SR), alpha, standard error (se), Appraisal ratio and Certainty Equivalent Return (CER) are annualised. Alpha and standard error (se) estimates are based on the time-series regression of the combined commodity portfolio $R_{t}^{c o m b}$ on the average commodity factor (AVG), i.e. $R_{t}^{c o m b}=$ $\alpha+\beta A V G_{t}+\varepsilon_{t}$.

Panel B of Table 6 shows that over the January 1970 - August 2018 period, a mean-variance based long-only factor portfolio achieved an annual excess return of $11.75 \%$ with a standard deviation of $17.20 \%$. Over the same period the average commodity portfolio had an annual excess return of $5.13 \%$ with $13.61 \%$ standard deviation. The Sharpe ratio of a mean-variance based commodity factor portfolio is almost double the return to risk offered by the average commodity portfolio $(0.683$ versus 0.377$)$. The difference in Sharpe ratios is statistically significant at the $1 \%$ level of significance. The mean-variance-based commodity factor portfolio has an annual alpha of $6.24 \%$ that is statistically different from zero and an appraisal ratio of 0.686 .

Alternative portfolio construction rules produce commodity factor portfolios with very similar or even higher performance. The Sharpe ratios range between 0.604 (minimum variance) and 0.716 (equally weighted) and are statistically significantly different from the Sharpe ratio of the average commodity portfolio. Alphas using the average commodity portfolio as the benchmark range between 3.84\% (MDP) and 5.34\% (EW) per year and are statistically significant. Appraisal ratios using the average commodity portfolio as the benchmark range between 0.572 (CS) and 1.083 (EW). Finally, the $C E R$ for a moderate risk average investor who invests in the EW, IV, MinVar, MDP and CS is equal to $5.23 \%, 5.08 \%, 3.68 \%, 3.71 \%$ and $3.06 \%$ per annum, respectively, whilst the CER for the same investor who invests in average commodity factor portfolio is equal to $0.43 \%$ per annum; the difference of the CERs between the combined portfolios 
and the average commodity portfolio is statistically significant (except for the MV and CS based portfolios).

Panel C of Table 6 shows that the mean-variance combined portfolio of the non-market longshort commodity portfolios of momentum, basis, basis-momentum, hedging pressure and value, over the January 1970 - August 2018 period exhibit a Sharpe ratio equal to 0.797 much higher than the corresponding of the average commodity portfolio (0.377); the difference in Sharpe ratios is statistically significant at the 5\% level of significance. The mean-variance-based commodity factor portfolio has an annual alpha of $10.67 \%$ that is statistically different from zero and an appraisal ratio of 0.751 . Our empirical evidence is robust to alternative weighting schemes. For instance, the Sharpe ratios range between 0.709 for the CS portfolio and 1.253 for the EW portfolio. The CERs range between $7.22 \%$ for the MDP and $9.25 \%$ for the IV per annum, compared to the annualised CER of the average commodity factor $(0.43 \%)$; the differences of the Sharpe ratio and CER between the combined long-short portfolios and the average commodity portfolio are statistically significant at $1 \%$ significance level.

Overall, our empirical evidence suggests that the combination of the basis, momentum, basismomentum, hedging pressure and value factor portfolios is clearly better than the equally weighted portfolio of individual commodities (average commodity factor). ${ }^{15}$

\footnotetext{
${ }^{15}$ Daskalaki, Skiadopoulos and Topaloglou (2017), using an SDE approach, find clear evidence of diversification benefits from the inclusion of second and third generation indices to traditional equity-bond portfolios. In contrast, Fethke and Prokopczuk (2018), using mean-variance spanning and out-of-sample portfolio analysis, find less clearcut diversification benefits. A comprehensive study of the benefits of including the combined commodity portfolio in the traditional bond-equity asset mix is beyond the scope of this paper. In the Internet Appendix we test whether the combined commodity portfolio enhances the traditional equity-bond efficient frontier. The evidence suggests that the adding the combined commodity portfolio to the traditional equity and bond portfolios does improve the investment efficient frontier.
} 


\section{Are commercial commodity indices spanned by commodity factor}

\section{portfolios?}

Miffre (2012) classifies commodity indices into three categories. First generation commodity indices are long-only commodity indices which capture broad commodity market movements but ignore the shape of term structure of commodity futures prices. Second generation commodity indices are constructed to avoid the harmful effects of contango and benefit from backwardation. The development of third generation commodity indices are based on commodity characteristics such as the basis or momentum while allowing for long and short positions.

In this Section we test whether commercially available first, second and third generation commodity indices are redundant in the presence of priced commodity factors discussed in Section 4. Following Daskalaki, Skiadopoulos and Topaloglou (2017) we consider the S\&P Goldman Sachs Commodity Index (S\&P GSCI), the Dow Jones-UBS Commodity Index (DJ UBSCI) and the Deutsche Bank Liquid Commodity Index (DBLCI) as first generation indices. ${ }^{16}$ For second generation indices we consider the Deutsche Bank Liquid Commodity Index-Optimum Yield (DBLCI-OY), the Morningstar Long-Only Commodity Index (MSDIL) and the Morningstar Long/Flat Commodity Index (MSDILF). Finally, third generation indices are represented by the Morningstar Short/Flat Commodity Index (MSDISF), the Morningstar Short-Only Commodity Index (MSDIS) and the Morningstar Long/Short Commodity Index (MSDILS). Commodities investment strategies based on the MSDILS and MSDISF are essentially similar to traditional trend strategies. Using the MSDILS the investor uses a momentum rule based on the 12-month moving

\footnotetext{
${ }^{16}$ Note that the S\&P GSCI is the industry-standard benchmark for commodities investing. The index has been "designed to reflect the relative significance of each of the constituent commodities to the world economy, while preserving the tradability of the index by limiting eligible contracts to those with adequate liquidity". While a capitalization weighted portfolio of all equities is consistent with the equilibrium world of the CAPM, the production weights used for the S\&P GSCI cannot be justified similarly. That leaves open the question of what is an appropriate proxy for the commodities "market" portfolio.
} 
average of a commodity's linked price to determine if a commodity will be held long or short. Using the MSDISF the investor takes only short positions and cash. A detailed description of the first, second and third generation indices can be found in Daskalaki, Skiadopoulos and Topaloglou (2017) and the Internet Appendix. We source monthly data of these indices from Bloomberg.

Table IA4 in the Internet Appendix tabulates the correlation matrix of the three generation indices and the commodity factor portfolios. We document high and positive correlation between first and second generation indices and the long-only factor portfolios, whilst the correlation between the third generation indices and the long-short commodity portfolios are close to zero in most cases (see also the discussion in Section A.3 of the Internet Appendix).

Are commercial commodity indices redundant if the investor had access to the commodity factor portfolios? To answer this question we run spanning regressions for the first, second and third generation commercial commodity indices and present the estimation results in Table 7 . The baseline model includes the average commodity factor (AVG) and the long-short commodity momentum, basis, basis-momentum, hedging pressure and value factors. Panel A of Table 7 shows that the intercept in the spanning regression for the commodity benchmark S\&P GSCI and the DBLCI is statistical insignificant, i.e. $-0.20 \%(\mathrm{t}-\mathrm{stat}=-1.522)$ and $0.10 \%(\mathrm{t}-\mathrm{stat}=0.737)$ per month, respectively. ${ }^{17}$ The intercept in the spanning regression for the broadly diversified index DJ UBSCI is negative and statistically significant. The intercepts and their t-statistics in the spanning regression of the second generation commodity indices DBLCI-OY, MSDIL and the MSDILF do

\footnotetext{
${ }^{17}$ The evidence that the intercept in the spanning regression for the S\&P GSCI is insignificant together with the evidence shown in subsection 4.1 that the S\&P SCI is an insignificant commodity factor in explaining the cross section of commodity returns, suggests that the widely used commodity benchmark S\&P GSCI is unlikely to be a portfolio on the efficient frontier.
} 
not add to our six factor commodity model's explanation of expected returns over the January 1970 - August 2018 period (see Panel B of Table 7).

Similarly, the intercept in the spanning regression using the six commodity factor model for the third generation short-only commodity Index MSDIS is statistically insignificant. As mentioned earlier the MSDILS and MSDISF indices represent momentum based timing strategies. It is therefore important to include, in addition to the six commodity factors, a variable that will capture a possible commodity market timing premium. Following the approach of Treynor and Mazuy (1966) we add the squared of the average commodity portfolio return to the six commodity factor premia. For both portfolios, the intercepts from the spanning regression are statistically insignificantly different from zero. The spanning regression results suggest that the MSDILS index can be replicated by combining the average commodity portfolio, the momentum commodity premium, the value commodity premium and a market timing factor. Similarly, the MSDISF index can be replicated by a short position in the average commodity portfolio, a positive position in the momentum commodity premium and a market commodity factor.

\section{Timing commodity factor portfolios}

An investor can capture the average premia offered by commodity factors through a passive investment strategy in commodity factor portfolios. The passive investment strategy rebalances periodically the commodity factor portfolios in accordance with the chosen portfolio construction methodology and will be optimal if return and risk are constant or unpredictable. Successful commodity timing strategies on the other hand, requires ability to forecast commodity returns, risks or both.

Evidence on the predictability of commodity returns is controversial. Bessembinder and Chan (1992) find weak evidence of predictability in agricultural, metal and currency future prices while 
Hong and Yogo (2012) find in-sample evidence of predictability of an equally weighted portfolio of four commodity sectors. Gargano and Timmermann (2014) use both financial and macroeconomic predictors to forecast returns of seven commodity spot indices. They find some evidence of out-of-sample predictability for monthly horizons for some of the commodity indices (industrials, metals and the total commodity index) but little or no predictability for fats/oils, foods, livestock and textiles indices. Ahmed and Tsvetanov (2016) use forecasts from a two-factor model based on an equally weighted index of commodity futures and the basis portfolios to predict the return of fifteen commodity futures. They find no evidence of either statistical or economic value added. Daskalaki, Skiadopoulos and Topaloglou (2017) test the predictive ability of macroeconomic and financial variables for equities, bonds and commodity indices. They find that equities and bonds can be predicted by some of the predictors but no evidence of commodity index return predictability. In contrast, Gao and Nardari (2018) report significant benefits from including commodities in a traditional mix of stocks and bonds when they use predictions for the expected return and risks of commodity futures.

Building on evidence suggesting that the value spread (the difference in value indicators in the long/short legs of the value premium) for US stocks predicts returns to the standard equity value strategy (Asness et al., 2000, Cohen, Polk, and Vuolteenaho, 2003), Baba Yara, Boons and Tamoni (2019) report predictive power for the value commodity premium at horizons longer than three months but not for shorter horizons. Koijen et al. (2018) examine the predictability of individual commodities (among other assets) and the profitability of investment strategies that time individual commodities using the basis. They find no statistical relation between individual commodity returns and commodity basis but some support for trading strategies based on carry. 
Finally, Boons and Prado (2019) find a positive and statistically significant relation between commodity variance and the returns of the basis-momentum factor portfolio but no predictability for the momentum and basis portfolios. Taken together with evidence from volatility timing strategies applied to equity factor premia (Barroso and Santa-Clara, 2015, Daniel and Moskowitz, 2016, Moreira and Muir, 2017) suggests the possibility of timing commodity factor premia using predictors of future commodity volatility.

\subsection{Predictor variables and return prediction models}

Following previous research on the predictability of commodity returns we consider (a) macroeconomic predictor variables (T-bill 1 month, yield spread, default spread, unemployment rate, money supply growth industrial production growth and the Kilian real economic activity index), (b) commodity-specific predictor variables (aggregate commodity basis, commodity market interest, the growth in "commodity currency" exchange rates (i.e. AUD-USD, NZD-USD, SA RAND- USD) and the 1-month lagged commodity return), (c) factor valuation spreads, defined as the difference in the value signal in the high and low commodity factor exposure portfolios and (d) factor exposure spreads defined as the difference in the factor exposure of the high and low commodity factor portfolios. A full description of the predictor variables ${ }^{18}$ can be found in Gargano and Timmermann (2014), Gao and Nardari (2018) and the Internet Appendix.

We employ four forecasting models: (a) the historical average, (b) the forecast combination (pooled average) model (Rapach, Strauss, and Zhou, 2010), (c) the diffusion index model (Ludvigson and $\mathrm{Ng}, 2007$ ) and (d) the multiple regression model. A detailed description of the forecasting models we use can be found in Rapach and Zhou (2013) and the Internet Appendix.

\footnotetext{
${ }^{18}$ In the Table IA6 of the Internet Appendix we report the descriptive statistics for the predictor variables for the January 1970 to August 2018 period
} 
We use ten years of data as the initial in-sample period and a recursive (i.e. expanding) window ${ }^{19}$ to generate monthly out-of-sample forecasts for the period January 1980 to August 2018. The out of sample forecasting statistics for the statistical evaluation of the predictor variables and forecasting models reported in Table IA7 and the discussion in Section A5 of the Internet Appendix suggest weak or non-existent predictive ability for most variables and forecasting models. In the next section we investigate the economic benefits from forecasts based on the various prediction models. Kandel and Stambaugh (1996) have shown that even statistically weak prediction models can produce non-trivial economic gains.

\subsection{Performance of commodity timing factor strategies}

In this subsection we report the performance of a dynamic strategy that adjusts the weight allocated to a commodity factor premium using the forecasts of risk and return described in Section 7.1. The portfolio construction rule follows Daniel and Moskowitz (2016) who show that for an investor whose objective is to maximize the $T$ periods from $1, \ldots ., T$ Sharpe ratio, the optimal weight in the commodity factor premium at time $\mathrm{t}$ is $w_{t}=\frac{1}{\gamma} \frac{\mu_{t}}{\sigma_{t}^{2}}$, where $\gamma$ is the coefficient of risk aversion, $\mu_{t}$ is the expected commodity factor premium and $\sigma_{t}^{2}$ is the expected variance over time t. The weight is proportional to the expected commodity premium and inversely proportional to the conditional variance of the commodity premium.

The weight, $w_{t}$, allocated to the commodity premium will be constant if the return to risk (variance) ratio is constant. If the return to volatility (Sharpe) ratio is constant or returns are negatively correlated with volatility, the weight on the commodity factor premium will be

\footnotetext{
${ }^{19}$ See Neely et al (2012), Gao and Nardari (2018), Rapach and Zhou (2013), among others. Hansen and Timmermann (2012) show that out-of-sample tests of predictive ability have had better size properties when the forecast evaluation period is a relatively large proportion of the available sample.
} 
inversely proportional to forecasts of commodity premium volatility. This is the basis for the volatility targeting strategies of Fleming, Kirby and Ostdiek (2001, 2003), Barroso and SantaClara (2015) and Moreira and Muir (2017). To exploit the predictive ability of past variance we assume that the investor cannot forecast the mean but can forecast future variance. In that case the optimal weight in the commodity factor premium is given by $w_{t}=\frac{c}{\sigma_{t}^{2}}$ where $\mathrm{c}$ is a constant, chosen so that the managed commodity portfolio has the same unconditional volatility as the unmanaged commodity portfolio (Moreira and Muir, 2017). The choice of a particular volatility target will affect the return, variance and alpha of the variance managed portfolio but will not affect portfolio performance measures such as the Sharpe ratio or the Appraisal ratio. The return of the variance timing strategy is then calculated as $w_{t} f_{t+1}$ where $f_{t+1}$ denotes the excess return of the unmanaged commodity portfolio. We investigate the predictive ability of lagged variance (based on one-month daily commodity factor premia) for next month's return, variance and Sharpe ratio (calculated monthly as the ratio of average portfolio return over the volatility of the portfolio based on daily observations in the month). The results reported in the Table IA8 of Internet Appendix suggest that past variance is a good predictor of future variance but largely unrelated to future commodity factor premia and Sharpe ratios, except for the commodity momentum premium where the relation is negative and significant.To exploit, in addition to the variance, the predictive ability of the commodity factor prediction models presented in section 7.1 we use $w_{t}=\frac{1}{\gamma} \frac{\mu_{t}}{\sigma_{t}^{2}}$ to calculate monthly optimal weights using as forecast of the future commodity premium the one month ahead forecast generated by the four prediction models: the historical average (histavg), the pooled average model (poolavg), the diffusion index model (DI) and the multiple regression model (MULT). 
Table 8 tabulates the annualised alpha and appraisal ratio for the variance-managed and the dynamic commodity portfolios that use forecasts of both return and variance. In Panel A we show results for the variance managed portfolios. In Panel B we present alpha and appraisal ratios for dynamic strategies that use the historical average as predictors of future commodity premia. In Panels C-F we show performance statistics of dynamic strategies that use as predictors commodity specific and macroeconomic variables (Panel C), factor valuation spreads (Panel D), factor exposure spreads (Panel E) and their combination (Panel F). Alpha is estimated based on the timeseries regression of the managed commodity portfolio on the unmanaged commodity portfolio controlling also for the long-short commodity factors. A positive alpha suggests that the managed commodity portfolios expands the mean-variance efficient frontier and increase the Sharpe Ratio compared to the passive (unmanaged) commodity portfolios. ${ }^{20}$

We find no evidence that variance timing will be beneficial to investors who hold the commodity average market factor ${ }^{21}$ over the January 1980 to August 2018 period. Over the same period, we find little evidence that variance timing will be beneficial to timing the basis, basismomentum, hedging pressure or value commodity premia. The only exception is the variance timing strategy applied to the commodity momentum premium which generates a statistically significant alpha of $7.62 \%$ per annum and an appraisal ratio of 0.634 .

As Table 8 shows, employing commodity premia prediction models does not improve the excess return generated by the variance managed strategies. The alphas that combine risk and return forecasts are statistically insignificant for all timing commodity factor premia strategies,

\footnotetext{
${ }^{20}$ We report in Table IA9 in the Internet Appendix detailed performance statistics for the variance-managed and the combined return-forecast and variance-managed commodity portfolios (i.e. average commodity factor and the longshort commodity momentum, long-short basis, long-short basis-momentum, long-short hedging pressure and longshort value).

${ }^{21}$ Similar results are reported in Harvey et al (2018). They find negligible effects from volatility timing to the Sharpe ratios of six agricultural, six energy and seven metal futures contracts.
} 
with the exception of the commodity momentum-based strategy. However, the timing alpha of the variance managed momentum factor is higher than most of the alphas of timing strategies that use in addition predictions of future commodity premia. The evidence suggests that when return forecasts are also used in the timing strategy, there is no improvement to the performance generated by variance timing alone. ${ }^{22}$

\subsection{Understanding the profitability of variance managed commodity momentum}

The profitability of a variance timing strategy of the long/short commodity momentum portfolio is consistent with the evidence on the success of variance timing of equity momentum reported in Barroso and Santa Clara (2015), Daniel and Moskowitz (2016) and Moreira and Muir (2017), and deserves further investigation. The positive alpha of the variance timing strategy means that the strategy is not simply compensation to commodity factor risk. It is however possible that the commodity momentum variance timing strategy is exposed to other risk factors beyond the commodity factors. In this Section we examine the exposure of the commodity momentum premium variance timing strategy to a set of macroeconomic, liquidity and market risk factors used in the study of Asness, Moskowitz and Pedersen (2013) to investigate the drivers of the returns of global value and momentum factors across markets and asset classes.

We use the business cycle, liquidity, volatility, the global equity market and the global value and momentum premiums as proxies for time-variation in the commodity momentum variance timing strategy. The business cycle is a standard indicator of bad times (measured by a dummy variable that takes the value of 1 when the economy is in recession and 0 otherwise). Asness,

\footnotetext{
${ }^{22} \mathrm{We}$ also considered the timing benefits for long-only commodity portfolios. The results reported in Table IA10 in Internet Appendix, suggest positive, albeit marginally statistically significant, benefits only for the low basis and high value commodity portfolios. As in the case of long/short commodity portfolios, there is no value added from using commodity factor return prediction models.
} 
Moskowitz and Pedersen (2013) find that funding liquidity, measured by innovations in the TED spread, and the market liquidity measure of Pastor and Stambaugh (2003), are significantly positively related to the global momentum factor constructed using equal volatility weights across markets and asset classes (equities, bonds, currencies and commodities). Volatility risk is used as a proxy for changes in the investment opportunity set. Investors require compensation for holding assets that pay poorly during periods of increasing volatility (Ang et al. 2006). Barosso and SantaClara (2015), Wang and Xu (2015) and Daniel and Moskowitz (2016) find that equity momentum tends to do badly in periods of high volatility. We use both global equity and commodity volatility to proxy for volatility risk. Finally, we use the three global factors of Asness, Moskowitz and Pedersen (2013). The three factors include the return of global equity market and the return of global value and momentum premiums constructed across markets and asset classes.

To find the exposure of the variance managed long-short commodity momentum portfolio, we regress the strategy's return on the set of risk factors. Table 9 shows the estimation results. Specification 1 shows the strategy's exposure to the world equity market portfolio and the global value and momentum factors. Exposure to the market and value factors is insignificant while the timing strategy has a beta of 1.019 with respect to the global momentum factor. Given that the global momentum factor includes commodity momentum the positive coefficient estimate is not surprising. When we include commodity momentum in the regression, the coefficient of the global momentum factor becomes insignificant (results available upon request). Exposure to the business cycle and the funding and market liquidity proxies is not significantly different form zero. The variance timing strategy's return is negatively correlated with innovations in world equity and 
commodity volatility but the coefficient is statistically significant only for world equity volatility. ${ }^{23}$ The negative exposure of the managed variance strategy to volatility suggests that the strategy does poorly when volatility is rising provides evidence in support of the hypothesis that the excess return might be partially compensation for volatility risk. However, given the low explanatory power of volatility for the strategy's returns, the profitability of the variance timing momentum strategy might also be indicative of market inefficiencies rather than systematic risk.

\section{Conclusions}

We use a factor-based approach to combine commodity factor portfolios with exposure to commodity factor momentum, the basis, the basis-momentum, hedging pressure and value. These factors were found to jointly explain best the cross-section of commodity returns. Irrespective of the portfolio construction methodology used to create the multifactor commodity portfolio, we find significant improvements in the return to risk trade-off offered by commodity portfolios benchmarked on the S\&P GSCI, the average commodity portfolio and other commercially available indices.

We find strong evidence in favour of variance timing the momentum commodity premium but no evidence that variance timing is beneficial to the other commodity factors. We predict commodity factor portfolio returns using state-of-the art forecasting methodologies and construct dynamic commodity allocation strategies combining expected returns with variance timing. Dynamic commodities strategies based on commodity factor return prediction models provide little value added.

\footnotetext{
${ }^{23}$ The weak relation between commodity volatility and the variance timing strategy might reflect the idiosyncrasies of the commodity market which could make commodity volatility a weak proxy for market wide risk.
} 


\section{References}

Ahmed, S. and Tsvetanov, D., 2016. The predictive performance of commodity futures risk factors. Journal of Banking and Finance, 71, 20-36.

Ang, A., Hodrick, R.J., Xing, Y. and Zhang, X., 2006. The cross-section of volatility and expected returns. Journal of Finance 61, 259-299.

Ang, A., Liu, J. and Schwarz, K., 2019. Using individual stocks or portfolios in tests of factor models. Journal of Financial and Quantitative Analysis, forthcoming.

Asness, C.S., Friedman, J.A., Krail, R.J. and Liew, J.M., 2000. Style timing: Value versus growth. Journal of Portfolio Management 26, 50-60.

Asness, C.S., Moskowitz, T.J. and Pedersen, L.H., 2013. Value and momentum everywhere. The Journal of Finance 68, 929-985.

Avramov, D. and T. Chordia, 2006. Asset pricing models and financial market anomalies. Review of Financial Studies 19, 1001-1040.

Baba Yara, F., Boons, M. and Tamoni, A., 2019. Value Return Predictability Across Asset Classes and Commonalities in Risk Premia. Working paper.

Bakshi, G., Gao, X. and Rossi, A.G., 2019. Understanding the Sources of Risk Underlying the Cross Section of Commodity Returns. Management Science 65, 459-954.

Barillas, F. and Shanken, J., 2017. Which alpha? Review of Financial Studies 30, 1316-1338.

Barroso, P. and Santa-Clara, P., 2015. Momentum has its moments. Journal of Financial Economics 116, 111-120.

Basu, D., Miffre, J., 2013. Capturing the risk premium of commodity futures: The role of hedging pressure. Journal of Banking and Finance 37, 2652-2664.

Bessembinder, H and Chan, K., 1992. Time-varying risk premia and forecastable returns in futures markets. Journal of Financial Economics 32, 169 - 193.

Bhardwaj, G., Gorton, G. and Rouwenhorst, G., 2015. Facts and fantasies about commodity futures ten years later. NBER Working paper, 21243. 
Bodie, Z. and Rosansky, V. 1980. Risk and returns in commodity futures. Financial Analysts Journal May/June, 27-39.

Bollerslev, T., Hood, B., Huss, J. and Pedersen, L.H., 2018. Risk everywhere: Modeling and managing volatility. Review of Financial Studies 31, 2729-2773.

Boons, M. and Prado, M.P., 2019. Basis momentum. Journal of Finance 74, 239-279.

Bork, L., Rovira Kaltwasser, P. and Sercu, P., 2014. Do Exchange Rates Really Help Forecasting Commodity Prices? Working paper.

Chen, Y., Rogoff, K. and Rossi, B., 2010. Can exchange rates forecast commodity prices?. Quarterly Journal of Economics 125, 1145-1194.

Cochrane, J.H., 1999. Portfolio Advice for a Multifactor World. National Bureau of Economic Research Paper, No. w7170.

Cohen, R.B., Polk, C. and Vuolteenaho, T., 2003. The value spread. Journal of Finance 58, 609641

Cootner, P., 1960. Returns to speculators: Telser vs. Keynes. Journal of Political Economy 68, 396-404.

Cootner, Paul H., 1967. Speculation and hedging, Food Research Institute Studies 7, 65-106.

Cumming, D., Hass, L.H. and Schweitzer, D., 2014. Strategic Asset Allocation and the Role of Alternative Investments. European Financial Management 20, 521-547.

Daniel, K. and Moskowitz, T.J., 2016. Momentum crashes. Journal of Financial Economics 122, 221-247.

Daskalaki, C., Kostakis, A. and Skiadopoulos, G., 2014. Are there common factors in individual commodity futures returns? Journal of Banking \& Finance 40, 346-363.

Daskalaki, C., Skiadopoulos, G. and Topaloglou, N., 2017. Diversification benefits of commodities: A stochastic dominance efficiency approach. Journal of Empirical Finance 44, 250269. 
DeMiguel, V., Martin-Utrera, A., Nogales, F. J. and Uppal, R., 2019. A transaction-cost perspective on the multitude of firm characteristics. Review of Financial Studies, forthcoming.

De Roon, F. A., Nijman, T. E., Veld, C., 2000. Hedging pressure effects in futures markets. Journal of Finance 55, 1437-1456.

Dewally, M., Ederington, L., Fernando, C., 2013. Determinants of trader profits in commodity futures markets. Review of Financial Studies 26, 2648-2683.

Dhume, Deepa, 2011. Using durable consumption risk to explain commodities returns, Working paper, Harvard University.

Diebold, F.X. and Mariano, R.S., 1995. Comparing predictive accuracy. Journal of Business \& economic statistics 13, 253-263.

Engle, R. 2002. Dynamic conditional correlation. Journal of Business and Economic Statistics 20, $339-350$.

Erb, C.B., and C.R. Harvey, 2006. The strategic and tactical value of commodity futures. Financial Analysts Journal 62, 69-97.

Fama, E.F., 1996. Multifactor portfolio efficiency and multifactor asset pricing. Journal of financial and quantitative analysis 31, 441-465.

Fama, E. E., 1976, Foundations of Finance, Basic Books, New York.

Fama, E. F. and J. D. MacBeth, 1973. Risk, return, and equilibrium: Empirical tests. Journal of Political Economy 81, 607-636.

Fama, E.F. and French, K.R., 2018. Choosing factors. Journal of Financial Economics 2, 234-252.

Fama, E. F., and French, K. R., 2019. Comparing Cross-Section and Time-Series Factor Models. Review of Financial Studies, forthcoming

Fernandez-Perez, A., Frijns, B., Fuertes, A.M. and Miffre, J., 2018. The skewness of commodity futures returns. Journal of Banking \& Finance 86, 143-158.

Fernandez-Perez, A., Fuertes, A. M. and Miffre, J., 2019. A Comprehensive Appraisal of StyleIntegration Methods. Journal of Banking \& Finance 105, 134-150. 
Fethke, T. and Prokopczuk, M., 2018. Is Commodity Index Investing Profitable? Journal of Index Investing Winter 9, 37-71.

Fleming, J., Kirby, C. and Ostdiek, B., 2001. The economic value of volatility timing. The Journal of Finance 56, 329-352.

Fleming, J., Kirby, C. and Ostdiek, B., 2003. The economic value of volatility timing using "realized" volatility. Journal of Financial Economics 67, 473-509.

Fuertes, A.M., Miffre, J. and Fernandez-Perez, A., 2015. Commodity strategies based on momentum, term structure, and idiosyncratic volatility. Journal of Futures Markets 35, $274-297$.

Gao, X. and Nardari, F., 2018. Do Commodities Add Economic Value in Asset Allocation? New Evidence From Time-varying Moments. Journal of Financial and Quantitative Analysis 53, 365393.

Gargano, A. and Timmermann, A., 2014. Forecasting commodity price indexes using macroeconomic and financial predictors. International Journal of Forecasting 30, 825-843.

Gibbons, M., Ross, S. and Shanken, J., 1989. A test of the efficiency of a given portfolio, Econometrica 57, 1121-1152.

Gorton, G.B., F. Hayashi and Rouwenhorst, K.G., 2013. The fundamentals of commodity futures returns. Review of Finance 17, 35-105.

Gorton, G., Rouwenhorst, G., 2006. Facts and fantasies about commodity futures. Financial Analysts Journal 62, 47-68.

Hansen, P.R. and Timmermann, A., 2012. Choice of sample split in out-of-sample forecast evaluation. European University Institute Working Paper, ECO 2012/10.

Harvey, C.R., Hoyle, E., Korgaonkar, R., Rattray, S., Sargaison, M. and Van Hemert, O., 2018. The Impact of Volatility Targeting. Journal of Portfolio Management 45, 14-33.

Harvey, C.R. and Liu, Y., 2019. Lucky factors. Working Paper, Duke University.

Hirshleifer, D., 1988. Residual risk, trading costs, and commodity futures risk premia. Review of Financial Studies 1, 173-193. 
Hong, H. and Yogo, M., 2012, What does futures market interest tell us about the macroeconomy and asset prices? Journal of Financial Economics 3, 473-490.

Huberman, G. and Kandel, S., 1987. Mean-variance spanning. Journal of Finance 42, 873-888.

Jensen, M.C., Black, F. and Scholes, M.S., 1972. The capital asset pricing model: Some empirical tests. Studies in the theory of capital 81, 79-121.

Kaldor, N., 1939. Speculation and economic stability. Review of Economic Studies 7, 1-27.

Kandel, S., and R. Stambaugh, R., 1996, On the predictability of stock returns: An asset allocation perspective, Journal of Finance, 51, 385-424.

Keynes, J., 1930. A Treatise on Money. Macmillan, London.

Koijen, R. S., Moskowitz, T. J., Pedersen, L. H., and Vrugt, E. B. 2018. Carry. Journal of Financial Economics, 127(2), 197-225.

Ledoit, O. and Wolf, M., 2008. Robust performance hypothesis testing with the Sharpe ratio. Journal of Empirical Finance 15, 850-859.

Levine, A., Ooi, Y.H., Richardson, M. and Sasseville, C., 2018. Commodities for the long run. Financial Analysts Journal 74, 55-68.

Lewellen, J., 2015. The cross section of expected stock returns. Critical Finance Review 4, 1-44.

Lewellen, J., S. Nagel and Shanken, J., 2010. A skeptical appraisal of asset pricing tests. Journal of Financial Economics 96, 175-194.

Lo, A. W., and MacKinlay, A. C., 1990. Data-snooping biases in tests of financial asset pricing models. Review of Financial Studies 3, 431-467.

Ludvigson, S.C. and Ng, S., 2007. The empirical risk-return relation: a factor analysis approach. Journal of Financial Economics 83, 171-222.

Marshall, B.R., Nhut, N.H. and Visaltanachoti, N., 2012. Commodity liquidity measurement and transaction costs. Review of Financial Studies 25, 599-638. 
Miffre, J. and Rallis, G.,2007. Momentum strategies in commodity futures markets. Journal of Banking and Finance 31, 1863-1886.

Miffre, J., 2012. Comparing first, second and third generation commodity indices. Working paper. Miffre, J., 2016. Long-short commodity investing: A review of the literature. Journal of Commodity Markets 1, 3-13.

Moreira, A. and Muir, T., 2017. Volatility-Managed Portfolios. Journal of Finance 72, 1611-1644.

Neely, C. J., D. E. Rapach, J. Tu, and G. Zhou., 2014. Forecasting the equity risk premium: the role of technical indicators. Management Science 60, 1772-1791.

Newey, W.K., West, K.D., 1987. A simple, positive semi-definite, heteroscedasticity and autocorrelation consistent covariance matrix. Econometrica 55, 703-708.

Pástor, L. and Stambaugh, R.F., 2003. Liquidity risk and expected stock returns. Journal of Political economy 111, 642-685.

Rapach, D. E., Strauss, J. K. and Zhou, G., 2010. Out-of-sample equity premium prediction: Combination forecasts and links to the real economy. Review of Financial Studies 23, 821- 862.

Rapach, D. and Zhou, G., 2013. Handbook of economic forecasting. Forthcoming in G. Elliott and A. Timmermann, Eds., Handbook of Economic Forecasting.

Skiadopoulos, G., 2013. Advances in the commodity futures literature: a review. Journal of Derivatives 20, 85-96.

Szymanowska, M., de Roon, F., Nijman, T. and Goorbergh, R. V. D., 2014. An anatomy of commodity futures risk premia. Journal of Finance 69, 453-482.

Treynor, J. and Mazuy, K., 1966. Can mutual funds outguess the market. Harvard business review 44, 131-136.

Yang, F., 2013, Investment shocks and the commodity basis spread. Journal of Financial Economics 110, 164-184.

Wang, K.Q. and Xu, J., 2015. Market volatility and momentum. Journal of Empirical Finance 30, 79-91. 


\section{Table 1. Commodity Futures Data}

This Table lists 38 commodities and tabulates the categories they belong, the exchange on which they are traded, the Bloomberg/CRB ticker symbol, the year of the first recorded observation, the delivery months and the code in the Commitment of Traders reports issued by the Commodity Futures Trading Commission (CFTC). The commodity futures contracts are traded on the Chicago Board of Trade (CBOT), the Chicago Mercantile Exchange (CME), the New York Commodities Exchange (COMEX), the Intercontinental Exchange (ICE), the London Metal Exchange (LME), the New York Mercantile Exchange (NYMEX) and the Tokyo Commodity Exchange (TOCOM).

\begin{tabular}{|c|c|c|c|c|c|c|}
\hline Category & Commodity futures & Exchange & Ticker & Start & Delivery Months & CFTC Code \\
\hline \multirow{7}{*}{ Energy } & Brent Crude Oil & ICE & $\mathrm{CO}$ & 1988:07 & $1: 12$ & ICE website \\
\hline & Gasoil Petroleum & ICE & QS & 1986:06 & $1: 12$ & ICE website \\
\hline & Gasoline & NYMEX & $\mathrm{HU} / \mathrm{XB}$ & 1984:12 & $1: 12$ & 111659 \\
\hline & Heating Oil & NYMEX & $\mathrm{HO}$ & 1978:11 & $1: 12$ & 22651 \\
\hline & Natural Gas & NYMEX & NG & 1990:04 & $1: 12$ & 23651 \\
\hline & Propane & NYMEX & PN & $1987: 08$ & $1: 12$ & 066651 \\
\hline & WTI Crude Oil & NYMEX & $\mathrm{CL}$ & 1983:04 & $1: 12$ & 67651 \\
\hline \multirow{8}{*}{$\begin{array}{c}\text { Grains \& } \\
\text { Oilseeds }\end{array}$} & Canola & WCE & $\mathrm{RC}$ & 1959:09 & $1,3,5,6,7,9,11$ & $\mathrm{NA}$ \\
\hline & Corn & CBOT & C- & 1959:07 & $3,5,7,9,12$ & 002601,002602 \\
\hline & Oats & CBOT & O- & 1986:08 & $3,5,6,9,12$ & 004601 \\
\hline & Rough Rice & CBOT & $\mathrm{RR}$ & 1959:07 & $1,3,5,7,9,11$ & 039601, 039781 \\
\hline & Soybean Meal & CBOT & SM & 1959:07 & $1,3,5,7,8,9,10,12$ & 026603 \\
\hline & Soybean Oil & CBOT & $\mathrm{BO}$ & 1959:07 & $1,3,5,7,8,9,10,12$ & 007601 \\
\hline & Soybeans & CBOT & S- & 1959:07 & $1,3,5,7,8,9,11$ & 005601,005602 \\
\hline & Wheat & CBOT & $\mathrm{W}$ & 1959:07 & $3,5,7,9,12$ & 001601,001602 \\
\hline \multirow{4}{*}{ Livestock } & Feeder Cattle & CME & FC & $1971: 12$ & $1,3,4,5,8,9,10,11$ & 061641 \\
\hline & Lean Hogs & CME & LH & 1966:03 & $2,4,6,7,8,10,12$ & 054641,054642 \\
\hline & Live Cattle & CME & $\mathrm{LC}$ & 1964:12 & $2,4,6,8,10,12$ & 057642 \\
\hline & Pork Belly & $\mathrm{CME}$ & $\mathrm{PB}$ & 1961:09 & $2,3,5,7,9$ & 056641 \\
\hline \multirow{10}{*}{ Metals } & Aluminium & LME & LA & 1998:01 & $1: 12$ & $\mathrm{NA}$ \\
\hline & Copper & NYMEX & HG & 1959:07 & $3,5,7,9,12$ & 085691,085692 \\
\hline & Gold & NYMEX & GC & 1975:01 & $2,4,6,8,10,12$ & 088691 \\
\hline & Lead & LME & LL & 1998:01 & $1: 12$ & NA \\
\hline & Nickel & LME & $\mathrm{LN}$ & 1998:01 & $1: 12$ & NA \\
\hline & Palladium & NYMEX & PA & 1977:01 & $3,6,9,12$ & 075651 \\
\hline & Platinum & NYMEX & PL & 1968:03 & $1,4,7,10$ & 076651 \\
\hline & Silver & NYMEX & SI & 1963:06 & $1,3,5,7,9,12$ & 084691 \\
\hline & Tin & LME & $\mathrm{LT}$ & 1998:01 & $1: 12$ & NA \\
\hline & Zinc & LME & LX & 1998:01 & $1: 12$ & NA \\
\hline \multirow{9}{*}{ Softs } & Cocoa & ICE & $\mathrm{CC}$ & 1959:07 & $3,5,7,9,12$ & 073732 \\
\hline & Coffee & ICE & $\mathrm{KC}$ & 1972:08 & $3,5,7,9,12$ & 083731 \\
\hline & Cotton & ICE & $\mathrm{CT}$ & 1959:07 & $3,5,7,10,12$ & 033661 \\
\hline & Ethanol & CME & DL & 2005:05 & $1: 12$ & 025601 \\
\hline & Lumber & CME & LB & 1969:10 & $1,3,5,7,9,11$ & 058641,058643 \\
\hline & Milk & CME & $\mathrm{DE}$ & 1996:01 & $1,2,3,6,8,9,10$ & 052641 \\
\hline & Orange Juice & ICE & $\mathrm{JO}$ & 1967:02 & $1,3,5,7,9,10$ & 040701 \\
\hline & Rubber & TOCOM & YR & 1992:01 & $1: 12$ & NA \\
\hline & Sugar & ICE & SB & 1961:02 & $3,5,7,10$ & 080732 \\
\hline
\end{tabular}




\section{Table 2. Summary Statistics of Commodities}

This Table reports summary statistics of the 38 commodity futures returns in excess of the risk-free rate for the period 1970:01 to 2018:08. N denotes the number of observations, Mean is the average return, SD is the standard deviation, Skew denotes the skewness, Kurt is the kurtosis, SR is the Sharpe Ratio, AR(1) is the autocorrelation of first order. The last column presents the average basis for each commodity. Mean, SD, Skew, Kurt and SR are annualised. For the annualized skewness and kurtosis, we follow Cumming et al (2014).

\begin{tabular}{|c|c|c|c|c|c|c|c|c|c|}
\hline Category & Commodity futures & $\mathbf{N}$ & Mean & SD & Skewness & Kurtosis & SR & $\operatorname{AR}(\mathbf{1})$ & $\begin{array}{c}\text { Basis } \\
(\text { mean })\end{array}$ \\
\hline \multirow{7}{*}{ Energy } & Brent Crude Oil & 344 & $11.44 \%$ & $32.18 \%$ & 0.128 & 3.282 & 0.355 & 0.232 & -0.001 \\
\hline & Gasoil Petroleum & 387 & $12.44 \%$ & $32.38 \%$ & 0.115 & 3.138 & 0.384 & 0.123 & -0.001 \\
\hline & Gasoline & 405 & $15.17 \%$ & $33.56 \%$ & 0.163 & 3.258 & 0.452 & 0.117 & -0.005 \\
\hline & Heating Oil & 478 & $9.12 \%$ & $31.31 \%$ & 0.249 & 3.379 & 0.291 & 0.116 & 0.000 \\
\hline & Natural Gas & 341 & $-8.17 \%$ & $47.06 \%$ & 0.172 & 3.127 & -0.174 & 0.100 & 0.020 \\
\hline & Propane & 266 & $23.01 \%$ & $46.57 \%$ & 1.071 & 5.972 & 0.494 & -0.010 & -0.006 \\
\hline & WTI Crude Oil & 425 & $8.28 \%$ & $32.45 \%$ & 0.104 & 3.228 & 0.255 & 0.183 & 0.000 \\
\hline \multirow{8}{*}{$\begin{array}{c}\text { Grains \& } \\
\text { Oilseeds }\end{array}$} & Canola & 528 & $-0.64 \%$ & $22.79 \%$ & 0.180 & 3.372 & -0.028 & 0.015 & 0.009 \\
\hline & Corn & 584 & $-2.23 \%$ & $26.19 \%$ & 0.304 & 3.443 & -0.085 & 0.000 & 0.018 \\
\hline & Oats & 584 & $1.04 \%$ & $33.14 \%$ & 0.564 & 4.323 & 0.031 & -0.043 & 0.015 \\
\hline & Rough Rice & 385 & $-5.23 \%$ & $27.65 \%$ & 0.254 & 3.377 & -0.189 & 0.061 & 0.021 \\
\hline & Soybean Meal & 584 & $10.50 \%$ & $33.78 \%$ & 0.609 & 4.237 & 0.311 & 0.049 & -0.001 \\
\hline & Soybean Oil & 584 & $6.31 \%$ & $31.37 \%$ & 0.419 & 3.562 & 0.201 & -0.045 & 0.002 \\
\hline & Soybeans & 584 & $5.31 \%$ & $28.03 \%$ & 0.377 & 3.727 & 0.189 & 0.012 & 0.004 \\
\hline & Wheat & 584 & $-2.13 \%$ & $27.66 \%$ & 0.191 & 3.205 & -0.077 & 0.038 & 0.016 \\
\hline \multirow{4}{*}{ Livestock } & Feeder Cattle & 561 & $2.92 \%$ & $16.79 \%$ & -0.119 & 3.197 & 0.174 & -0.015 & 0.000 \\
\hline & Lean Hogs & 584 & $4.02 \%$ & $27.07 \%$ & 0.040 & 3.085 & 0.149 & -0.033 & 0.016 \\
\hline & Live Cattle & 584 & $4.31 \%$ & $17.56 \%$ & -0.041 & 3.123 & 0.245 & 0.027 & 0.000 \\
\hline & Pork Belly & 496 & $1.17 \%$ & $37.57 \%$ & 0.158 & 3.130 & 0.031 & -0.074 & 0.005 \\
\hline \multirow{10}{*}{ Metals } & Aluminium & 248 & $-1.16 \%$ & $19.76 \%$ & 0.069 & 3.022 & -0.059 & 0.032 & 0.004 \\
\hline & Copper & 584 & $5.94 \%$ & $27.03 \%$ & 0.106 & 3.252 & 0.220 & 0.119 & 0.000 \\
\hline & Gold & 524 & $1.29 \%$ & $19.02 \%$ & 0.133 & 3.283 & 0.068 & -0.002 & 0.008 \\
\hline & Lead & 248 & $9.03 \%$ & $29.30 \%$ & 0.010 & 3.083 & 0.308 & 0.007 & 0.001 \\
\hline & Nickel & 248 & $10.43 \%$ & $35.41 \%$ & 0.071 & 3.014 & 0.295 & 0.039 & 0.000 \\
\hline & Palladium & 500 & $9.91 \%$ & $34.82 \%$ & 0.090 & 3.243 & 0.285 & -0.002 & 0.005 \\
\hline & Platinum & 584 & $3.50 \%$ & $27.08 \%$ & 0.136 & 3.372 & 0.129 & -0.014 & 0.007 \\
\hline & Silver & 584 & $3.06 \%$ & $31.94 \%$ & 0.170 & 3.434 & 0.096 & 0.050 & 0.012 \\
\hline & Tin & 248 & $9.75 \%$ & $24.14 \%$ & 0.128 & 3.111 & 0.404 & 0.082 & -0.001 \\
\hline & Zinc & 248 & $3.13 \%$ & $26.36 \%$ & -0.018 & 3.140 & 0.119 & 0.005 & 0.003 \\
\hline \multirow{9}{*}{ Softs } & Cocoa & 584 & $6.53 \%$ & $31.94 \%$ & 0.187 & 3.107 & 0.204 & -0.051 & 0.003 \\
\hline & Coffee & 553 & $5.18 \%$ & $37.09 \%$ & 0.335 & 3.276 & 0.140 & -0.031 & 0.007 \\
\hline & Cotton & 584 & $4.52 \%$ & $26.27 \%$ & 0.142 & 3.179 & 0.172 & 0.051 & 0.006 \\
\hline & Ethanol & 160 & $36.62 \%$ & $38.16 \%$ & 0.334 & 3.279 & 0.960 & 0.120 & -0.022 \\
\hline & Lumber & 584 & $-2.53 \%$ & $29.53 \%$ & 0.097 & 3.107 & -0.086 & 0.043 & 0.018 \\
\hline & Milk & 272 & $2.02 \%$ & $19.56 \%$ & -0.106 & 3.551 & 0.103 & 0.039 & 0.001 \\
\hline & Orange Juice & 584 & $4.08 \%$ & $31.85 \%$ & 0.435 & 3.704 & 0.128 & -0.078 & 0.006 \\
\hline & Rubber & 320 & $2.35 \%$ & $35.33 \%$ & 0.083 & 3.038 & 0.067 & 0.081 & 0.005 \\
\hline & Sugar & 584 & $5.93 \%$ & $40.27 \%$ & 0.374 & 3.382 & 0.147 & 0.177 & 0.010 \\
\hline
\end{tabular}


Table 3. Commodity Factor Portfolios

This Table presents the descriptive statistics for the period 1970:01 to 2018:08 of the commodity benchmarks i.e. S\&P GSCI and the Average commodity market factor based on the individual commodities (AVG) and the commodity factor portfolios of the low, medium, high and long-short commodity momentum (Panel B), basis (Panel C), basis-momentum (Panel D), skewness (Panel E), inflation beta (Panel F), volatility (Panel G), hedging pressure (Panel H), open interest (Panel I) and value (Panel J). The low and high commodity portfolio returns are returns of equally weighted commodity portfolios of the bottom 30 percent and top 30 percent of the 38 commodities we have in our sample. The mean, standard deviation (SD), Skewness, Kurtosis, Sharpe Ratio (SR) and Adjusted Sharpe Ratio (SR Adjusted, assuming half spread of 4.4 basis points) are annualized.

\begin{tabular}{|c|c|c|c|c|c|c|c|}
\hline & $\mathbf{N}$ & Mean & SD & Skewness & Kurtosis & SR & $\begin{array}{c}\text { SR } \\
\text { adjusted }\end{array}$ \\
\hline \multicolumn{8}{|c|}{ Panel A. Commodity Benchmarks } \\
\hline S\&P GSCI & 584 & $3.90 \%$ & $19.64 \%$ & 0.007 & 3.203 & 0.198 & - \\
\hline AVG & 584 & $5.13 \%$ & $13.61 \%$ & 0.020 & 3.313 & 0.377 & 0.300 \\
\hline \multicolumn{8}{|c|}{ Panel B. Commodity Momentum } \\
\hline Low & 584 & $-1.79 \%$ & $17.29 \%$ & 0.227 & 3.447 & -0.104 & -0.165 \\
\hline Medium & 584 & $4.58 \%$ & $13.85 \%$ & 0.075 & 3.286 & 0.331 & 0.255 \\
\hline High & 584 & $13.13 \%$ & $20.09 \%$ & 0.042 & 3.340 & 0.654 & 0.601 \\
\hline Long Short (High-Low) & 584 & $14.93 \%$ & $20.80 \%$ & 0.076 & 3.144 & 0.718 & 0.616 \\
\hline \multicolumn{8}{|c|}{ Panel C. Commodity Basis } \\
\hline Low & 584 & $12.25 \%$ & $17.57 \%$ & 0.108 & 3.297 & 0.697 & 0.637 \\
\hline Medium & 584 & $4.94 \%$ & $15.70 \%$ & -0.049 & 3.257 & 0.314 & 0.247 \\
\hline High & 584 & $-1.52 \%$ & $15.58 \%$ & 0.108 & 3.199 & -0.097 & -0.165 \\
\hline Long Short (Low-High) & 584 & $13.76 \%$ & $16.98 \%$ & 0.029 & 3.097 & 0.811 & 0.686 \\
\hline \multicolumn{8}{|c|}{ Panel D. Commodity Basis-Momentum } \\
\hline Low & 584 & $-1.69 \%$ & $16.34 \%$ & 0.303 & 3.636 & -0.103 & -0.168 \\
\hline Medium & 584 & $3.22 \%$ & $15.80 \%$ & -0.027 & 3.262 & 0.204 & 0.137 \\
\hline High & 584 & $14.68 \%$ & $16.92 \%$ & 0.184 & 3.289 & 0.867 & 0.805 \\
\hline Long Short (High - Low) & 584 & $16.36 \%$ & $17.60 \%$ & 0.064 & 3.371 & 0.930 & 0.810 \\
\hline \multicolumn{8}{|c|}{ Panel E. Commodity Skewness } \\
\hline Low & 584 & $6.29 \%$ & $16.21 \%$ & 0.064 & 3.150 & 0.388 & 0.323 \\
\hline Medium & 584 & $5.81 \%$ & $15.21 \%$ & 0.020 & 3.246 & 0.382 & 0.312 \\
\hline High & 584 & $3.46 \%$ & $17.63 \%$ & 0.307 & 3.625 & 0.196 & 0.136 \\
\hline Long Short (Low-High) & 584 & $2.84 \%$ & $17.56 \%$ & -0.047 & 3.230 & 0.162 & 0.041 \\
\hline
\end{tabular}




\begin{tabular}{|c|c|c|c|c|c|c|c|}
\hline \multicolumn{8}{|c|}{ Table 3. (Cont'd) } \\
\hline & $\mathbf{N}$ & Mean & SD & Skewness & Kurtosis & SR & $\begin{array}{c}\text { SR } \\
\text { adjusted }\end{array}$ \\
\hline \multicolumn{8}{|c|}{ Panel F. Commodity Inflation beta } \\
\hline Low & 584 & $2.90 \%$ & $17.45 \%$ & 0.259 & 3.565 & 0.166 & 0.106 \\
\hline Medium & 584 & $5.49 \%$ & $14.20 \%$ & 0.135 & 3.241 & 0.387 & 0.312 \\
\hline High & 584 & $6.12 \%$ & $20.45 \%$ & 0.046 & 3.318 & 0.299 & 0.248 \\
\hline Long Short (High - Low) & 584 & $3.22 \%$ & $20.19 \%$ & 0.090 & 3.154 & 0.159 & 0.055 \\
\hline \multicolumn{8}{|c|}{ Panel G. Commodity Volatility } \\
\hline Low & 584 & $1.39 \%$ & $16.63 \%$ & 0.033 & 3.202 & 0.084 & 0.020 \\
\hline Medium & 584 & $5.48 \%$ & $15.86 \%$ & 0.096 & 3.342 & 0.346 & 0.279 \\
\hline High & 584 & $8.48 \%$ & $17.17 \%$ & 0.104 & 3.454 & 0.494 & 0.432 \\
\hline Long Short (High - Low) & 584 & $7.09 \%$ & $17.10 \%$ & 0.123 & 3.215 & 0.415 & 0.291 \\
\hline \multicolumn{8}{|c|}{ Panel H. Commodity Hedging Pressure } \\
\hline Low & 584 & $1.67 \%$ & $19.51 \%$ & 0.807 & 4.957 & 0.085 & 0.031 \\
\hline Medium & 584 & $3.95 \%$ & $17.22 \%$ & 0.214 & 3.524 & 0.230 & 0.168 \\
\hline High & 584 & $6.62 \%$ & $18.16 \%$ & 0.039 & 3.195 & 0.365 & 0.306 \\
\hline Long Short (High - Low) & 584 & $4.95 \%$ & $20.37 \%$ & -0.335 & 3.608 & 0.243 & 0.139 \\
\hline \multicolumn{8}{|c|}{ Panel I. Commodity Open Interest } \\
\hline Low & 584 & $4.54 \%$ & $17.74 \%$ & 0.214 & 3.471 & 0.256 & 0.196 \\
\hline Medium & 584 & $4.14 \%$ & $15.98 \%$ & 0.228 & 3.550 & 0.259 & 0.193 \\
\hline High & 584 & $4.09 \%$ & $18.81 \%$ & 0.364 & 3.696 & 0.217 & 0.161 \\
\hline Long Short (High - Low) & 584 & $-0.45 \%$ & $16.38 \%$ & 0.097 & 3.123 & -0.027 & -0.156 \\
\hline \multicolumn{8}{|c|}{ Panel J. Commodity Value } \\
\hline Low & 584 & $3.54 \%$ & $21.06 \%$ & 0.203 & 3.452 & 0.168 & 0.118 \\
\hline Medium & 584 & $4.51 \%$ & $15.52 \%$ & 0.134 & 3.450 & 0.290 & 0.222 \\
\hline High & 584 & $6.41 \%$ & $16.38 \%$ & 0.277 & 3.512 & 0.391 & 0.327 \\
\hline Long Short (Low-High) & 584 & $2.87 \%$ & $21.15 \%$ & -0.070 & 3.107 & 0.136 & 0.036 \\
\hline
\end{tabular}


Table 4. Cross-Sectional Tests

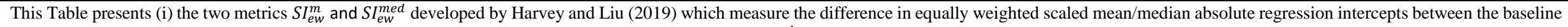

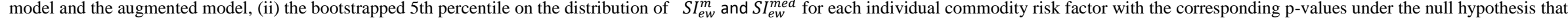

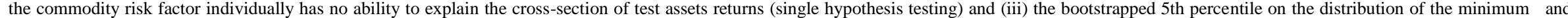

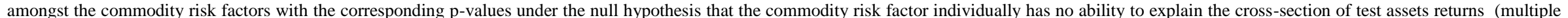

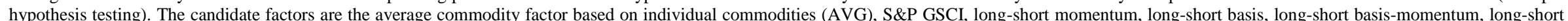

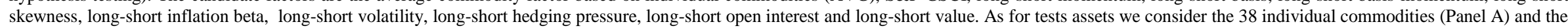
27 commodity portfolio factors, i.e. low, medium and high portfolios (Panel B). The period spans from January 1970 to August 2018.

\begin{tabular}{|c|c|c|c|c|c|c|c|c|c|c|c|c|c|}
\hline \multicolumn{14}{|c|}{ Panel A. Test Assets: Individual Commodities } \\
\hline \multicolumn{7}{|c|}{ Panel A.1: Baseline = No Factor } & \multicolumn{7}{|c|}{ Panel A.2: Baseline $=$ AVG } \\
\hline & \multicolumn{3}{|c|}{ single test } & \multicolumn{3}{|c|}{ single test } & & \multicolumn{3}{|c|}{ single test } & \multicolumn{3}{|c|}{ single test } \\
\hline Factor & $\begin{array}{c}S I_{e w}^{m} \\
(\text { mean })\end{array}$ & $\begin{array}{c}5 \text {-th } \\
\text { percentile }\end{array}$ & p-value & $\begin{array}{c}S I_{e w}^{\text {med }} \\
\text { (median) }\end{array}$ & $\begin{array}{c}5-\text {-th } \\
\text { percentile }\end{array}$ & p-value & Factor & $\begin{array}{c}S I_{e w}^{m} \\
(\text { mean })\end{array}$ & $\begin{array}{c}5 \text {-th } \\
\text { percentile }\end{array}$ & p-value & $\begin{array}{c}S I_{e w}^{\text {med }} \\
\text { (median) }\end{array}$ & $\begin{array}{c}5 \text {-th } \\
\text { percentile }\end{array}$ & p-value \\
\hline AVG & -0.307 & -0.216 & 0.010 & -0.356 & -0.285 & 0.017 & AVG & & & & & & \\
\hline Momentum & -0.119 & -0.033 & 0.000 & -0.001 & -0.079 & 0.386 & Momentum & -0.012 & -0.022 & 0.120 & 0.046 & -0.091 & 0.795 \\
\hline Basis & -0.271 & -0.045 & 0.000 & -0.218 & -0.074 & 0.002 & Basis & -0.215 & -0.038 & 0.000 & -0.292 & -0.081 & 0.000 \\
\hline Basis Momentum & -0.195 & -0.028 & 0.000 & -0.293 & -0.070 & 0.000 & Basis Momentum & -0.172 & -0.030 & 0.000 & -0.118 & -0.082 & 0.021 \\
\hline Skewness & -0.042 & -0.066 & 0.209 & 0.008 & -0.135 & 0.771 & Skewness & -0.052 & -0.052 & 0.048 & 0.077 & -0.120 & 0.929 \\
\hline Inflation beta & -0.058 & -0.085 & 0.111 & 0.071 & -0.094 & 0.795 & Inflation beta & -0.045 & -0.097 & 0.214 & 0.004 & -0.143 & 0.474 \\
\hline Volatility & -0.010 & -0.021 & 0.126 & 0.057 & -0.071 & 0.894 & Volatility & -0.016 & -0.025 & 0.106 & -0.078 & -0.078 & 0.050 \\
\hline Hedging Pressure & -0.037 & -0.064 & 0.173 & -0.146 & -0.161 & 0.068 & Hedging Pressure & 0.130 & -0.041 & 0.992 & 0.258 & -0.118 & 0.975 \\
\hline Open Interest & 0.002 & -0.033 & 0.596 & 0.009 & -0.070 & 0.701 & Open Interest & 0.013 & -0.031 & 0.763 & -0.032 & -0.084 & 0.211 \\
\hline Value & 0.043 & -0.063 & 0.903 & 0.014 & -0.108 & 0.640 & Value & -0.008 & -0.030 & 0.307 & -0.057 & -0.085 & 0.123 \\
\hline \multirow[t]{2}{*}{ SPGSCI } & -0.137 & -0.166 & 0.088 & -0.173 & -0.187 & 0.069 & SPGSCI & 0.180 & -0.121 & 0.974 & 0.091 & -0.168 & 0.675 \\
\hline & \multicolumn{3}{|c|}{ Multiple test } & \multicolumn{3}{|c|}{ Multiple test } & & \multicolumn{3}{|c|}{ Multiple test } & \multicolumn{3}{|c|}{$\begin{array}{c}\text { Multiple test } \\
-0.208 \\
\end{array}$} \\
\hline \multicolumn{14}{|c|}{ Panel A.3: Baseline = AVG + Basis } \\
\hline & \multicolumn{3}{|c|}{ single test } & \multicolumn{3}{|c|}{ single test } & & & & & & & \\
\hline Factor & $\begin{array}{c}S I_{e w}^{m} \\
(\text { mean })\end{array}$ & $\begin{array}{c}5 \text {-th } \\
\text { percentile }\end{array}$ & p-value & $\begin{array}{c}S I_{e w}^{\text {med }} \\
\text { (median) }\end{array}$ & $\begin{array}{c}5 \text {-th } \\
\text { percentile }\end{array}$ & p-value & & & & & & & \\
\hline $\begin{array}{c}\text { AVG } \\
\text { Momentum } \\
\text { Basis }\end{array}$ & 0.039 & -0.031 & 0.971 & 0.169 & -0.109 & 0.985 & & & & & & & \\
\hline Basis Momentum & -0.046 & -0.038 & 0.027 & 0.008 & -0.105 & 0.601 & & & & & & & \\
\hline Skewness & -0.008 & -0.036 & 0.309 & -0.083 & -0.117 & 0.085 & & & & & & & \\
\hline Inflation beta & -0.014 & -0.113 & 0.628 & -0.020 & -0.195 & 0.516 & & & & & & & \\
\hline Volatility & 0.007 & -0.032 & 0.664 & 0.017 & -0.103 & 0.660 & & & & & & & \\
\hline Hedging Pressure & 0.186 & -0.060 & 1.000 & 0.480 & -0.144 & 1.000 & & & & & & & \\
\hline Open Interest & 0.015 & -0.030 & 0.824 & 0.045 & -0.090 & 0.829 & & & & & & & \\
\hline Value & -0.056 & -0.031 & 0.006 & 0.014 & -0.085 & 0.644 & & & & & & & \\
\hline \multirow[t]{2}{*}{ SPGSCI } & 0.395 & -0.122 & 1.000 & 0.531 & -0.192 & 1.000 & & & & & & & \\
\hline & \multicolumn{3}{|c|}{ Multiple test } & \multicolumn{2}{|c|}{$\begin{array}{c}\text { Multiple test } \\
-0.248\end{array}$} & 0.605 & & \multicolumn{3}{|c|}{ Multiple test } & \multicolumn{3}{|c|}{ Multiple test } \\
\hline
\end{tabular}


Table 4. (Cont'd)

\begin{tabular}{|c|c|c|c|c|c|c|c|c|c|c|c|c|c|}
\hline \multicolumn{14}{|c|}{$\begin{array}{l}\text { Table 4. (Cont'd) } \\
\end{array}$} \\
\hline \multicolumn{14}{|c|}{ Panel B. Test Assets: Commodity Portfolios } \\
\hline \multicolumn{7}{|c|}{ Panel B.1: Baseline = No Factor } & \multicolumn{7}{|c|}{ Panel B.2: Baseline = AVG } \\
\hline & \multicolumn{3}{|c|}{ single test } & \multicolumn{3}{|c|}{ single test } & \multicolumn{4}{|c|}{ single test } & \multicolumn{3}{|c|}{ single test } \\
\hline Factor & $\begin{array}{c}S I_{e w}^{m} \\
(\text { mean })\end{array}$ & $\begin{array}{c}5-\text {-th } \\
\text { percentile }\end{array}$ & p-value & $\begin{array}{c}S I_{e w}^{\text {med }} \\
\text { (median) }\end{array}$ & $\begin{array}{c}5-\text {-th } \\
\text { percentile }\end{array}$ & p-value & Factor & $\begin{array}{c}S I_{e w}^{m} \\
(\text { mean })\end{array}$ & $\begin{array}{c}5 \text {-th } \\
\text { percentile }\end{array}$ & $p$-value & $\begin{array}{c}S I_{e w}^{\text {med }} \\
\text { (median) }\end{array}$ & $\begin{array}{c}5 \text {-th } \\
\text { percentile }\end{array}$ & $p$-value \\
\hline AVG & -0.479 & -0.350 & 0.002 & -0.604 & -0.401 & 0.000 & AVG & & & & & & \\
\hline Momentum & -0.216 & -0.101 & 0.003 & -0.230 & -0.117 & 0.006 & Momentum & -0.288 & -0.100 & 0.000 & -0.168 & -0.126 & 0.028 \\
\hline Basis & -0.272 & -0.106 & 0.000 & -0.270 & -0.119 & 0.000 & Basis & -0.287 & -0.087 & 0.000 & -0.279 & -0.105 & 0.000 \\
\hline Basis Momentum & -0.123 & -0.080 & 0.014 & -0.042 & -0.093 & 0.151 & Basis Momentum & -0.360 & -0.091 & 0.000 & -0.109 & -0.092 & 0.030 \\
\hline Skewness & 0.038 & -0.077 & 0.920 & 0.083 & -0.130 & 0.941 & Skewness & -0.069 & -0.075 & 0.062 & -0.047 & -0.196 & 0.279 \\
\hline Inflation beta & -0.050 & -0.083 & 0.139 & -0.123 & -0.124 & 0.051 & Inflation beta & -0.007 & -0.068 & 0.392 & -0.063 & -0.177 & 0.225 \\
\hline Volatility & -0.054 & -0.056 & 0.052 & -0.043 & -0.062 & 0.105 & Volatility & -0.111 & -0.066 & 0.004 & -0.070 & -0.065 & 0.043 \\
\hline Hedging Pressure & 0.022 & -0.081 & 0.938 & -0.064 & -0.115 & 0.134 & Hedging Pressure & -0.040 & -0.048 & 0.072 & -0.132 & -0.168 & 0.090 \\
\hline Open Interest & 0.003 & -0.055 & 0.665 & -0.002 & -0.119 & 0.553 & Open Interest & -0.003 & -0.042 & 0.416 & -0.002 & -0.160 & 0.519 \\
\hline Value & 0.070 & -0.108 & 0.857 & 0.056 & -0.139 & 0.778 & Value & 0.027 & -0.033 & 0.990 & -0.178 & -0.164 & 0.041 \\
\hline \multirow[t]{3}{*}{ SPGSCI } & -0.313 & -0.289 & 0.040 & -0.312 & -0.351 & 0.082 & SPGSCI & 0.013 & -0.034 & 0.902 & -0.125 & -0.102 & 0.034 \\
\hline & \multicolumn{3}{|c|}{ Multiple test } & \multicolumn{3}{|c|}{ Multiple test } & & \multicolumn{3}{|c|}{ Multiple test } & \multicolumn{3}{|c|}{ Multiple test } \\
\hline & & -0.362 & 0.003 & & -0.420 & 0.000 & & & -0.126 & 0.000 & & -0.265 & 0.041 \\
\hline \multicolumn{4}{|c|}{ Panel B.3: Baseline =AVG + Basis-Momentum } & \multicolumn{3}{|c|}{ Panel B.3: Baseline = AVG + Basis } & \multicolumn{4}{|c|}{$\begin{array}{c}\text { Panel B.4: Baseline =AVG + Basis-Momentum } \\
+ \text { Momentum }\end{array}$} & \multicolumn{3}{|c|}{$\begin{array}{l}\text { Panel B.4: Baseline = AVG + } \\
\text { Basis + Hedging Pressure }\end{array}$} \\
\hline & \multicolumn{3}{|c|}{ single test } & \multicolumn{3}{|c|}{ single test } & \multicolumn{4}{|c|}{$\begin{array}{ll}\text { single test } \\
\end{array}$} & & & \\
\hline Factor & $\begin{array}{c}S I_{e w}^{m} \\
(\text { mean })\end{array}$ & $\begin{array}{c}\text { 5-th } \\
\text { percentile }\end{array}$ & p-value & $\begin{array}{c}S I_{e w}^{\text {med }} \\
\text { (median) }\end{array}$ & $\begin{array}{c}5 \text {-th } \\
\text { percentile }\end{array}$ & p-value & Factor & $\begin{array}{c}S I_{e w}^{m} \\
(\text { mean })\end{array}$ & $\begin{array}{c}5 \text {-th } \\
\text { percentile }\end{array}$ & p-value & $\begin{array}{c}S I_{e w}^{\text {med }} \\
\text { (median) }\end{array}$ & $\begin{array}{c}5 \text {-th } \\
\text { percentile }\end{array}$ & p-value \\
\hline Momentum & -0.190 & -0.115 & 0.005 & -0.167 & -0.101 & 0.008 & Momentum & & & & 0.067 & -0.101 & 0.794 \\
\hline Basis & -0.147 & -0.086 & 0.003 & & & & Basis & -0.079 & -0.056 & 0.016 & & & \\
\hline Basis Momentum & & & & -0.102 & -0.089 & 0.036 & Basis Momentum & & & & 0.235 & -0.118 & 0.989 \\
\hline Skewness & -0.011 & -0.076 & 0.414 & -0.078 & -0.203 & 0.197 & Skewness & -0.021 & -0.085 & 0.353 & 0.017 & -0.224 & 0.827 \\
\hline Inflation beta & 0.000 & -0.082 & 0.804 & 0.005 & -0.218 & 0.672 & Inflation beta & -0.036 & -0.138 & 0.285 & 0.057 & -0.226 & 0.818 \\
\hline Volatility & -0.121 & -0.086 & 0.012 & -0.112 & -0.109 & 0.047 & Volatility & -0.067 & -0.084 & 0.097 & 0.253 & -0.116 & 0.963 \\
\hline Hedging Pressure & -0.114 & -0.080 & 0.016 & -0.511 & -0.150 & 0.000 & Hedging Pressure & -0.113 & -0.086 & 0.018 & & & \\
\hline Open Interest & -0.020 & -0.071 & 0.273 & -0.076 & -0.160 & 0.170 & Open Interest & -0.004 & -0.075 & 0.533 & -0.025 & -0.212 & 0.374 \\
\hline Value & 0.009 & -0.034 & 0.862 & -0.287 & -0.073 & 0.000 & Value & -0.207 & -0.077 & 0.000 & 0.305 & -0.101 & 0.986 \\
\hline \multirow[t]{2}{*}{ SPGSCI } & 0.015 & -0.044 & 0.884 & -0.162 & -0.113 & 0.022 & SPGSCI & -0.012 & -0.030 & 0.176 & 0.228 & -0.122 & 0.977 \\
\hline & \multicolumn{3}{|c|}{ Multiple test } & \multicolumn{3}{|c|}{ Multiple test } & \multicolumn{4}{|c|}{ Multiple test } & & -0.317 & 0.929 \\
\hline
\end{tabular}


Table 4. (Cont'd)

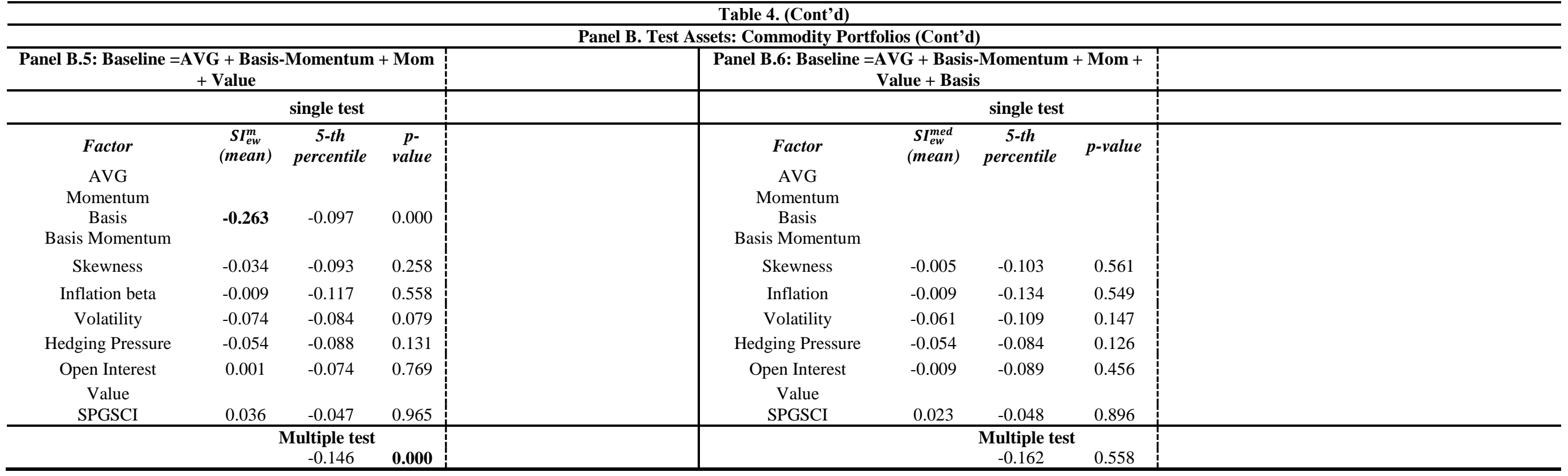




\section{Table 6. Commodity Portfolios Under Different Weighting Schemes}

This Table tabulates the results for the equally weighted portfolio of the individual commodities (average commodity factor (i.e. AVG) (Panel A), the combined long-only commodity factor portfolios (Panel B) and the combined long-short commodity factor portfolios (Panel C). We consider different portfolio construction techniques, i.e. equal (EW), inverse variance (IV), minimum variance (MinVar), maximum diversification portfolio (MDP), Mean-Variance (MV, $\gamma=5$ ) weighting schemes and the crosssectional strategy (CS) following Lewellen (2015). Average return (Mean), standard deviation (SD), Skewness (Skew), Kurtosis (Kurt), Sharpe Ratio (SR), alpha (against the average commodity factor (AVG)), standard error (se), Appraisal Ratio $\left(\frac{\text { alpha }}{\text { se }}\right)$ and Certainty Equivalent Return (CER, assuming power utility and $\gamma=5$ ) is annualised. Alpha and se estimates are based on the timeseries regression of the combined commodity portfolio $R_{t}^{c o m b}$ on the average commodity factor (AVG), i.e. $R_{t}^{c o m b}=\alpha+\beta A V G_{t}+\varepsilon_{t}$. The last column denotes the p-value of the difference in the CERs of the commodity portfolio and the AVG commodity factor using the Diebold and Mariano (1995) test). The covariance matrix of average realized utility is estimated using Newey and West (1987) HAC standard errors. We test the hypothesis that the Sharpe ratios of the combined portfolio and the average commodity factor are equal using the methodology of Ledoit and Wolf (2008) with 5000 bootstrap resamples and a block size equal to $b=5$. The forecast evaluation period spans January 1970 to August 2018. We generate forecasts using a rolling window approach of 60 months. We use Newey-West (1987) standard errors for the statistical significance of alpha. * denotes significance at $10 \%$ level, ** denotes significance at $5 \%$ level and $* * *$ denotes significance at $1 \%$ level.

\begin{tabular}{|c|c|c|c|c|c|c|c|c|c|c|c|}
\hline & $\mathbf{N}$ & Mean & SD & Skew & Kurt & SR & alpha & se & $\begin{array}{c}\text { Appraisal } \\
\text { Ratio }\end{array}$ & CER & $\begin{array}{l}\text { p-value } \\
(\Delta C E R)\end{array}$ \\
\hline \multicolumn{12}{|c|}{ Panel A. Average Commodity Factor } \\
\hline AVG & 584 & $5.13 \%$ & $13.61 \%$ & 0.020 & 3.313 & 0.377 & - & - & - & $0.43 \%$ & - \\
\hline \multicolumn{12}{|c|}{ Panel B. Combined Long-only factor portfolios } \\
\hline $\mathbf{E W}$ & 584 & $10.62 \%$ & $14.82 \%$ & 0.047 & 3.268 & $0.716^{* * *}$ & $5.34 \% * * *$ & 0.049 & 1.083 & $5.23 \%$ & 0.000 \\
\hline IV & 584 & $10.24 \%$ & $14.57 \%$ & 0.073 & 3.271 & $0.703 * * *$ & $5.08 \% * * *$ & 0.050 & 1.009 & $5.08 \%$ & 0.000 \\
\hline MinVar & 584 & $8.77 \%$ & $14.53 \%$ & 0.161 & 3.339 & $0.604 * * *$ & $3.95 \% * * *$ & 0.069 & 0.572 & $3.68 \%$ & 0.002 \\
\hline MDP & 584 & $8.94 \%$ & $14.62 \%$ & 0.075 & 3.299 & $0.612 * * *$ & $3.84 \% * * *$ & 0.056 & 0.691 & $3.71 \%$ & 0.009 \\
\hline MV & 584 & $11.75 \%$ & $17.20 \%$ & 0.019 & 3.385 & $0.683 * * *$ & $6.24 \% * * *$ & 0.091 & 0.686 & $4.14 \%$ & 0.942 \\
\hline CS & 584 & $11.59 \%$ & $18.40 \%$ & 0.089 & 3.388 & $0.630 * * *$ & $5.86 \% * * *$ & 0.104 & 0.564 & $3.06 \%$ & 0.586 \\
\hline \multicolumn{12}{|c|}{ Panel C. Combined Long-short factor portfolios } \\
\hline $\mathbf{E W}$ & 584 & $10.58 \%$ & $8.44 \%$ & 0.057 & 3.205 & $1.253 * * *$ & $9.70 \% * * *$ & 0.089 & 1.087 & $9.18 \%$ & 0.001 \\
\hline IV & 584 & $10.76 \%$ & $8.75 \%$ & 0.067 & 3.198 & $1.230 * * *$ & $10.68 \% * * *$ & 0.088 & 1.220 & $9.25 \%$ & 0.001 \\
\hline MinVar & 584 & $8.69 \%$ & $8.23 \%$ & -0.018 & 3.308 & $1.056^{* * *}$ & $8.98 \% * * *$ & 0.082 & 1.096 & $7.23 \%$ & 0.007 \\
\hline MDP & 584 & $8.69 \%$ & $8.22 \%$ & -0.019 & 3.295 & $1.057 * * *$ & $9.01 \% * * *$ & 0.082 & 1.102 & $7.22 \%$ & 0.007 \\
\hline MV & 584 & $11.44 \%$ & $14.35 \%$ & 0.117 & 3.318 & $0.797 * *$ & $10.67 \% * * *$ & 0.142 & 0.751 & $6.56 \%$ & 0.078 \\
\hline CS & 584 & $12.96 \%$ & $18.29 \%$ & 0.087 & 3.158 & $0.709 * *$ & $11.77 \%$ *** & 0.180 & 0.653 & $4.92 \%$ & 0.644 \\
\hline
\end{tabular}




\section{Table 7. Spanning Regressions of $1^{\text {st }}, 2^{\text {nd }}$ and $3^{\text {rd }}$ Generation Commodity Indices}

Panels A, B and C of Table 7 present the spanning regressions of the first, second and third generation commodity indices, respectively. The baseline model includes the average commodity factor (AVG) and the long short commodity factors, i.e. Momentum, Basis, Basis-Momentum, Hedging Pressure and Value. The sample period spans from January 1970 to August 2018. Int. denotes the intercept of the time series regression, $R_{a d j}^{2}$ denotes the adjusted $R^{2}$ of the regression, and $s e$ denotes the standard error of the time series regressions. Newey-West (1987) t-statistics are in parenthesis. For first generation commodity indices we consider the S\&P Goldman Sachs Commodity Index (SPGSCI), Dow-Jones-UBS Commodity Index (DJUBS) and the Deutsche Bank Liquid Commodity Index (DBLCI). For second generation commodity indices we consider DBLCI-Optimum Yield (DBLCI-OY), Morningstar Long-Only Commodity Index (MSDIL) and the Morningstar Long/Flat Commodity Index (MSDILF). For the third generation commodity indices we consider the Morningstar Short-Only Commodity Index (MSDIS), Morningstar Long/Short Commodity Index (MSDILS) and Morningstar Short/Flat Commodity Index (MSDISF). Note that MSDIL, MSDILF, MSDIS, MSDILS and MSDISF start from January 1980, DJUBS from February 1991, DBLCI from February 1990 and DBLCI-OY from February 1989. The end date is August 2018.

Panel A. 1st generation commodity indices

\begin{tabular}{lcccccccccc}
\hline & Int. & AVG & Momentum & Basis & $\begin{array}{c}\text { Basis- } \\
\text { Momentum }\end{array}$ & $\begin{array}{c}\text { Hedging } \\
\text { Pressure }\end{array}$ & Value & $\boldsymbol{R}_{\text {adj }}^{2}$ & se & \\
\hline \multirow{2}{*}{ SPGSCI } & -0.002 & 1.117 & 0.012 & 0.120 & -0.036 & -0.047 & -0.042 & $65.23 \%$ & 0.033 \\
& $(-1.522)$ & $(21.602)$ & $(0.183)$ & $(2.695)$ & $(-0.788)$ & $(-1.042)$ & $(-0.740)$ & \\
\multirow{2}{*}{ DJUBS } & -0.003 & 1.107 & 0.020 & -0.011 & -0.026 & -0.050 & -0.076 & $86.75 \%$ & 0.015 \\
& $(-3.005)$ & $(36.087)$ & $(0.764)$ & $(-0.357)$ & $(-0.745)$ & $(-2.462)$ & $(-3.046)$ & & \\
\multirow{2}{*}{ DBLCI } & 0.001 & 0.594 & 0.170 & 0.024 & 0.057 & -0.087 & 0.039 & $45.83 \%$ & 0.026 \\
& $(0.737)$ & $(10.275)$ & $(4.996)$ & $(0.524)$ & $(1.182)$ & $(-2.558)$ & $(0.871)$ & \\
\hline
\end{tabular}

\begin{tabular}{|c|c|c|c|c|c|c|c|c|c|}
\hline \multicolumn{10}{|c|}{ Panel B. 2nd generation commodity indices } \\
\hline & Int. & AVG & Momentum & Basis & $\begin{array}{c}\text { Basis- } \\
\text { Momentum }\end{array}$ & $\begin{array}{l}\text { Hedging } \\
\text { Pressure }\end{array}$ & Value & $R_{a d j}^{2}$ & se \\
\hline \multirow[t]{2}{*}{ DBLCI-OY } & 0.001 & 1.175 & 0.068 & 0.007 & -0.018 & -0.114 & -0.046 & $71.71 \%$ & 0.026 \\
\hline & $(0.649)$ & $(19.218)$ & $(1.111)$ & $(0.134)$ & $(-0.358)$ & $(-2.846)$ & $(-0.878)$ & & \\
\hline \multirow[t]{2}{*}{ MSDIL } & 0.000 & 1.109 & 0.018 & -0.003 & -0.016 & -0.048 & -0.062 & $83.12 \%$ & 0.018 \\
\hline & $(-0.315)$ & $(35.527)$ & $(0.688)$ & $(-0.113)$ & $(-0.504)$ & $(-2.416)$ & $(-2.264)$ & & \\
\hline \multirow[t]{2}{*}{ MSDILF } & 0.001 & 0.483 & 0.166 & -0.007 & -0.025 & -0.001 & -0.050 & $63.26 \%$ & 0.016 \\
\hline & $(1.220)$ & $(10.500)$ & (9.642) & $(-0.354)$ & $(-1.055)$ & $(-0.046)$ & $(-1.997)$ & & \\
\hline
\end{tabular}

\begin{tabular}{|c|c|c|c|c|c|c|c|c|c|c|}
\hline \multicolumn{11}{|c|}{ Panel C. 3rd generation commodity indices } \\
\hline & Int. & AVG & Momentum & Basis & $\begin{array}{c}\text { Basis- } \\
\text { Momentum }\end{array}$ & $\begin{array}{l}\text { Hedging } \\
\text { Pressure }\end{array}$ & Value & $\mathbf{A V G}^{\wedge} \mathbf{2}$ & $R_{a d j}^{2}$ & se \\
\hline \multirow[t]{2}{*}{ MSDIS } & 0.000 & -1.097 & 0.050 & 0.000 & 0.037 & 0.057 & 0.027 & - & $81.49 \%$ & 0.018 \\
\hline & $(-0.101)$ & $(-37.593)$ & $(1.908)$ & $(-0.005)$ & $(1.147)$ & (3.113) & $(1.114)$ & - & & \\
\hline \multirow[t]{2}{*}{ MSDILS } & 0.000 & 0.144 & 0.244 & -0.001 & -0.054 & 0.003 & -0.082 & 2.223 & $36.52 \%$ & 0.023 \\
\hline & $(0.266)$ & $(2.439)$ & $(9.062)$ & $(-0.019)$ & $(-1.795)$ & $(0.094)$ & $(-2.693)$ & (3.011) & & \\
\hline \multirow[t]{2}{*}{ MSDISF } & 0.001 & -0.368 & 0.075 & 0.003 & -0.023 & 0.002 & -0.030 & 1.115 & $54.18 \%$ & 0.013 \\
\hline & (1.176) & $(-10.952)$ & (4.232) & $(0.172)$ & $(-1.327)$ & (0.129) & $(-1.597)$ & (3.891) & & \\
\hline
\end{tabular}




\section{Table 8. Variance Managed and Return-forecast Commodity Portfolios}

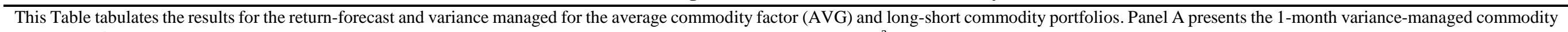

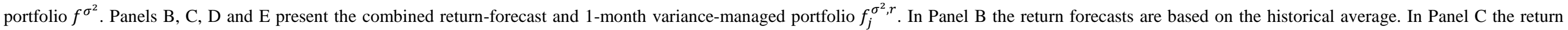

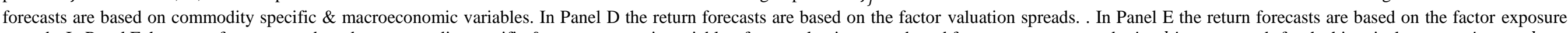

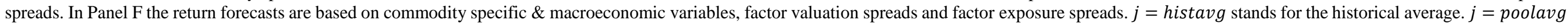

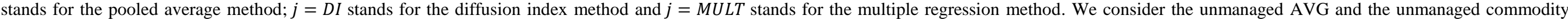

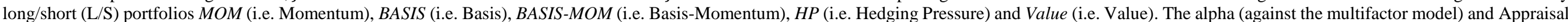

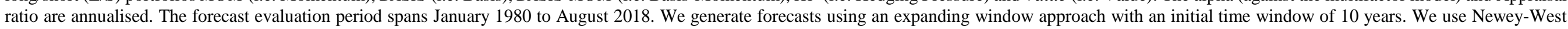
(1987) standard errors for the statistical significance of alpha.* denotes significance at $10 \%$ level, ** denotes significance at $5 \%$ level and $* * *$ denotes significance at $1 \%$ level.

\begin{tabular}{|c|c|c|c|c|c|c|c|c|c|c|c|c|}
\hline & \multicolumn{2}{|c|}{$f \equiv A V G$} & \multicolumn{2}{|c|}{$f \equiv L / S M O M$} & \multicolumn{2}{|c|}{$f \equiv L / S$ BASIS } & \multicolumn{2}{|c|}{$f \equiv L / S \quad B A S I S-M O M$} & \multicolumn{2}{|c|}{$f \equiv L / S H P$} & \multicolumn{2}{|c|}{$f \equiv L / S V A L U E$} \\
\hline & alpha & $\begin{array}{c}\text { Appraisal } \\
\text { Ratio }\end{array}$ & alpha & $\begin{array}{c}\text { Appraisal } \\
\text { Ratio }\end{array}$ & alpha & $\begin{array}{c}\text { Appraisal } \\
\text { Ratio }\end{array}$ & alpha & $\begin{array}{c}\text { Appraisal } \\
\text { Ratio }\end{array}$ & alpha & $\begin{array}{c}\text { Appraisal } \\
\text { Ratio }\end{array}$ & alpha & $\begin{array}{c}\text { Appraisal } \\
\text { Ratio }\end{array}$ \\
\hline \multicolumn{13}{|c|}{ Panel A. Variance Managed Portfolios } \\
\hline$f^{\sigma^{2}}$ & $-0.18 \%$ & -0.020 & $7.62 \% * * *$ & 0.634 & $-0.37 \%$ & -0.044 & $2.49 \%$ & 0.198 & $1.17 \%$ & 0.139 & $0.15 \%$ & 0.013 \\
\hline \multicolumn{13}{|c|}{ Panel B. Return-forecast and Variance Managed commodity portfolios using historical average } \\
\hline$f_{\text {histavg }}^{\sigma^{2}, r}$ & $-1.65 \%$ & -0.198 & $7.35 \% * * *$ & 0.634 & $-0.72 \%$ & -0.084 & $2.53 \%$ & 0.198 & $-1.85 \%$ & -0.136 & $-2.44 \%$ & -0.177 \\
\hline \multicolumn{13}{|c|}{ Panel C. Variance Managed and Return-forecast commodity portfolios using commodity specific \& macroeconomic variables } \\
\hline$f_{\text {poolavg }}^{\sigma^{2}, r}$ & $-1.34 \%$ & -0.157 & $6.97 \% * * *$ & 0.627 & $-0.74 \%$ & -0.083 & $2.41 \%$ & 0.188 & $1.09 \%$ & 0.087 & $-3.11 \%$ & -0.205 \\
\hline$f_{D I}^{\sigma^{2}, r}$ & $1.32 \%$ & 0.124 & $5.59 \% * * *$ & 0.450 & $-2.89 \%$ & -0.277 & $1.27 \%$ & 0.099 & $1.31 \%$ & 0.088 & $-6.47 \%$ & -0.367 \\
\hline$f_{M U L T}^{\sigma^{2}, r}$ & $-0.85 \%$ & -0.078 & $1.31 \%$ & 0.076 & $3.55 \%$ & 0.248 & $2.69 \%$ & 0.188 & $-0.67 \%$ & -0.043 & $-2.65 \%$ & -0.138 \\
\hline \multicolumn{13}{|c|}{ Panel D. Variance Managed and Return-forecast commodity portfolios using factor valuation spreads } \\
\hline$f_{M U L T}^{\sigma^{2}, r}$ & - & - & $8.07 \% * * *$ & 0.644 & $-0.94 \%$ & -0.106 & $1.69 \%$ & 0.143 & $-0.40 \%$ & -0.028 & $2.48 \%$ & 0.128 \\
\hline \multicolumn{13}{|c|}{ Panel E. Variance Managed and Return-forecast commodity portfolios using factor exposure spreads } \\
\hline$f_{M U L T}^{\sigma^{2}, r}$ & - & - & $7.03 \%$ *** & 0.628 & $-0.23 \%$ & -0.022 & $1.70 \%$ & 0.130 & $-2.40 \%$ & -0.156 & $2.48 \%$ & 0.128 \\
\hline \multicolumn{13}{|c|}{ 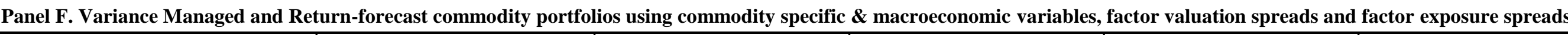 } \\
\hline$f_{\text {poolavg }}^{\sigma^{2}, r}$ & - & - & $7.06 \% * * *$ & 0.632 & $-0.73 \%$ & -0.082 & $2.33 \%$ & 0.183 & $0.80 \%$ & 0.064 & $-2.87 \%$ & -0.193 \\
\hline$f_{D I}^{\sigma^{2}, r}$ & - & - & $5.31 \% * * *$ & 0.453 & $-2.91 \%$ & -0.262 & $1.05 \%$ & 0.081 & $1.31 \%$ & 0.090 & $-6.03 \%$ & -0.334 \\
\hline$f_{M U L T}^{\sigma^{2}, r}$ & - & - & $3.30 \% *$ & 0.192 & $3.85 \%$ & 0.270 & $1.11 \%$ & 0.081 & $-1.94 \%$ & -0.122 & $-2.16 \%$ & -0.111 \\
\hline
\end{tabular}




\section{Table 9. Risk Exposures of Variance Managed Long-Short Commodity Momentum}

Table 9 presents the risk exposures of the variance managed long-short commodity momentum portfolio. We run 6 regressions, where we regress the variance managed long-short commodity momentum portfolio on the following risk factors: (a) the returns of the global equity index and the value and momentum "everywhere" factors of Asness, Moskowitz, and Pedersen (2013), (b) the business cycle, a dummy variables that takes the value of 1 when the US economy is in recession and 0 when in expansion), (c) the innovations in the global equity volatility, measured as the change in the monthly global equity volatility based on the daily returns of the global equity index, (d) the innovations in the commodity volatility, measured as the change in monthly commodity volatility based on the daily returns of the average commodity factor, (e) innovations of the TED spread, and (f) innovations in the market liquidity measure of Pastor and Stambaugh (2003). $R_{a d j}^{2}$ is the adjusted $R^{2}$ of the regression. * denotes significance at $10 \%$ level, ** denotes significance at $5 \%$ level and $* * *$ denotes significance at $1 \%$ level.

\begin{tabular}{|c|c|c|c|c|c|c|}
\hline & 1 & 2 & 3 & 4 & 5 & 6 \\
\hline Constant & $0.009 * * *$ & $0.015^{* * *}$ & $0.014 * * *$ & $0.014 * * *$ & $0.014 * * *$ & $0.014 * * *$ \\
\hline Global equity & 0.062 & & & & & \\
\hline Value "everywhere" & $0.234^{*}$ & & & & & \\
\hline Momentum "everywhere" & $1.019 * * *$ & & & & & \\
\hline Business cycle & & -0.006 & & & & \\
\hline Innovations in world equity volatility & & & $-1.180 * * *$ & & & \\
\hline Innovations in commodity volatility & & & & -0.108 & & \\
\hline Innovations in TED & & & & & -0.006 & \\
\hline Innovation in market liquidity & & & & & & 0.013 \\
\hline
\end{tabular}




\title{
Internet Appendix to "Factor Based Commodity Investing"
}

\author{
Athanasios Sakkas ${ }^{1}$, Nikolaos Tessaromatis ${ }^{2}$
}

\begin{abstract}
The Internet Appendix comprises five sections. In Section A, we provide additional analysis and tables. In Section B, we provide an analytical description of the commodity factors and the $1^{\text {st }}, 2^{\text {nd }}$ and $3^{\text {rd }}$ generation commercial commodity indices, employed in the study. In Section $\mathrm{C}$, we provide a description of the predictor variables used for timing commodity factor portfolios. Section D presents the portfolio construction techniques. Finally, Section E describes the return forecasting methodologies and statistics used for evaluation.
\end{abstract}

\footnotetext{
${ }^{1}$ Contact address: Nottingham University Business School, University of Nottingham, Nottingham, UK. Tel: +44(0) 115 9515264. Email: athanasios.sakkas@nottingham.ac.uk

${ }^{2}$ Contact address: EDHEC Business School and EDHEC Risk Institute, Nice, France. Tel: +44(0) 2073325605.

E-mail: nikolaos.tessaromatis@edhec.edu
} 


\section{A. Additional Analysis \& Supplementary Tables}

\section{A.1 The return and risk of commodity portfolios in sub-sample periods}

In our analysis in the main paper we present the performance of the commodity factor portfolios based on the full sample period (January 1970 - August 2018). In this section, we investigate the performance of the commodity benchmarks and the long-short commodity factors before and after the financialization of commodity futures, i.e. January 1970 to December 2004 and January 2005 to August 2018. We choose December 2004 motivated by a number of academic studies that dates the start of the financialization of commodity futures around 2004 (see e.g. Büyüksahin, Haigh and Robe, 2010, Irwin and Sanders, 2011, Tang and Xiong, 2012, Hamilton and Wu, 2015, Boons, De Roon, and Szymanowska, 2014, Basak and Pavlova, 2016, among others). On average, across commodity portfolios returns and risks are higher in the pre-financialization period (see Table IA1). The average Sharpe ratios of commodity factor premia in the pre-financialization period $1970-2004$ is 0.42 . In the postfinancialization period 2005-2018 the combination of lower returns and standard deviations results in Sharpe ratios that are lower ( 0.34 across all commodity premia) but still economically significant. We also examine the performance of commodity portfolios for the period spanning from January 1990 to August 2018, a period which coincides with the advent of commercial commodity indices. Performance statistics are similar to the full sample period (Table 3 of the main paper). Table IA 2 tabulates the results.

\section{A.2 Commodity factor portfolios using alternative weighting schemes}

The commodity factor portfolios presented in Table 3 of the main paper are constructed by equally weighting individual commodities. Since equal weighting does not require estimates of return, risk and correlations is by definition free from estimation risk. At the other 
extreme, portfolios based on mean-variance optimization require estimation of expected returns and the variance covariance matrix and are therefore sensitive to estimation risk. In between the polar cases of equal weights (no information about returns and risks) and meanvariance optimization (full information about returns and risks) there are portfolio construction methodologies that only require variance and correlations estimates (minimum variance and maximum diversification) or variance estimates (inverse variance). Alternative portfolio construction methodologies represent different trade-offs between estimation risk and the risk of using the wrong portfolio construction model ${ }^{3}$ (optimality risk). Since there is little agreement about which of the alternative methodologies is superior, we use all of them in subsequent analysis.

In this section we construct high, low and long-short commodity portfolios using, in addition to equal weights (EW), mean-variance optimization (MV), minimum variance (MinVar), inverse variance (IV) and maximum diversification (MDP). ${ }^{4}$ We report in Table IA3 the annualized average, standard deviation and Sharpe ratios of alternative commodity factor portfolios. We test the hypothesis that the Sharpe ratios of the IV or MDP or MinVar or MV and the equally weighting scheme (EW) of the low, high, long-short and market commodity portfolios are equal, using the methodology of Ledoit and Wolf (2008) with 5000 bootstrap resamples and a block size equal to $b=5$.

We find that the differences in the Sharpe Ratios of equally weighted commodity factor portfolios and commodity factor portfolios based on alternative portfolio construction methodologies are statistically insignificant for most portfolios. Only 5 out of 108 commodity

\footnotetext{
${ }^{3}$ The alternative weighting methodologies considered here are consistent with mean-variance optimization under specific assumptions about expected returns and risk (see Hallerbach, 2015). For the mean-variance, inverse variance, the minimum variance and the maximum diversification portfolios the estimation of variances and covariances are based on a rolling window approach with an initial sample of 5 years (60 months). For the meanvariance portfolio we also generate forecasts of returns based on a rolling window approach with an initial sample of 5 years (60 months).

${ }^{4}$ See Section D for a detailed description of the portfolio construction techniques.
} 
portfolios, namely the IV high basis, MinVar long-short inflation beta, MDP high hedging pressure, IV and MinVar low value, exhibit statistically significant higher Sharpe Ratio relative to the Sharpe Ratio of the corresponding EW commodity portfolios. The evidence suggests that the risk adjusted performance of equally weighted long-only (low/high), long-short and market commodity factor portfolios is robust to alternative weighting schemes. Since equally weighted commodity portfolios have similar performance to portfolios based on alternative weighting schemes, from this point on we report only results based on the EW weighting scheme.

An alternative to factor-based portfolios are commodity portfolios based on individual commodities. The average commodity portfolio (AVG) is constructed by weighting individual commodities equally. It is however possible that the alternative portfolio construction rules discussed earlier might produce better commodity portfolios than the average commodity portfolio. The last line in Table IA3 shows performance statistics for commodity portfolios based on individual commodities and alternative portfolio construction methods. As the table shows, commodity portfolios based on inverse volatility, maximum diversification and minimum variance weights achieve higher Sharpe ratios than the average commodity portfolio. However, the differences in Sharpe ratios are not statistically significant.

\section{A.3 Correlation Matrix of Commercial Indices and Commodity Factors}

Table IA4 tabulates the correlation matrix of the long-only, long-short commodity factors and the three generation of commercial indices. The high and positive correlation between first and second generation indices and the long-only factor portfolios is expected since a large part of all long-only portfolio returns is due to the return of the commodity market portfolio. The average correlation between the factor portfolios and first generation indices is 0.65 . The average correlation between commodity factor portfolios and second generation indices is slightly higher at 0.67 , a surprising result given that second generation indices are constructed 
on the basis of exposure to some of the commodity factors. The correlation between the third generation indices and the long-short commodity portfolios are close to zero in most cases, except the positive but low correlation between the MSDILS and the long/short momentum commodity factor. The zero correlation between the commodity factor premia and the MSDIS and MSDISF is due the fact that both indices are essentially short (rather than long/short) positions in commodities. The positive but low correlation between the MSDILS and the momentum premium should reflect the fact that the MSDILS is a momentum timing strategy as opposed to the purely momentum strategy driving the return of the commodity momentum factor.

\section{A.4 Do commodity factor portfolios add value to the traditional equity-bond}

\section{asset mix?}

Belousova and Dorfleitner (2012) provide a brief taxonomy of studies and the methodologies used to assess the benefits of adding commodities in traditional portfolios. The evidence from recent studies remain controversial and inconclusive. Daskalaki and Skiadopoulos (2011) conclude that commodities add little value to traditional stock/bond portfolios. Bessler and Wolff (2015) using various asset allocation techniques, document mixed results on the diversification benefits of individual commodities and passive commodity indices in a traditional asset mix. Daskalaki, Skiadopoulos and Topaloglou (2017) use a stochastic dominance approach and find that commodities (especially active and enhanced commodity indices) add value when incorporated in a stock-bond-cash portfolio. Fethke and Prokopczuk (2018) provide mixed evidence on the ability of commodities proxied by various enhanced commodity indices to add, out of sample, value in the traditional stock/bond mix. 
In this section we test whether the combined commodity portfolio enhances the traditional equity-bond efficient frontier. To do so, we run spanning regressions on the equally weighted long-only and long-short combined commodity portfolios on equities and bonds. We use the MSCI US Equity Index and the Bloomberg Barclays US Aggregate Bond Index to proxy for the traditional asset classes. We also include the Fama-French US equity small minus big portfolio (SMB), the high minus low portfolio (HML), the winners minus losers (WML), the robust minus weak portfolio (RMW) and the conservative minus aggressive portfolio (CMA). The evidence presented in Table IA5 suggests that the equity market, equity factors and bonds do not span the return of long-short or long-only combined commodity factor portfolios. The intercepts from the spanning regressions are positive and statistically significantly different from zero. Adding the combined commodity portfolio to the traditional equity and bond portfolios does improve the investment efficient frontier.

\section{A.5 Predictor variables statistics and statistics for forecasting evaluation}

Table IA6 tabulates the descriptive statistics of the predictor variables used in Section 7 of the main paper.

Table IA7 reports the out-of-sample forecasting statistics $R_{O S}^{2}($ Campbell and Thompson, 2008) and MSFE-adjusted (Clark and West, 2007) for the individual predictor variables (Panel A) and the forecasting methods based on macroeconomic \& commodity predictor variables (Panel B), factor valuation spreads (Panel C), factor exposure spreads (Panel D) and macroeconomic \& commodity variables, factor valuation spreads and factor exposure spreads (Panel E). The evidence suggests that macroeconomic and commodity specific variables have some ability to forecast returns when using the average pooled and diffusion index methodologies to combine individual variable forecasts but the evidence is weak. The multiple regression model performs the worst producing consistently negative for all portfolios. 
Forecasts based on valuation spreads are uniformly worse than the historical average with negative for most portfolios except the basis-momentum factor premium. Similarly, factor exposure spreads are not better than the historical average, except for the high basis-momentum factor portfolio. Combining macroeconomic and commodity specific variables with valuation and factor exposure spreads does not improve forecasting performance.

\section{A.6 The Relation between Commodity Variance and Next Month Commodity Return, Variance and Sharpe ratio}

Table IA8 reports the results from the predictive regression of lagged variance (based on one-month daily commodity factor premia) for next month's return, variance and Sharpe ratio (calculated monthly as the ratio of average portfolio return over the volatility of the portfolio based on daily observations in the month).

The results suggest that past variance is a good predictor of future variance but largely unrelated to future commodity factor premia and Sharpe ratios, except for the commodity momentum premium where the relation is negative and significant. Boons and Prado (2019) examine the predictive ability of aggregate commodity variance for the basis-momentum, the basis and the momentum commodity factors using data over the period August 1960-February 2014. Using weighted least squares, they find a positive and statistically significant predictive coefficient for the basis-momentum factor portfolio but no predictability for the momentum and basis portfolios. This is inconsistent with the evidence of no relationship between the basis and the basis-momentum factors and the negative and significant relation for the momentum commodity factor portfolio and commodity variance reported in this paper. The difference in the results reported by Boons and Prado (2019) could be due to (a) the different periods used (Boons and Prado: August 1960-February 2014, this paper: January 1970-August 2018), (b) the different number of commodity futures included in the long/short basis-momentum 
portfolio of Boons and Prado (four long/four short) and this paper (11 long/11 short, at the end of the sample) and c) the use of market commodity variance (Boons and Prado (2019) use the variance of the equally weighted portfolio of individual commodities, instead of the factor portfolio variance used in our paper and by Moreira and Muir, 2017, in their study of variance timing of equity factor). When we also use lagged market commodity variance instead of the factor portfolio variance, we find no relation between commodity factor portfolio returns and variance.

\section{A.7 Detailed performance statistics for the timing average commodity and long-short commodity factor portfolios}

Table IA9 tabulates the detailed descriptive statistics shown in Table 8 of the main paper. Specifically, in Table IA9 we present the detailed performance statistics for the variancemanaged and the combined return-forecast and variance-managed commodity portfolios, i.e. (a) average commodity factor, (b) the long-short commodity momentum, (c) long-short commodity basis, (d) long-short commodity basis-momentum, (e) long-short commodity hedging pressure, (f) long-short commodity value.

\section{A.8 The timing benefits for long-only commodity portfolios}

In this section we report the performance statistics of the timing long-only commodity factor portfolios, i.e. (a) long-only momentum, (b) long-only basis, (c) long-only basismomentum, (d) long-only hedging pressure, (e) long-only value. Table IA10 tabulates the results. The results suggest positive, albeit marginally statistically significant, benefits only for the low basis and high value commodity portfolios. 


\section{B. Description of Commodity Factors and $1^{\text {st }}, 2^{\text {nd }}$ and $3^{\text {rd }}$ Generation Commercial Commodity Indices}

\section{B.1 Commodity Factors}

Momentum: We define momentum for each commodity $j$ as the cumulative excess futures returns from the prior 12 months, i.e. Momentum $\mathrm{m}_{\mathrm{t}}^{\mathrm{j}}=\prod_{\mathrm{s}=\mathrm{t}-11}^{\mathrm{t}}\left(1+\mathrm{R}_{\mathrm{j}, \mathrm{t}, \mathrm{s}}^{\mathrm{T}_{1}}\right)-1$, where $\mathrm{R}_{\mathrm{j}, \mathrm{t}, \mathrm{s}}^{\mathrm{T}_{1}}$ denotes the future returns of the nearby contracts of commodity $j$.

Basis: The basis for each commodity $j$ is defined as $B a s i s_{t}^{j}=\frac{F_{j, t}^{T_{2}}}{F_{j, t}^{T_{1}}}-1$, where $F_{j, t}^{T_{1}}$ and $F_{j, t}^{T_{2}}$ are the futures prices of the nearby and next-to-nearby contracts, respectively.

Basis-Momentum: The basis-momentum is defined as the difference between momentum in a first- and second-nearby futures strategy, i.e. BasisMomentun $n_{t}^{j}=\prod_{s=t-11}^{t}\left(1+R_{j, t, s}^{T_{1}}\right)-$ $\prod_{s=t-11}^{t}\left(1+R_{j, t, s}^{T_{2}}\right)$, where $R_{j, t}^{T_{1}}$ and $R_{j, t}^{T_{2}}$ stand for the future returns of the nearby and nextto-nearby contracts of commodity $j$, respectively.

Skewness: We compute the Pearson's moment coefficient of skewness $\left(S k^{j}\right)$ of each commodity $j$, at end-of-month $t$ based on the daily first-nearby futures returns $\left(R_{d, j}^{T_{1}}\right)$ of the previous 12-months, i.e. $S k_{t}^{j}=\frac{\frac{1}{d} \Sigma_{d=1}^{D}\left(R_{d 1}^{T_{1}}-\mu_{j, t}\right)^{3}}{\sigma_{j, t}^{3}}$, where $D$ is the number of daily observations; $\mu$ and $\sigma$ stand for the mean and variance estimates of the daily return distribution, respectively.

Inflation beta: The inflation beta $\left(\beta^{C P I}\right)$ is defined as the slope $\left(\beta_{j}^{C P I}\right)$ of a regression of 60month first-nearby futures returns $\left(R_{j, t}^{T_{1}}\right)$ of commodity $j$, on unexpected inflation changes in monthly inflation $(\triangle C P I)$, i.e. $R_{j, t}^{T_{1}}=a_{j}+\beta_{j, t}^{C P I} \Delta C P I_{s}+e_{j, s}, s=t-59, \ldots, t$. 
Volatility: We define the volatility as the coefficient of variation $(C V)$, i.e. the variance-per absolute mean first-nearby futures returns during prior 36 month, $C V_{t}^{j}=\frac{\sigma_{j, t}^{2}}{\left|\mu_{j, t}\right|}$, where $\sigma_{j, t}^{2}$ and $\left|\mu_{j, t}\right|$ stand for the variance and mean absolute mean returns of the first nearby contract of commodity $j$, respectively

Hedging Pressure: Hedging Pressure $\left(H P_{t}^{j}\right)$ for each commodity $j$ is defined as the net short open interest (i.e. short minus long) over total open interest of hedgers during the last 12 months of the commodity j, i.e. $H P_{t}^{j}=\sum_{i=0}^{12-1} \frac{\text { Short }_{H, j, t-i}-\text { Long }_{H, j, t-i}}{\text { Long }_{H, j, t-i}+\text { Short }_{H, j, t-i}}$.

Open Interest: The open interest $(O I)$ factor for each commodity $j$ is defined as the monthly change in total open interest, i.e. $\Delta O I_{j, t}=O I_{j, t}-O I_{j, t-1}$.

Value: We measure the Value for each commodity $j$ as the average futures prices of the first nearby futures contracts 4.5 to 5.5 years ago over the futures price of the first nearby futures contract at time $t$ for each commodity $j$, i.e. Value $_{t}^{j}=\ln \left(\frac{F_{j, t-60}^{T_{1}}}{F_{j, t}^{T_{1}}}\right)$, where $F_{j, t-60}^{T_{1}}$ is the average futures price of the first nearby (nearest to maturity) futures contract from 4.5 to 5.5 years ago.

\section{B.2 $1^{\text {st }}, 2^{\text {nd }}$ and $3^{\text {rd }}$ Generation Commercial Commodity Indices}

\section{B.2.1 First Generation Commercial Commodity Indices}

Deutsche Bank Liquid Commodity Index (DBLCI): DBLCI includes 6 commodities from the energy, precious metals, industrial metals and grain sectors, namely the WTI Crude Oil, Heating Oil, Aluminium, Gold, Wheat and Corn. The weight of each commodity is held fixed and is determined by world production and inventory data. WTI Crude Oil and Heating Oil are rolled over on a monthly basis, whilst Aluminium, Gold, Wheat and Corn are rolled over on an annual basis. 
S\&P Goldman Sachs Commodity Index (S\&P GSCI): The S\&P Goldman Sachs Commodity Index (S\&P GSCI) is a buy and hold world production-based index, with a large weight in the energy sector (approximately 70\%). It is one of the most popular commodity benchmarks used by institutional investors and can be traded via over-the-counter swap agreements, exchange-traded funds (ETF) and exchange-traded notes (ETN) (Stoll and Whaley, 2010). The S\&P GSCI consists of 24 deep and liquid individual commodity futures indices. These include six energy related commodities (crude oil, Brent crude oil, heating oil, gasoil, natural gas and unleaded gasoline), seven metals (gold, silver, copper, aluminium, zinc, nickel and lead), and eleven agricultural commodities (corn, soybeans, wheat (CBOT), wheat (Kansas), sugar, coffee, cocoa, cotton, lean hogs, live cattle and feeder cattle). Geman (2009) and Erb and Harvey (2006) provide a detailed description of the S\&P GSCI commodity index.

Dow-Jones-UBS Commodity Index (DJ UBSCI): DJ UBSCI is a broadly diversified index comprised of 19 commodities and priced by reference to commodity futures contracts from major commodity sectors: Energy, Agriculture, Industrial Metals, Precious Metals and Livestock. The weight of each commodity is determined primarily by liquidity data, and to a smaller extent by production. The maximum acceptable weight per sector is $33 \%$ and per individual commodity is $15 \%$. Allocation to individual commodities face an additional lower bound constrain of $2 \%$

\section{B.2.2 Second Generation Commercial Commodity Indices}

DBLCI-Optimum Yield (DBLCI-OY): DBLCI-OY includes 6 commodities, namely the WTI Crude Oil, Heating Oil, Aluminium, Gold, Wheat and Corn. The weight of each commodity is held fixed and is determined by world production and inventory data. It employs a rule based approach when it 'rolls' from one futures contract to another contract for each commodity (from the list of tradable futures which expire in the next thirteen months) that 
maximises the positive roll yield in backwardated markets and minimise the negative roll yield in contango markets.

Morningstar Long-Only Commodity Index (MSDIL): MSDIL includes the 20 most liquid commodity futures contracts, traded in US exchanges and ranked in the top $95 \%$ by the 12 month average of total dollar value of open interest. The index take a long position in all eligible commodities.

Morningstar Long/Flat Commodity Index (MSDILF): MSDILF includes the 20 most liquid commodity futures contracts, traded in US exchanges and ranked in the top $95 \%$ by the 12 month average of total dollar value of open interest. The index uses a momentum rule based on the 12-month moving average of a commodity's linked price (which includes both price changes and roll yield) to determine on a monthly basis if it will hold long or flat positions in each commodity. If the commodity's price is above its moving average, the index goes long; if the price is below the moving average, the index takes a flat position (moves into cash).

\section{B.2.3 Third Generation Commercial Commodity Indices}

Morningstar Short-Only Commodity Index (MSDIS): MSDIS includes the 20 most liquid commodity futures contracts, traded in US exchanges and ranked in the top $95 \%$ by the 12 month average of total dollar value of open interest. The index is short all eligible commodities.

Morningstar Long/Short Commodity Index (MSDILS): MSDILS includes the 20 most liquid commodity futures contracts, traded in US exchanges and ranked in the top $95 \%$ by the 12-month average of total dollar value of open interest. The index uses a momentum rule based on the 12-month moving average of a commodity's linked price (which includes both price changes and roll yield) to determine on a monthly basis if it will hold long or short positions in each commodity. If the commodity's price is above its moving average, the index goes long; if the price is below the moving average, the index goes short. 
Morningstar Short/Flat Commodity Index (MSDISF): MSDISF includes the 20 most liquid commodity futures contracts, traded in US exchanges and ranked in the top $95 \%$ by the 12 month average of total dollar value of open interest. The index uses a momentum rule based on the 12-month moving average of a commodity's linked price (which includes both price changes and roll yield) to determine on a monthly basis if it will hold short or flat positions in each commodity. If the commodity's price is below its moving average, the index goes short; if the price is above the moving average, the index takes a flat position (moves into cash).

\section{Description of Predictor Variables}

\section{C.1 Macroeconomic \& Commodity Specific Variables}

Aggregate basis: To construct the aggregate commodity basis we follow Hong and Yogo(2012); first, we calculate the basis for each individual commodity $j$ as $\operatorname{Basis}_{t}^{j}=\left(\frac{F_{j, t}^{T_{2}}}{F_{j, t}^{T_{1}}}\right)^{\frac{1}{\left(T_{2}-T_{1}\right)}}-1$, then we compute the sector basis based on the median basis within sector $^{5}$ and finally we compute the equally weighted average of sector basis across the five sectors.

AUD-USD growth: Growth of the exchange rate of the Australian Dollar to 1 USD. We source the data from Datastream.

CAD-USD growth: Growth of the exchange rate of the Canadian Dollar to 1 USD. We source the data from Datastream.

Default spread: The Default Spread is the difference between BAA corporate bond yield and the yield on the 10-year US Treasury Bond. We source the data from Datastream.

\footnotetext{
${ }^{5}$ We use the median basis and not mean (average) basis, since the former is less sensitive to outliers (Hong and Yogo, 2012).
} 
IP production growth: The monthly growth in industrial production sourced from FRED.

Kilian: Kilian's real economic activity index (Kilian, 2009, 2019) as s proxy for the demand for industrial commodities in global markets. We source the index from Kilian's personal website, i.e. https://sites.google.com/site/lkilian2019/research/data-sets

M1 growth: The log growth in the monthly M1 money stock, sourced from FRED.

Market interest: To construct the commodity market interest we follow Hong and Yogo (2012). First, we sum the total number of futures (outstanding or traded) across all commodities in each of the five sectors to get the dollar open interest within each sector. Then we compute the monthly growth rates of the sector open interest and the aggregate growth rate of open interest as an equally weighted average of the growth rate for each of the five sectors. Finally, we smooth these monthly growth rate series by taking a 12-month geometric average. Data on open interest have been sourced from the Commitment of Traders reports issued by the Commodity Futures Trading Commission (CFTC). CFTC data are available electronically since January 1986. For the period that spans July 1960 to December 1985 we collect the data from Yogo's web page. ${ }^{6}$ The CFTC data for Brent Crude Oil and Gasoil are sourced from the Intercontinental Exchange (ICE) website. ${ }^{7}$

NZD-USD growth: Growth of the exchange rate of the New Zealand Dollar to 1 USD. We source the data from Datastream.

SA RAND-USD growth: Growth of the exchange rate of the South African RAND to 1 USD. We source the data from Datastream.

\footnotetext{
${ }^{6}$ Yogo's website: https://sites.google.com/site/motohiroyogo/home/research.

${ }^{7}$ ICE's website: https://www.theice.com/marketdata/reports/122
} 
T-bill 1m: 1-month T-bill rate source from French Library, i.e. http://mba.tuck.dartmouth.edu/pages/faculty/ken.french/data_library.html

Unemployment rate: The monthly unemployment rate sourced from FRED.

Yield spread: The yield spread is defined as the difference between the US 10-year long term yield on government bonds and the Treasury bill rate (T-bill $1 \mathrm{~m})$. We source the US 10 -year long term yield from Datastream.

\section{C.2 Factor Valuation Spreads}

MOM valuation spread: The commodity momentum valuation spread is defined as the difference in the value signals of the winner and loser commodity portfolios.

BASIS valuation spread: The commodity basis valuation spread is defined as the difference in the value signals of the low basis and high basis commodity portfolio.

BASIS-MOM valuation spread: The commodity basis-momentum valuation spread is defined as the difference in the value signals of the high and low basis-momentum commodity portfolios

HP valuation spread: The commodity hedging pressure valuation spread is defined as the difference in the value signals of the high and low hedging pressure commodity portfolios.

VALUE spread: The value spread is the difference in the value signals of the high and low value commodity portfolios.

\section{C.3 Factor Exposure Spreads}

MOM exposure spread: The commodity momentum exposure spread is defined as the difference in the factor exposure of the high and low momentum portfolios. 
BASIS exposure spread: The commodity basis exposure spread is defined as the difference in the factor exposure of the high and low basis portfolios.

BASIS-MOM exposure spread: The commodity basis-momentum exposure spread is defined as the difference in the factor exposure of the high and low basis-momentum portfolios.

HP exposure spread: The commodity hedging pressure exposure spread is defined as the difference in the factor exposure of the high and low hedging pressure portfolios.

VALUE exposure spread: The value exposure spread is defined as the difference in the factor exposure of the high and low value portfolios.

\section{Portfolio Construction Techniques}

The equally weighted commodity factor portfolio invests proportionally in each of the three commodity factors and since it does not use estimates of return or risk, is by definition free of estimation risk. EW will be mean-variance optimal when commodity factor expected returns, variances, and correlations are the same.

The inverse variance (IV) portfolio rule (Kirby and Ostdiek, 2012) depends only on variance and assumes that the correlation between the factors is zero. IV weights are calculated according to the following equation:

$$
w_{i t}=\frac{\left(1 / \sigma_{i t}^{2}\right)^{h}}{\sum_{i=1}^{N}\left(1 / \sigma_{i t}^{2}\right)^{h}}, i=1,2,3
$$

where $\sigma_{i t}^{2}$ the estimated variance of commodity $i$.

MinVar rule is the short sale-constrained minimum-variance portfolio of commodity factors. The weights of the minimum- variance portfolio are defined in the following equation: 


$$
\min _{w} w^{T} \sum w, \text { s.t. } \mathbf{1}^{T} w=1 \text { and } w_{i} \geq 0, i=1,2,3
$$

MinVar portfolios will be mean-variance optimal under the assumption that expected returns are equal.

The maximum diversification portfolio (MDP) has been proposed by Choueifaty and Coignard (2008) and maximizes the diversification ratio defined as

$$
\frac{w^{T} \sigma}{\sqrt{w^{T} \Sigma w}}, \text { and } w_{i} \geq 0, i=1,2,3
$$

where $\sigma=\left[\begin{array}{l}\sigma_{1} \\ \sigma_{2} \\ \sigma_{3}\end{array}\right]$. The numerator is equal to portfolio volatility ignoring correlations while the denominator is the portfolio volatility that takes into account correlation (diversification). The MDP portfolio will be optimal if the assets included in the portfolio have the same Sharpe ratio.

The cross-sectional strategy proposed by Lewellen (2015) involves running each month $t$ a cross-sectional regression of the individual commodities on their corresponding lagged characteristics; in our setting as per commodity characteristics we employ the basis, momentum, basis-momentum, hedging pressure and value for each individual commodity. The cross-sectional regression is defined as $R_{j, t}^{T_{1}}=\gamma_{0, t}+\gamma_{1, t}^{\prime} C_{j, t-1}+e_{j, t}$, where $R_{j}^{T_{1}}$ stands for the futures monthly excess (of the risk-free rate) returns on a fully collateralized futures position of the first nearby contracts, for each commodity $j$ and $\boldsymbol{C}_{j}$ is a vector of the five commodity characteristics basis, momentum, basis-momentum, hedging pressure and value for each commodity $j$. Hence, for each month $t$ we have an estimate of the coefficients $\widehat{\gamma_{0, t}}$ and $\widehat{\gamma_{1, t}}$. Then, using a rolling window of 60 months we estimate the expected cross-sectional forecasts for each commodity $j$ each month $t$ as $E\left(R_{j, t}^{T_{1}}\right)$ defined as follows: $E\left(R_{j, t}^{T_{1}}\right)=\widehat{\gamma_{1, s}}{ }^{\prime} C_{j, t-1}$, where $\widehat{\gamma_{1, S}}$ is the 60-month average coefficients for every rolling period $s$. 
To construct the commodity factor strategy, we sort at the end of each month the future returns of the 38 commodities based on their expected cross sectional forecasts and then calculate the equally weighted return of the top 30 percent and bottom 30 percent of the commodities.

\section{E. Return Forecasting Methodologies and Evaluation}

Model 1: the historical average.

Model 2: the forecast combination model (pooled average model)

We use the following linear model:

$$
r_{i, t+1}=a_{i}+\beta_{\iota} x_{i, t}+\varepsilon_{\iota, t+1} \text { where } i=1,2, \ldots K
$$

where $r_{i, t+1}$ is excess return at time $t+1, x_{i, t}$ is the $i$ th predictor at time $t$, and $K$ is the total number of predictive variables. We produce the next period out-of-sample individual forecasts $\hat{r}_{i, t+1}$ using the available information up to time $t$ as follows:

$$
\hat{r}_{i, t+1}=\hat{a}_{i, t}+\hat{\beta}_{l, t} x_{i, t}
$$

where $\hat{a}_{i, t}$ and $\widehat{\beta}_{l, t}$ are the estimates of $a_{i}$ and $\beta_{\iota}$, respectively. Finally, we combine the individual forecasts $\hat{r}_{i, t+1}$ with equal weights and the combination forecast $\hat{r}_{t+1}^{\text {poolavg }}$ is given by:

$$
\hat{r}_{t+1}^{\text {poolavg }}=\frac{1}{K} \sum_{i=1}^{K} \hat{r}_{i, t+1}
$$

We use the predictive variables for each asset and detail them in Section 7.1.

Model 3: the diffusion index model.

The latent factor model is defined as follows:

$$
r_{t+1}=a+\sum_{i=1}^{K} \beta_{i} l_{i, t}+\varepsilon_{t+1}
$$

We estimate the latent factors $l$ based on a principal component analysis (Bai, 2003; Stock and Watson, 2006). The diffusion index forecast $\hat{r}_{t+1}^{D I}$ is given by

$$
\hat{r}_{t+1}^{D I}=\hat{a}+\sum_{i=1}^{K} \hat{\beta}_{i} \hat{l}_{i, t}
$$


where $\hat{a}$ and $\hat{\beta}$ are the OLS estimates of $a$ and $\beta$, and $\hat{l}$ is the principal component estimate of $l$ using the conditional information up to time $t$.

Model 4: the multiple regression model

The multiple regression is defined as follows:

$$
r_{t+1}=a+\sum_{i=1}^{K} \beta_{i} x_{i, t}+\varepsilon_{t+1}
$$

where $r_{t+1}$ is excess return at time $t+1, x_{i, t}$ is the $i$ th predictor at time $t$, and $K$ is the total number of predictive variables. The multiple regression forecast $\hat{r}_{t+1}^{M U K T}$ is given by

$$
\hat{r}_{t+1}^{M U L T}=\hat{a}+\sum_{i=1}^{K} \hat{\beta}_{i} x_{i, t}
$$

where $\hat{a}$ and $\hat{\beta}$ are the OLS estimates of $a$ and $\beta$ using data available up to the time $t$.

We employ two measures to assess the predictability of commodity returns out-of-sample. The first measure is the out-of-sample $R^{2}$ (Campbell and Thompson, 2008), denoted by $R_{O S}^{2}$, defined as:

$$
R_{O S}^{2}=1-\frac{M S F E_{i}}{M S F E_{0}}
$$

where $M S F E_{i}=\frac{1}{T-n_{1}} \sum_{s=1}^{T-n_{1}}\left(r_{i, n_{1}+s}-\hat{r}_{i, n_{1}+s}\right)^{2}$ is the mean squared forecast error for the predictive regression forecast $i$ over the forecast evaluation period, $M S F E_{0}=$ $\frac{1}{T-n_{1}} \sum_{s=1}^{T-n_{1}}\left(r_{n_{1}+s}-\bar{r}_{n_{1}+s}\right)^{2}$ is the mean squared forecast error of historical average benchmark forecast, $r$ denotes the realised return , $\hat{r}$ denotes the return forecast from the predictive regression, $\bar{r}$ denotes the average expected return, $n_{1}$ stands for the initial in-sample estimation period, $T$ denotes the number full-sample observations. Positive values $R_{O S}^{2}$ indicates that the predictive regression-forecasting model outperforms the historical average model in terms of $\operatorname{MSFE}\left(M S F E_{0}<M S F E_{i}\right)$.

The MSFE-adjusted test of Clark and West (2007), tests the null hypothesis that the historical average $M S F E_{0}$ is less than or equal to the predictive regression $M S F E_{i}$ against the 
one-sided alternative hypothesis that the historical average $M S F E_{0}$ is greater than the predictive regression $M S F E_{i}$; this corresponds to $H_{0}: R_{O S}^{2} \leq 0$ against $H_{1}: R_{O S}^{2}>0$. Clark and West (2007) define:

$$
\hat{f}_{i, n_{1}+s}=\hat{u}_{0, n_{1}+s}-\left[\hat{u}_{1, n_{1}+s}-\left(\bar{r}_{n_{1}+s}-\hat{r}_{i, n_{1}+s}\right)^{2}\right]
$$

where $\hat{u}_{0, n_{1}+s}=\left(r_{n_{1}+s}-\bar{r}_{n_{1}+s}\right)^{2}, \hat{u}_{1, n_{1}+s}=\left(r_{n_{1}+s}-\bar{r}_{n_{1}+s}\right)^{2}$ and then regress $\hat{f}_{i, n_{1}+s}$ on a constant for $s=1,2, \ldots . T-n_{1}$. The $M S F E$-adjusted is the t-statistic corresponding to the constant. The out-of-sample forecast based on an individual predictor variable is given by

$$
\hat{r}_{i, t+1}=\hat{a}_{i, t}+\hat{\beta}_{\iota, t} x_{i, t}
$$

where $\hat{a}_{i, t}$ and $\hat{\beta}_{l, t}$ are the OLS estimates from regressing $\left\{\hat{r}_{i, s}\right\}_{2}^{T}$ on a constant and $\left\{x_{i, s}\right\}_{1}^{T-1}$.

\section{References}

Bai, J., 2003. Inferential theory for factor models of large dimension. Econometrica 71, 135171.

Basak, S. and Pavlova, A., 2016. A model of financialization of commodities. The Journal of Finance 71, 1511-1556.

Belousova, J. and Dorfleitner, G., 2012. On the diversification benefits of commodities from the perspective of euro investors. Journal of Banking and Finance 36, 2455-2472.

Bessler, W. and Wolff, D., 2015. Do commodities add value in multi-asset portfolios? An outof-sample analysis for different investment strategies. Journal of Banking and Finance 60, 120.

Boons, M. and Prado, M.P., 2019. Basis momentum. Journal of Finance 74, 239-279.

Büyüksahin, B., Haigh, M.S., Robe, M.A., 2010. Commodities and equities: ever a "Market of one"? Journal of Alternative Investments 12, 76-95.

Campbell, J.Y. and Thompson, S.B., 2008. Predicting excess stock returns out of sample: can anything beat the historical average? Review of Financial Studies 21, 1509-1531. 
Choueifaty, Y. and Coignard, Y., 2008. Toward maximum diversification. The Journal of Portfolio Management 35, 40-51.

Clark, T.E. and West, K.D., 2007. Approximately normal tests for equal predictive accuracy in nested models. Journal of Econometrics 138, 291-311.

Daskalaki, C. and Skiadopoulos, G., 2011. Should investors include commodities in their portfolios after all? New evidence. Journal of Banking and Finance 35, 2606-2626.

Daskalaki, C., Skiadopoulos, G. and Topaloglou, N., 2017. Diversification benefits of commodities: A stochastic dominance efficiency approach. Journal of Empirical Finance 44, $250-269$.

Erb, C.B., and C.R. Harvey, 2006. The strategic and tactical value of commodity futures. Financial Analysts Journal 62, 69-97.

Fethke, T. and Prokopczuk, M., 2018. Is Commodity Index Investing Profitable? Journal of Index Investing Winter 9, 37-71.

Geman, Helyette, 2009. Commodities and commodity derivatives: modeling and pricing for agriculturals, metals and energy, John Wiley \& Sons.

Hallerbach, Winfried, 2015. Advances in Portfolio Risk Control. In E. Jurczenko, ed., Riskbased and Factor Investing, Elsevier: 1-30.

Hamilton, J.D. and Wu, J.C., 2015. Effects of index-fund investing on commodity futures prices. International economic review 56, 187-205.

Hong, H. and Yogo, M., 2012, What does futures market interest tell us about the macroeconomy and asset prices? Journal of Financial Economics 3, 473-490.

Irwin, S.H. and Sanders, D.R., 2011. Index funds, financialization, and commodity futures markets. Applied Economic Perspectives and Policy 33, 1-31.

Kilian, Lutz., 2009. Not all oil price shocks are alike: Disentangling demand and supply shocks in the crude oil market. American Economic Review 99, 1053-69.

Kilian, Lutz., 2019. Measuring Global Economic Activity: Do Recent Critiques Hold Up to Scrutiny?, Economics Letters 178, 106-110.

Kirby, C. and Ostdiek, B., 2012. It's all in the timing: simple active portfolio strategies that outperform naive diversification. Journal of Financial and Quantitative Analysis 47, 437-467. 
Lewellen, J., 2015. The cross section of expected stock returns. Critical Finance Review 4, 144.

Moreira, A. and Muir, T., 2017. Volatility-Managed Portfolios. Journal of Finance 72, 16111644.

Newey, W.K., West, K.D., 1987. A simple, positive semi-definite, heteroscedasticity and autocorrelation consistent covariance matrix. Econometrica 55, 703-708.

Stock, J.H. and Watson, M.W., 2006. Forecasting with many predictors. In: Elliott, G., Granger, C.W.J., Timmermann, A. (Eds.), Handbook of Economic Forecasting, vol. 1. Elsevier, Amsterdam.

Stoll, Hans R. and Robert E Whaley., 2010. Commodity index investing and commodity futures prices. Journal of Applied Finance 20, 7-46.

Tang, K. and Xiong, W., 2012. Index investment and the financialization of commodities. Financial Analysts Journal 68, 54-74. 
Tables

\section{Table IA1. Sub-sample Analysis}

This Table presents the descriptive statistics for the period 1970:01 to 2004:12 (Panel A) prefinancialization period and 2005:01 to 2018:08 (Panel B) post-financialization period, of the commodity benchmarks, i.e. S\&P GSCI and the average commodity market factor based on the individual commodities (AVG) and the long-short (L/S) commodity portfolios. The mean, standard deviation (SD), Skewness (Skew), Kurtosis (Kurt), Sharpe Ratio (SR) are annualized. AR (1) stands for the autocorrelation of order (1).

\begin{tabular}{|c|c|c|c|c|c|c|c|}
\hline \multicolumn{8}{|c|}{ Panel A. January 1970 - Dec 2004} \\
\hline & $\mathbf{N}$ & Mean & SD & Skew & Kurt & SR & $\mathbf{A R}(\mathbf{1})$ \\
\hline \multicolumn{8}{|c|}{ Benchmark } \\
\hline SPGSCI & 420 & $6.76 \%$ & $18.45 \%$ & 0.149 & 3.203 & 0.366 & 0.110 \\
\hline AVG & 420 & $5.74 \%$ & $13.22 \%$ & 0.148 & 3.326 & 0.434 & 0.034 \\
\hline \multicolumn{8}{|c|}{ Long - Short Portfolios } \\
\hline L/S Momentum & 420 & $18.10 \%$ & $22.47 \%$ & 0.069 & 3.122 & 0.806 & 0.047 \\
\hline L/S Basis & 420 & $14.80 \%$ & $18.31 \%$ & 0.017 & 3.077 & 0.808 & 0.163 \\
\hline L/S Basis-Momentum & 420 & $17.70 \%$ & $19.34 \%$ & 0.053 & 3.319 & 0.915 & 0.005 \\
\hline L/S Skewness & 420 & $0.64 \%$ & $19.25 \%$ & -0.044 & 3.193 & 0.033 & 0.061 \\
\hline L/S Inflation beta & 420 & $6.53 \%$ & $21.40 \%$ & 0.077 & 3.152 & 0.305 & 0.086 \\
\hline L/S Volatility & 420 & $10.42 \%$ & $18.49 \%$ & 0.105 & 3.194 & 0.564 & 0.018 \\
\hline L/S Hedging Pressure & 420 & $3.38 \%$ & $21.86 \%$ & -0.384 & 3.611 & 0.155 & -0.033 \\
\hline L/S Open Interest & 420 & $1.29 \%$ & $17.30 \%$ & 0.116 & 3.123 & 0.075 & -0.008 \\
\hline L/S Value & 420 & $2.51 \%$ & $22.68 \%$ & -0.089 & 3.084 & 0.110 & 0.071 \\
\hline \multicolumn{8}{|c|}{ Panel B. January 2005 - August 2018} \\
\hline \multicolumn{8}{|c|}{ Benchmarks } \\
\hline SPGSCI & 164 & $-3.43 \%$ & $22.34 \%$ & -0.174 & 3.153 & -0.153 & 0.247 \\
\hline AVG & 164 & $3.59 \%$ & $14.60 \%$ & -0.223 & 3.278 & 0.246 & 0.131 \\
\hline \multicolumn{8}{|c|}{ Long - Short Portfolios } \\
\hline L/S Momentum & 164 & $6.81 \%$ & $15.56 \%$ & -0.023 & 3.041 & 0.438 & -0.055 \\
\hline L/S Basis & 164 & $11.11 \%$ & $12.95 \%$ & 0.058 & 3.056 & 0.858 & -0.027 \\
\hline L/S Basis-Momentum & 164 & $12.95 \%$ & $12.03 \%$ & 0.043 & 3.161 & 1.076 & 0.083 \\
\hline L/S Skewness & 164 & $8.46 \%$ & $12.12 \%$ & 0.120 & 3.035 & 0.698 & 0.011 \\
\hline L/S Inflation beta & 164 & $-5.26 \%$ & $16.54 \%$ & 0.069 & 3.045 & -0.318 & 0.193 \\
\hline L/S Volatility & 164 & $-1.45 \%$ & $12.59 \%$ & 0.050 & 3.018 & -0.115 & -0.012 \\
\hline L/S Hedging Pressure & 164 & $8.97 \%$ & $15.94 \%$ & 0.097 & 3.045 & 0.563 & 0.168 \\
\hline L/S Open Interest & 164 & $-4.91 \%$ & $13.74 \%$ & -0.054 & 3.011 & -0.357 & -0.078 \\
\hline L/S Value & 164 & $3.81 \%$ & $16.66 \%$ & 0.080 & 3.124 & 0.229 & -0.008 \\
\hline
\end{tabular}


Table IA2. Descriptive Statistics for the Period January 1990 - August 2018

This Table presents the descriptive statistics for the period 1990:01 to 2018:08, a period which coincides with the advent of commercial commodity indices, of the commodity benchmarks, i.e. S\&P GSCI and the average commodity market factor based on the individual commodities (AVG), the long-only commodity portfolios and the long-short (L/S) commodity portfolios. The mean, standard deviation (SD), Skewness (Skew), Kurtosis (Kurt), Sharpe Ratio (SR) are annualized. AR (1) stands for the autocorrelation of order (1).

\begin{tabular}{|c|c|c|c|c|c|c|c|}
\hline & $\mathbf{N}$ & Mean & SD & Skew & Kurt & SR & $\mathbf{A R}(\mathbf{1})$ \\
\hline \multicolumn{8}{|c|}{ Benchmarks } \\
\hline SPGSCI & 344 & $0.67 \%$ & $20.72 \%$ & -0.042 & 3.158 & 0.032 & 0.185 \\
\hline AVG & 344 & $3.82 \%$ & $11.93 \%$ & -0.199 & 3.349 & 0.320 & 0.117 \\
\hline \multicolumn{8}{|c|}{ Long-only portfolios } \\
\hline High Momentum & 344 & $10.24 \%$ & $17.74 \%$ & -0.017 & 3.335 & 0.577 & 0.108 \\
\hline Low Basis & 344 & $9.66 \%$ & $15.20 \%$ & -0.151 & 3.229 & 0.635 & 0.151 \\
\hline High Basis Momentum & 344 & $11.69 \%$ & $14.88 \%$ & 0.052 & 3.196 & 0.786 & 0.036 \\
\hline Low Skewness & 344 & $10.10 \%$ & $14.85 \%$ & -0.087 & 3.153 & 0.680 & 0.051 \\
\hline High Inflation beta & 344 & $7.01 \%$ & $18.39 \%$ & -0.127 & 3.163 & 0.381 & 0.164 \\
\hline High Volatility & 344 & $9.88 \%$ & $15.57 \%$ & 0.211 & 3.342 & 0.634 & 0.103 \\
\hline High Hedging Pressure & 344 & $6.41 \%$ & $15.27 \%$ & 0.001 & 3.151 & 0.420 & 0.058 \\
\hline High Open Interest & 344 & $3.65 \%$ & $15.11 \%$ & -0.033 & 3.072 & 0.242 & 0.100 \\
\hline High Value & 344 & $5.17 \%$ & $14.09 \%$ & 0.046 & 3.021 & 0.367 & -0.049 \\
\hline \multicolumn{8}{|c|}{ Long - Short Portfolios } \\
\hline L/S Momentum & 344 & $11.37 \%$ & $19.30 \%$ & 0.080 & 3.196 & 0.589 & 0.009 \\
\hline L/S Basis & 344 & $11.59 \%$ & $14.61 \%$ & 0.012 & 3.075 & 0.793 & -0.032 \\
\hline L/S Basis-Momentum & 344 & $14.20 \%$ & $14.11 \%$ & 0.118 & 3.090 & 1.006 & -0.027 \\
\hline L/S Skewness & 344 & $10.11 \%$ & $14.80 \%$ & 0.011 & 3.114 & 0.683 & 0.043 \\
\hline L/S Inflation beta & 344 & $6.50 \%$ & $17.89 \%$ & 0.117 & 3.082 & 0.364 & 0.067 \\
\hline L/S Volatility & 344 & $11.18 \%$ & $15.86 \%$ & 0.271 & 3.291 & 0.705 & -0.001 \\
\hline L/S Hedging Pressure & 344 & $7.81 \%$ & $15.54 \%$ & 0.033 & 3.022 & 0.503 & 0.087 \\
\hline L/S Open Interest & 344 & $-1.00 \%$ & $14.41 \%$ & 0.023 & 3.007 & -0.070 & -0.043 \\
\hline L/S Value & 344 & $3.05 \%$ & $19.16 \%$ & -0.036 & 3.094 & 0.159 & 0.032 \\
\hline
\end{tabular}


Table IA3. Commodity Factor Portfolios and Individual Commodities Under Different Portfolio Construction Techniques

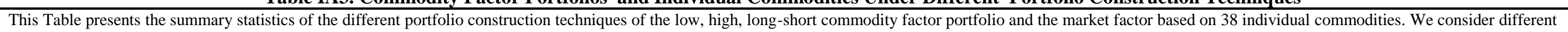

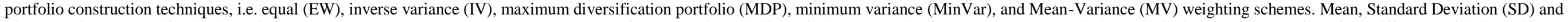

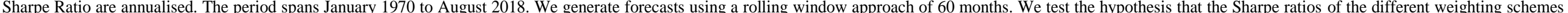
(i.e. IV, MDP, MinVar and MV) and the EW are equal following Ledoit and Wolf (2008). * denotes significance at $10 \%$ level, ** denotes significance at 5\% level and *** denotes significance at $1 \%$ level.

\begin{tabular}{|c|c|c|c|c|c|c|c|c|c|c|c|c|c|c|c|}
\hline \multirow{2}{*}{$\begin{array}{l}\text { Schemes } \\
\text { Factors }\end{array}$} & \multicolumn{3}{|c|}{ EW } & \multicolumn{3}{|c|}{ IV } & \multicolumn{3}{|c|}{ MDP } & \multicolumn{3}{|c|}{ MinVar } & \multicolumn{3}{|c|}{ MV } \\
\hline & Mean & SD & SR & Mean & SD & SR & Mean & SD & SR & Mean & SD & SR & Mean & SD & SR \\
\hline Low Momentum & $-1.79 \%$ & $17.29 \%$ & -0.104 & $-1.10 \%$ & $17.27 \%$ & -0.064 & $-2.56 \%$ & $17.57 \%$ & -0.146 & $-1.66 \%$ & $17.62 \%$ & -0.094 & $-2.65 \%$ & $17.40 \%$ & -0.152 \\
\hline High Mom & $13.13 \%$ & $20.09 \%$ & 0.654 & $13.01 \%$ & $19.20 \%$ & 0.678 & $13.79 \%$ & $18.80 \%$ & 0.734 & $12.57 \%$ & $18.87 \%$ & 0.666 & $14.64 \%$ & $21.34 \%$ & 0.686 \\
\hline L/S Mom & $14.93 \%$ & $20.80 \%$ & 0.718 & $14.11 \%$ & $20.72 \%$ & 0.681 & $16.35 \%$ & $20.95 \%$ & 0.780 & $14.22 \%$ & $21.45 \%$ & 0.663 & $17.29 \%$ & $21.77 \%$ & 0.794 \\
\hline Low Basis & $12.25 \%$ & $17.57 \%$ & 0.697 & $11.02 \%$ & $15.84 \%$ & 0.695 & $9.97 \%$ & $16.06 \%$ & 0.621 & $10.21 \%$ & $15.29 \%$ & 0.668 & $12.35 \%$ & $18.72 \%$ & 0.660 \\
\hline High Basis & $-1.52 \%$ & $15.58 \%$ & -0.097 & $0.19 \%$ & $15.12 \%$ & $0.012 *$ & $-1.05 \%$ & $14.82 \%$ & -0.071 & $0.32 \%$ & $14.77 \%$ & 0.021 & $-1.53 \%$ & $15.95 \%$ & -0.096 \\
\hline L/S Basis & $13.76 \%$ & $16.98 \%$ & 0.811 & $10.83 \%$ & $15.81 \%$ & 0.685 & $11.02 \%$ & $16.51 \%$ & 0.668 & $9.89 \%$ & $16.39 \%$ & 0.604 & $13.89 \%$ & $18.08 \%$ & 0.768 \\
\hline Low Basis-Momentum & $-1.69 \%$ & $16.34 \%$ & -0.103 & $-0.35 \%$ & $15.11 \%$ & -0.023 & $-1.83 \%$ & $15.31 \%$ & -0.119 & $-0.16 \%$ & $14.95 \%$ & -0.011 & $-2.77 \%$ & $16.44 \%$ & -0.168 \\
\hline High Basis-Momentum & $14.68 \%$ & $16.92 \%$ & 0.867 & $13.24 \%$ & $15.86 \%$ & 0.835 & $12.16 \%$ & $15.53 \%$ & 0.783 & $11.82 \%$ & $16.23 \%$ & 0.728 & $13.88 \%$ & $17.32 \%$ & 0.801 \\
\hline L/S Basis-Momentum & $16.36 \%$ & $17.60 \%$ & 0.930 & $13.59 \%$ & $16.73 \%$ & 0.812 & $13.99 \%$ & $16.94 \%$ & 0.825 & $11.98 \%$ & $17.82 \%$ & 0.672 & $16.65 \%$ & $17.52 \%$ & 0.950 \\
\hline Low Skewness & $6.29 \%$ & $16.21 \%$ & 0.388 & $5.35 \%$ & $15.47 \%$ & 0.346 & $6.63 \%$ & $15.45 \%$ & 0.429 & $5.14 \%$ & $15.85 \%$ & 0.325 & $5.51 \%$ & $16.33 \%$ & $0.337^{*}$ \\
\hline High Skewness & $3.46 \%$ & $17.63 \%$ & 0.196 & $4.39 \%$ & $16.07 \%$ & 0.273 & $3.17 \%$ & $16.27 \%$ & 0.195 & $4.70 \%$ & $15.39 \%$ & 0.306 & $2.41 \%$ & $18.66 \%$ & 0.129 \\
\hline L/S Skewness & $2.84 \%$ & $17.56 \%$ & 0.162 & $0.96 \%$ & $16.89 \%$ & 0.057 & $3.46 \%$ & $17.72 \%$ & 0.195 & $0.44 \%$ & $18.29 \%$ & 0.024 & $3.10 \%$ & $19.55 \%$ & 0.159 \\
\hline Low Inflation beta & $2.90 \%$ & $17.45 \%$ & 0.166 & $3.21 \%$ & $16.12 \%$ & 0.199 & $2.48 \%$ & $16.87 \%$ & 0.147 & $2.08 \%$ & $15.78 \%$ & 0.132 & $2.46 \%$ & $18.06 \%$ & 0.136 \\
\hline High Inflation beta & $6.12 \%$ & $20.45 \%$ & 0.299 & $6.45 \%$ & $19.21 \%$ & 0.336 & $5.88 \%$ & $18.30 \%$ & 0.322 & $5.28 \%$ & $18.12 \%$ & 0.291 & $5.42 \%$ & $20.24 \%$ & 0.268 \\
\hline L/S Inflation beta & $3.22 \%$ & $20.19 \%$ & 0.159 & $3.24 \%$ & $19.19 \%$ & 0.169 & $3.41 \%$ & $19.34 \%$ & 0.176 & $3.20 \%$ & $19.23 \%$ & $0.166 * *$ & $2.96 \%$ & $20.41 \%$ & 0.145 \\
\hline Low Volatility & $1.39 \%$ & $16.63 \%$ & 0.084 & $1.88 \%$ & $15.23 \%$ & 0.124 & $0.21 \%$ & $15.18 \%$ & 0.014 & $0.62 \%$ & $14.49 \%$ & 0.043 & $0.99 \%$ & $16.72 \%$ & 0.059 \\
\hline High Volatility & $8.48 \%$ & $17.17 \%$ & 0.494 & $7.27 \%$ & $16.16 \%$ & 0.450 & $7.27 \%$ & $16.30 \%$ & 0.446 & $6.34 \%$ & $15.61 \%$ & 0.406 & $6.10 \%$ & $17.40 \%$ & $0.350 * *$ \\
\hline L/S Volatility & $7.09 \%$ & $17.10 \%$ & 0.415 & $5.39 \%$ & $15.23 \%$ & 0.354 & $7.07 \%$ & $16.42 \%$ & 0.430 & $5.72 \%$ & $15.71 \%$ & 0.364 & $5.11 \%$ & $17.29 \%$ & 0.295 \\
\hline Low Hedging Pressure & $1.67 \%$ & $19.51 \%$ & 0.085 & $3.21 \%$ & $17.29 \%$ & 0.185 & $2.81 \%$ & $17.40 \%$ & 0.161 & $3.92 \%$ & $16.82 \%$ & 0.233 & $1.72 \%$ & $20.23 \%$ & 0.085 \\
\hline High Hedging Pressure & $6.62 \%$ & $18.16 \%$ & 0.365 & $7.03 \%$ & $17.00 \%$ & 0.414 & $7.98 \%$ & $17.84 \%$ & $0.447 * *$ & $7.67 \%$ & $16.82 \%$ & 0.456 & $6.77 \%$ & $17.98 \%$ & 0.376 \\
\hline L/S Hedging Pressure & $4.95 \%$ & $20.37 \%$ & 0.243 & $3.83 \%$ & $18.84 \%$ & 0.203 & $5.18 \%$ & $19.44 \%$ & 0.266 & $3.75 \%$ & $19.47 \%$ & 0.193 & $5.05 \%$ & $21.08 \%$ & 0.240 \\
\hline Low Open Interest & $4.54 \%$ & $17.74 \%$ & 0.256 & $3.82 \%$ & $16.10 \%$ & 0.237 & $4.37 \%$ & $16.65 \%$ & 0.263 & $4.07 \%$ & $16.02 \%$ & 0.254 & $4.42 \%$ & $18.91 \%$ & 0.234 \\
\hline High Open Interest & $4.09 \%$ & $18.81 \%$ & 0.217 & $4.25 \%$ & $17.49 \%$ & 0.243 & $3.85 \%$ & $17.71 \%$ & 0.217 & $4.88 \%$ & $17.30 \%$ & 0.282 & $3.71 \%$ & $19.30 \%$ & 0.192 \\
\hline L/S Open Interest & $-0.45 \%$ & $16.38 \%$ & -0.027 & $0.43 \%$ & $15.69 \%$ & 0.027 & $-0.53 \%$ & $16.56 \%$ & -0.032 & $0.80 \%$ & $17.58 \%$ & 0.046 & $-0.71 \%$ & $17.99 \%$ & -0.039 \\
\hline Low Value & $3.54 \%$ & $21.06 \%$ & 0.168 & $6.07 \%$ & $20.08 \%$ & $0.302 * *$ & $4.78 \%$ & $19.41 \%$ & 0.246 & $7.42 \%$ & $19.32 \%$ & $0.384 * * *$ & $4.46 \%$ & $22.62 \%$ & 0.197 \\
\hline High Value & $6.41 \%$ & $16.38 \%$ & 0.391 & $6.41 \%$ & $15.44 \%$ & 0.415 & $5.34 \%$ & $15.65 \%$ & 0.341 & $5.89 \%$ & $15.45 \%$ & 0.381 & $4.88 \%$ & $16.12 \%$ & $0.302 * *$ \\
\hline L/S Value & $2.87 \%$ & $21.15 \%$ & 0.136 & $0.34 \%$ & $20.13 \%$ & $0.017 *$ & $0.57 \%$ & $20.08 \%$ & 0.028 & $-1.53 \%$ & $20.42 \%$ & $-0.075^{* *}$ & $0.42 \%$ & $22.72 \%$ & $0.018 * *$ \\
\hline Market & $5.13 \%$ & $13.61 \%$ & 0.377 & $5.23 \%$ & $12.33 \%$ & 0.424 & $4.49 \%$ & $11.36 \%$ & 0.395 & $4.64 \%$ & $11.59 \%$ & 0.400 & $4.78 \%$ & $13.42 \%$ & 0.356 \\
\hline
\end{tabular}


Table IA4. Correlation Matrix of Commercial Indices and Commodity Factors

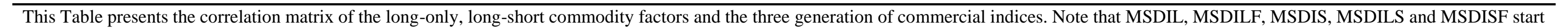

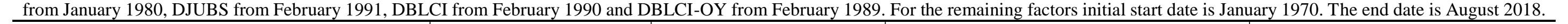

\begin{tabular}{|c|c|c|c|c|c|c|c|c|c|c|c|c|c|c|c|c|c|c|c|c|c|}
\hline & & \multicolumn{3}{|c|}{ First Generation } & \multicolumn{3}{|c|}{ Second Generation } & \multicolumn{3}{|c|}{ Third Generation } & \multicolumn{6}{|c|}{ Long-only Portfolios } & \multicolumn{5}{|c|}{ Long-short Portfolios } \\
\hline & & SPGSCI & DJUBS & DBLCI & $\begin{array}{c}\text { DBLCI- } \\
\text { OY }\end{array}$ & MSDIL & MSDIL & MSDIS & MSDILS & MSDISF & AVG & $\begin{array}{l}\text { High } \\
\text { Mom }\end{array}$ & $\begin{array}{l}\text { Low } \\
\text { Basis }\end{array}$ & $\begin{array}{l}\text { High } \\
\text { Basis- } \\
\text { Mom } \\
\end{array}$ & $\begin{array}{l}\text { High } \\
\text { HP }\end{array}$ & $\begin{array}{l}\text { High } \\
\text { Value }\end{array}$ & $\begin{array}{l}\text { LS } \\
\text { Mom }\end{array}$ & $\begin{array}{l}\text { LS } \\
\text { Basis }\end{array}$ & $\begin{array}{c}\text { LS } \\
\text { Basis- } \\
\text { Mom } \\
\end{array}$ & $\begin{array}{l}\text { LS } \\
\text { HP }\end{array}$ & $\begin{array}{c}\text { LS } \\
\text { Value }\end{array}$ \\
\hline \multirow{3}{*}{$\begin{array}{c}1^{\text {st }} \\
\text { Generation }\end{array}$} & SPGSCI & 1.00 & & & & & & & & & & & & & & & & & & & \\
\hline & DJUBS & 0.89 & 1.00 & & & & & & & & & & & & & & & & & & \\
\hline & DBLCI & 0.66 & 0.65 & 1.00 & & & & & & & & & & & & & & & & & \\
\hline \multirow{3}{*}{$\begin{array}{c}2^{\text {nd }} \\
\text { Generation }\end{array}$} & DBLCI-OY & 0.92 & 0.90 & 0.72 & 1.00 & & & & & & & & & & & & & & & & \\
\hline & MSDIL & 0.89 & 0.96 & 0.65 & 0.91 & 1.00 & & & & & & & & & & & & & & & \\
\hline & MSDILF & 0.69 & 0.75 & 0.72 & 0.70 & 0.78 & 1.00 & & & & & & & & & & & & & & \\
\hline \multirow{3}{*}{$\begin{array}{c}3^{\text {rd }} \\
\text { Generation }\end{array}$} & MSDIS & -0.85 & -0.94 & -0.58 & -0.87 & -0.96 & -0.69 & 1.00 & & & & & & & & & & & & & \\
\hline & MSDILS & 0.38 & 0.43 & 0.57 & 0.43 & 0.32 & 0.78 & -0.21 & 1.00 & & & & & & & & & & & & \\
\hline & MSDISF & -0.42 & -0.57 & -0.23 & -0.47 & -0.63 & -0.25 & 0.68 & 0.41 & 1.00 & & & & & & & & & & & \\
\hline \multirow{6}{*}{$\begin{array}{l}\text { Long-only } \\
\text { Portfolios }\end{array}$} & AVG & 0.80 & 0.93 & 0.61 & 0.84 & 0.91 & 0.69 & -0.90 & 0.21 & -0.68 & 1.00 & & & & & & & & & & \\
\hline & High Mom & 0.68 & 0.78 & 0.63 & 0.74 & 0.77 & 0.76 & -0.69 & 0.44 & -0.43 & 0.81 & 1.00 & & & & & & & & & \\
\hline & Low Basis & 0.70 & 0.76 & 0.53 & 0.69 & 0.74 & 0.60 & -0.72 & 0.21 & -0.54 & 0.82 & 0.76 & 1.00 & & & & & & & & \\
\hline & $\begin{array}{l}\text { High Basis- } \\
\text { Mom }\end{array}$ & 0.68 & 0.75 & 0.61 & 0.69 & 0.74 & 0.62 & -0.71 & 0.24 & -0.53 & 0.81 & 0.79 & 0.78 & 1.00 & & & & & & & \\
\hline & High HP & 0.52 & 0.67 & 0.39 & 0.52 & 0.66 & 0.54 & -0.65 & 0.15 & -0.55 & 0.74 & 0.58 & 0.56 & 0.53 & 1.00 & & & & & & \\
\hline & High Value & 0.55 & 0.63 & 0.40 & 0.57 & 0.63 & 0.37 & -0.67 & -0.06 & -0.62 & 0.73 & 0.44 & 0.51 & 0.57 & 0.59 & 1.00 & & & & & \\
\hline \multirow{5}{*}{$\begin{array}{l}\text { Long-short } \\
\text { Portfolios }\end{array}$} & LS Mom & 0.16 & 0.14 & 0.36 & 0.21 & 0.18 & 0.48 & -0.07 & 0.54 & 0.13 & 0.13 & 0.64 & 0.27 & 0.33 & 0.06 & -0.21 & 1.00 & & & & \\
\hline & LS Basis & 0.21 & 0.16 & 0.21 & 0.19 & 0.14 & 0.19 & -0.09 & 0.18 & 0.00 & 0.12 & 0.29 & 0.59 & 0.28 & 0.01 & -0.06 & 0.35 & 1.00 & & & \\
\hline & $\begin{array}{l}\text { LS Basis- } \\
\text { Mom }\end{array}$ & 0.06 & 0.07 & 0.26 & 0.15 & 0.08 & 0.10 & -0.04 & 0.05 & -0.06 & 0.05 & 0.21 & 0.23 & 0.55 & -0.10 & -0.01 & 0.31 & 0.36 & 1.00 & & \\
\hline & LS HP & -0.08 & 0.16 & 0.02 & 0.06 & 0.17 & 0.22 & -0.14 & 0.15 & -0.09 & -0.03 & -0.02 & -0.11 & -0.12 & 0.49 & -0.03 & 0.04 & -0.10 & -0.14 & 1.00 & \\
\hline & LS Value & -0.26 & -0.28 & -0.15 & -0.20 & -0.21 & -0.35 & 0.13 & -0.38 & -0.08 & -0.22 & -0.44 & -0.37 & -0.22 & -0.11 & 0.39 & -0.50 & -0.34 & -0.05 & 0.06 & 1.00 \\
\hline
\end{tabular}




\section{Table IA5. Spanning Regressions of Combined Commodity Portfolio Against Equities and Bonds}

This Table presents the spanning regressions of the equally weighted long-only combined commodity portfolio (Panel A) and the equally weighted long-short combined commodity portfolio (Panel B) based on three baseline models. The three baseline models are the following: (a) a model that includes the MSCI Equity Index and the Bloomberg Barclays US Aggregate Bond Index, (b) a model that includes the MSCI Equity Index, the Bloomberg Barclays US Aggregate Bond Index, the small minus big portfolio (SMB), the high minus low portfolio (HML), and the winners minus losers (WML), (c) a model which includes the MSCI Equity Index, the Bloomberg Barclays US Aggregate Bond Index, the small minus big portfolio (SMB), the high minus low portfolio (HML), the winners minus losers (WML), the robust minus weak portfolio (RMW) and the conservative minus aggressive portfolio (CMA). The equally weighted combined commodity portfolios is the equally weighted portfolios of the commodity factors Momentum, Basis, Basis-Momentum, Hedging Pressure and Value. The sample period spans from January 1970 to August 2018. Int. denotes the intercept of the time series regression, $R_{a d j}^{2}$ denotes the adjusted $R^{2}$ of the regression, and $s e$ denotes the standard error of the time series regressions. Newey-West (1987) t-statistics are in parenthesis.

Panel A. Combined Long-only Commodity Portfolios

\begin{tabular}{|c|c|c|c|c|c|c|c|c|c|c|}
\hline $\mathbf{a} / \mathbf{a}$ & Int. & $\begin{array}{l}\text { MSCI US } \\
\text { Equity } \\
\text { Index }\end{array}$ & $\begin{array}{c}\text { Bloomberg } \\
\text { Barclays U.S. } \\
\text { Aggregate Bond } \\
\text { Index } \\
\end{array}$ & $\begin{array}{c}\text { Equity } \\
\text { SMB }\end{array}$ & $\begin{array}{l}\text { Equity } \\
\text { HML }\end{array}$ & $\begin{array}{l}\text { Equity } \\
\text { WML }\end{array}$ & RMW & CMA & $R_{a d j}^{2}$ & se \\
\hline \multirow[t]{2}{*}{ (1) } & 0.006 & 0.219 & -0.313 & & & & & & $5.37 \%$ & 0.038 \\
\hline & (3.076) & (3.146) & $(-3.093)$ & & & & & & & \\
\hline \multirow[t]{2}{*}{ (2) } & 0.006 & 0.229 & -0.300 & 0.113 & 0.085 & 0.040 & & & $5.82 \%$ & 0.038 \\
\hline & (2.609) & (3.236) & $(-2.961)$ & $(1.860)$ & $(1.306)$ & $(0.810)$ & & & & \\
\hline \multirow[t]{2}{*}{ (3) } & 0.006 & 0.228 & -0.290 & 0.074 & 0.045 & 0.044 & -0.105 & 0.100 & $5.87 \%$ & 0.038 \\
\hline & $(2.585)$ & (3.067) & $(-2.905)$ & 1.024 & $(0.503)$ & $(0.886)$ & $(-1.215)$ & $(0.681)$ & & \\
\hline \multicolumn{11}{|c|}{ Panel B. Combined Long-Short Commodity Portfolios } \\
\hline $\mathbf{a} / \mathbf{a}$ & Int. & $\begin{array}{l}\text { MSCI US } \\
\text { Equity } \\
\text { Index }\end{array}$ & $\begin{array}{c}\text { Bloomberg } \\
\text { Barclays U.S. } \\
\text { Aggregate Bond } \\
\text { Index } \\
\end{array}$ & $\begin{array}{l}\text { Equity } \\
\text { SMB }\end{array}$ & $\begin{array}{l}\text { Equity } \\
\text { HML }\end{array}$ & $\begin{array}{l}\text { Equity } \\
\text { WML }\end{array}$ & RMW & CMA & $R_{a d j}^{2}$ & se \\
\hline \multirow[t]{2}{*}{ (1) } & 0.009 & 0.002 & -0.117 & & & & & & $0.24 \%$ & 0.022 \\
\hline & $(8.557)$ & $(0.076)$ & $(-1.615)$ & & & & & & & \\
\hline \multirow[t]{2}{*}{ (2) } & 0.009 & 0.002 & -0.115 & 0.024 & -0.033 & 0.051 & & & $1.19 \%$ & 0.022 \\
\hline & $(8.519)$ & $(0.078)$ & $(-1.627)$ & $(0.713)$ & $-0.831)$ & $(1.907)$ & & & & \\
\hline \multirow[t]{2}{*}{ (3) } & 0.009 & 0.016 & -0.112 & 0.032 & -0.095 & 0.043 & 0.034 & 0.130 & $1.45 \%$ & 0.022 \\
\hline & (7.917) & $(0.547)$ & $(-1.616)$ & $(0.753)$ & $(-1.716)$ & (1.555) & $(0.643)$ & (1.508) & & \\
\hline
\end{tabular}


Table IA6. Descriptive Statistics of the Commodity Specific \& Macroeconomic Variables

This Table presents the descriptive statistics (Panel A) and the correlation matrix (Panel B) for the period 1970:01 to 2018:08 of the predictor (commodity specific \& macroeconomic) variables. The mean, standard deviation (SD), Skewness and Kurtosis are annualized.

\begin{tabular}{|c|c|c|c|c|c|c|c|c|c|c|c|c|c|}
\hline \multicolumn{14}{|c|}{ Panel A. Summary Statistics } \\
\hline & $\mathbf{N}$ & Mean & SD & Skew & Kurt & & & & & & & & \\
\hline T-bill 1m & 584 & $0.38 \%$ & $0.28 \%$ & 0.569 & 3.346 & & & & & & & & \\
\hline aggregate basis & 584 & $0.28 \%$ & $0.51 \%$ & 0.084 & 3.905 & & & & & & & & \\
\hline yield spread & 584 & $2.05 \%$ & $1.44 \%$ & -0.655 & 3.460 & & & & & & & & \\
\hline default spread & 584 & $2.22 \%$ & $0.71 \%$ & 1.377 & 7.282 & & & & & & & & \\
\hline market interest & 584 & $0.96 \%$ & $2.01 \%$ & 0.868 & 13.856 & & & & & & & & \\
\hline Kilian & 584 & 0.539 & 54.835 & 0.825 & 3.981 & & & & & & & & \\
\hline Unemployment rate & 584 & $5.51 \%$ & $1.48 \%$ & 0.832 & 3.032 & & & & & & & & \\
\hline IP growth rate & 584 & $0.17 \%$ & $0.73 \%$ & -1.085 & 8.140 & & & & & & & & \\
\hline M1 growth & 584 & $0.50 \%$ & $0.74 \%$ & 1.434 & 13.650 & & & & & & & & \\
\hline AUD-USD growth & 584 & $0.07 \%$ & $3.15 \%$ & 0.986 & 8.336 & & & & & & & & \\
\hline NZD-USD growth & 584 & $0.03 \%$ & $1.90 \%$ & 0.616 & 9.025 & & & & & & & & \\
\hline SA RAND-USD growth & 584 & $0.52 \%$ & $4.05 \%$ & 0.898 & 8.071 & & & & & & & & \\
\hline CAD-USD growth & 584 & $0.09 \%$ & $3.39 \%$ & 1.043 & 10.532 & & & & & & & & \\
\hline \multicolumn{14}{|c|}{ Panel B. Correlation Matrix } \\
\hline & T-bill $1 \mathrm{~m}$ & $\begin{array}{c}\text { Aggregate } \\
\text { basis }\end{array}$ & $\begin{array}{l}\text { Yield } \\
\text { spread }\end{array}$ & $\begin{array}{l}\text { default } \\
\text { spread }\end{array}$ & $\begin{array}{l}\text { market } \\
\text { interest }\end{array}$ & Kilian & $\begin{array}{l}\text { Unemployment } \\
\text { rate }\end{array}$ & $\begin{array}{l}\text { IP } \\
\text { growth }\end{array}$ & $\begin{array}{c}\text { M1 } \\
\text { growth }\end{array}$ & $\begin{array}{l}\text { AUD- } \\
\text { USD } \\
\text { growth }\end{array}$ & $\begin{array}{l}\text { NZD- } \\
\text { USD } \\
\text { growth }\end{array}$ & $\begin{array}{c}\text { SA } \\
\text { RAND- } \\
\text { USD } \\
\text { growth }\end{array}$ & $\begin{array}{l}\text { CAD- } \\
\text { USD } \\
\text { growth }\end{array}$ \\
\hline T-bill 1m & 1.000 & & & & & & & & & & & & \\
\hline aggregate basis & 0.098 & 1.000 & & & & & & & & & & & \\
\hline yield spread & -0.588 & -0.192 & 1.000 & & & & & & & & & & \\
\hline default spread & -0.429 & 0.211 & 0.418 & 1.000 & & & & & & & & & \\
\hline market interest & -0.084 & -0.074 & -0.032 & -0.315 & 1.000 & & & & & & & & \\
\hline Kilian & 0.143 & 0.199 & -0.234 & -0.172 & 0.034 & 1.000 & & & & & & & \\
\hline Unemployment rate & -0.044 & 0.091 & 0.515 & 0.447 & -0.218 & -0.123 & 1.000 & & & & & & \\
\hline IP growth rate & -0.033 & -0.118 & 0.087 & -0.310 & 0.251 & -0.087 & -0.004 & 1.000 & & & & & \\
\hline M1 growth & -0.142 & -0.006 & 0.252 & 0.283 & -0.032 & -0.161 & 0.305 & -0.121 & 1.000 & & & & \\
\hline AUD-USD growth & 0.063 & 0.000 & -0.020 & -0.021 & -0.061 & -0.061 & -0.001 & -0.018 & 0.044 & 1.000 & & & \\
\hline NZD-USD growth & 0.011 & 0.015 & 0.006 & -0.009 & -0.015 & -0.078 & 0.006 & 0.072 & 0.016 & 0.563 & 1.000 & & \\
\hline SA RAND-USD growth & 0.073 & -0.028 & -0.020 & -0.030 & -0.026 & -0.068 & -0.008 & 0.009 & 0.001 & 0.441 & 0.360 & 1.000 & \\
\hline CAD-USD growth & 0.107 & 0.044 & -0.080 & -0.016 & -0.052 & -0.042 & -0.002 & 0.009 & 0.001 & 0.687 & 0.443 & 0.403 & 1.000 \\
\hline
\end{tabular}


Table IA7. Commodities Out-of-Sample Forecasting Statistics, January 1980- August 2018

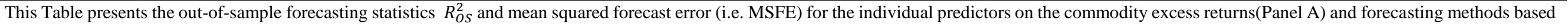

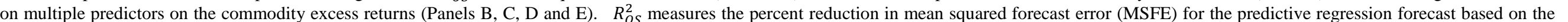

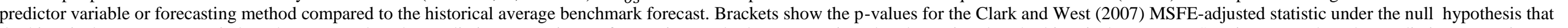

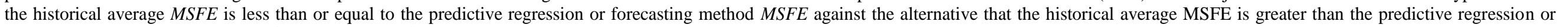
forecasting method MSFE, i.e. $H_{0} R_{O S}^{2} \leq 0$ against : $R_{O S}^{2}>0$.

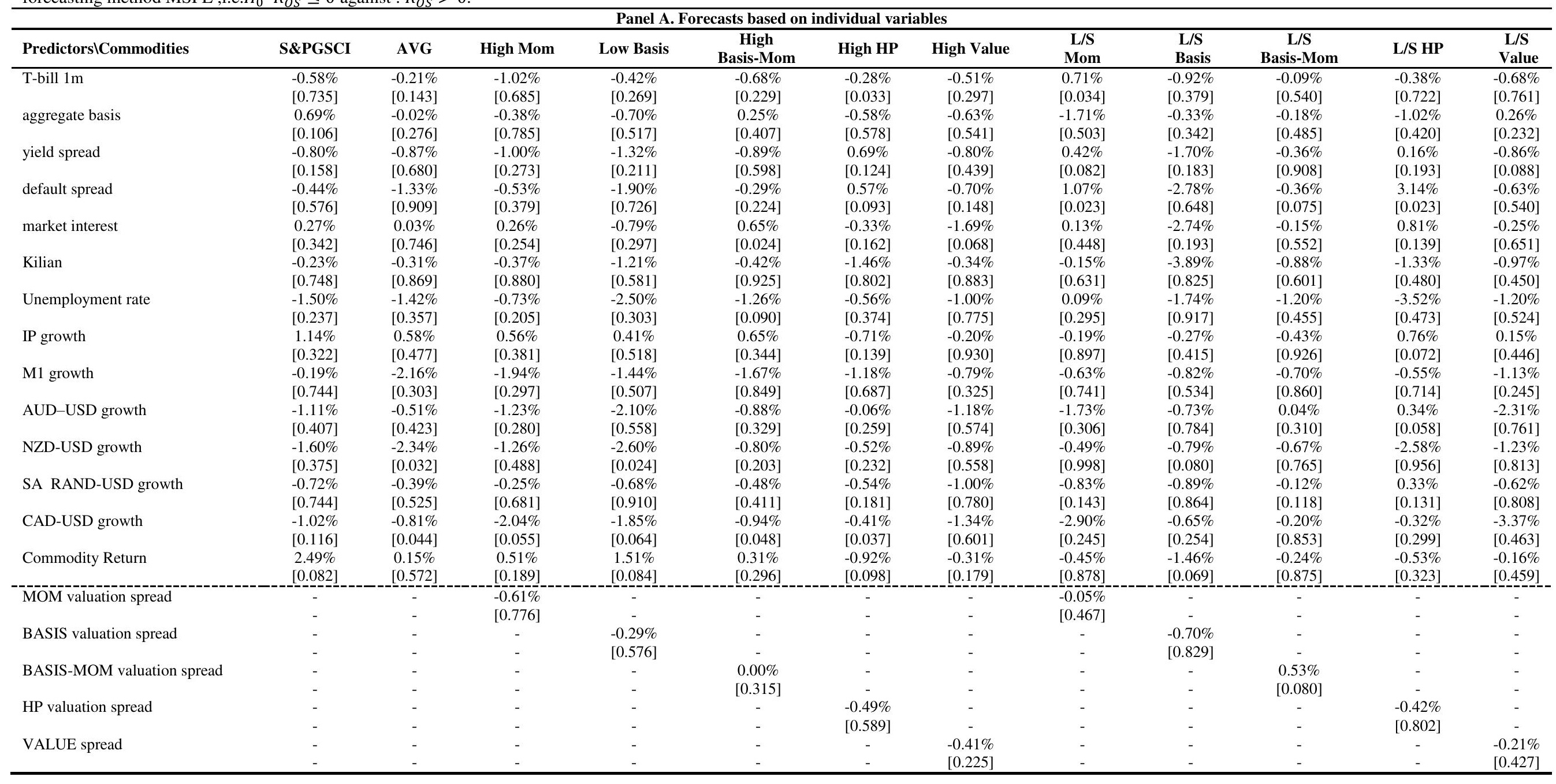




\begin{tabular}{|c|c|c|c|c|c|c|c|c|c|c|c|c|}
\hline \multicolumn{13}{|c|}{ Panel A. Forecasts based on individual variables (Cont'd) } \\
\hline PredictorsiCommodities & S\&PGSCI & AVG & High Mom & $\begin{array}{l}\text { Low } \\
\text { Basis }\end{array}$ & $\begin{array}{c}\text { High } \\
\text { Basis-Mom }\end{array}$ & High HP & High Value & $\begin{array}{c}\text { L/S } \\
\text { Mom } \\
\end{array}$ & $\begin{array}{l}\mathrm{L} / \mathrm{S} \\
\text { Basis }\end{array}$ & $\begin{array}{c}\text { L/S } \\
\text { Basis-Mom }\end{array}$ & L/S HP & $\begin{array}{c}\text { L/S } \\
\text { Value }\end{array}$ \\
\hline \multirow[t]{2}{*}{ MOM exposure spread } & - & - & $-0.49 \%$ & - & - & - & - & $0.07 \%$ & - & - & - & - \\
\hline & - & - & [0.189] & - & - & - & - & {$[0.549]$} & - & - & - & - \\
\hline \multirow[t]{2}{*}{ BASIS exposure spread } & - & - & - & $0.44 \%$ & - & - & - & - & $-0.53 \%$ & - & - & - \\
\hline & - & - & - & {$[0.106]$} & - & - & - & - & [0.149] & - & - & - \\
\hline \multirow[t]{2}{*}{$\begin{array}{l}\text { BASIS-MOM exposure } \\
\text { spread }\end{array}$} & - & - & - & - & $1.60 \%$ & - & - & - & - & $0.13 \%$ & - & - \\
\hline & - & - & - & - & {$[0.021]$} & - & - & - & - & {$[0.148]$} & - & - \\
\hline \multirow[t]{2}{*}{ HP exposure spread } & - & - & - & - & - & $-0.55 \%$ & - & - & - & - & $-0.18 \%$ & - \\
\hline & - & - & - & - & - & {$[0.354]$} & - & - & - & - & {$[0.828]$} & - \\
\hline \multirow[t]{2}{*}{ VALUE spread } & - & - & - & - & - & - & $-0.41 \%$ & - & - & - & - & $-0.21 \%$ \\
\hline & - & - & - & - & - & - & {$[0.225]$} & - & - & - & - & {$[0.427]$} \\
\hline Models|Commodities & S\&PGSCI & AVG & $\begin{array}{r}\text { Pa } \\
\text { High Mom }\end{array}$ & \begin{tabular}{|l} 
B. Forec: \\
Low \\
Basis \\
\end{tabular} & $\begin{array}{c}\text { ased on macr } \\
\text { High } \\
\text { Basis-Mom } \\
\end{array}$ & $\frac{\text { onomic \& con }}{\text { High HP }}$ & $\frac{\text { odity specific ve }}{\text { High Value }}$ & $\begin{array}{r}\text { iables } \\
\text { L/S } \\
\text { Mom } \\
\end{array}$ & $\begin{array}{l}\mathbf{L} / \mathbf{S} \\
\text { Basis } \\
\end{array}$ & $\begin{array}{c}\text { L/S } \\
\text { Basis-Mom } \\
\end{array}$ & L/S HP & $\begin{array}{l}\mathbf{L} / \mathbf{S} \\
\text { Value } \\
\end{array}$ \\
\hline \multirow[t]{2}{*}{ Historical Avg. } & - & - & - & - & - & - & - & - & - & - & - & - \\
\hline & - & - & - & - & - & - & - & - & - & - & - & - \\
\hline \multirow[t]{2}{*}{ Avg. Pooled } & $0.64 \%$ & $0.40 \%$ & $0.01 \%$ & $0.26 \%$ & $0.70 \%$ & $0.79 \%$ & $-0.13 \%$ & $0.22 \%$ & $-0.13 \%$ & $0.29 \%$ & $1.39 \%$ & $0.03 \%$ \\
\hline & {$[0.138]$} & {$[0.317]$} & {$[0.812]$} & {$[0.376]$} & {$[0.147]$} & {$[0.085]$} & {$[0.871]$} & {$[0.329]$} & {$[0.996]$} & {$[0.103]$} & {$[0.034]$} & {$[0.701]$} \\
\hline \multirow[t]{2}{*}{ Diffusion Index } & $0.43 \%$ & $0.59 \%$ & $-0.71 \%$ & $-0.74 \%$ & $0.34 \%$ & $0.67 \%$ & $-1.05 \%$ & $-0.50 \%$ & $-4.00 \%$ & $-0.65 \%$ & $0.51 \%$ & $-2.71 \%$ \\
\hline & {$[0.226]$} & {$[0.170]$} & {$[0.565]$} & {$[0.417]$} & {$[0.162]$} & {$[0.064]$} & {$[0.482]$} & {$[0.100]$} & {$[0.511]$} & {$[0.244]$} & [0.109] & [0.043] \\
\hline \multirow[t]{2}{*}{ Multiple Regression } & $-6.46 \%$ & $-12.54 \%$ & $-12.41 \%$ & $-18.82 \%$ & $-11.04 \%$ & $-9.38 \%$ & $-11.58 \%$ & $-10.45 \%$ & $-16.32 \%$ & $-10.77 \%$ & $-17.07 \%$ & $-13.53 \%$ \\
\hline & [0.263] & [0.951] & [0.515] & [0.534] & [0.493] & [0.351] & [0.430] & [0.954] & [0.398] & [0.573] & [0.186] & [0.689] \\
\hline
\end{tabular}


Table IA7. Commodities Out-of-Sample Forecasting Statistics, January 1980 - August 2018 (Cont'd)

\begin{tabular}{|c|c|c|c|c|c|c|c|c|c|c|c|c|}
\hline \multicolumn{13}{|c|}{ Panel C. Forecasts based on factor valuation spreads } \\
\hline Models/Commodities & S\&PGSCI & AVG & High Mom & $\begin{array}{l}\text { Low } \\
\text { Basis } \\
\end{array}$ & $\begin{array}{c}\text { High } \\
\text { Basis-Mom } \\
\end{array}$ & High HP & High Value & $\begin{array}{c}\text { L/S } \\
\text { Mom } \\
\end{array}$ & $\begin{array}{l}\mathbf{L} / \mathbf{S} \\
\text { Basis } \\
\end{array}$ & $\begin{array}{c}\text { L/S } \\
\text { Basis-Mom } \\
\end{array}$ & L/S HP & $\begin{array}{l}\text { L/S } \\
\text { Value } \\
\end{array}$ \\
\hline \multirow[t]{2}{*}{ Historical Avg. } & - & - & - & - & - & - & - & - & - & - & - & - \\
\hline & - & - & - & - & - & - & - & - & - & - & - & - \\
\hline \multirow[t]{2}{*}{ Multiple Regression } & - & - & $-0.61 \%$ & $-0.29 \%$ & $0.00 \%$ & $-0.49 \%$ & $-0.41 \%$ & $-0.05 \%$ & $-0.70 \%$ & $0.53 \%$ & $-0.42 \%$ & $-0.21 \%$ \\
\hline & - & - & {$[0.776]$} & {$[0.576]$} & {$[0.315]$} & [0.589] & {$[0.225]$} & {$[0.467]$} & [0.829] & {$[0.080]$} & [0.802] & [0.427] \\
\hline \multicolumn{13}{|c|}{ Panel D. Forecasts based on factor exposure spreads } \\
\hline ModelsICommodities & S\&PGSCI & AVG & High Mom & $\begin{array}{l}\text { Low } \\
\text { Basis } \\
\end{array}$ & $\begin{array}{c}\text { High } \\
\text { Basis-Mom } \\
\end{array}$ & High HP & High Value & $\begin{array}{c}\text { L/S } \\
\text { Mom } \\
\end{array}$ & $\begin{array}{l}\mathbf{L} / \mathbf{S} \\
\text { Basis } \\
\end{array}$ & $\begin{array}{c}\mathbf{L} / \mathbf{S} \\
\text { Basis-Mom } \\
\end{array}$ & L/S HP & $\begin{array}{l}\mathrm{L} / \mathrm{S} \\
\text { Value } \\
\end{array}$ \\
\hline \multirow[t]{2}{*}{ Historical Avg. } & - & - & - & - & - & - & - & - & - & - & - & - \\
\hline & - & - & - & - & - & - & - & - & - & - & - & - \\
\hline \multirow[t]{2}{*}{ Multiple Regression } & - & - & $-0.49 \%$ & $0.44 \%$ & $-1.60 \%$ & $-0.55 \%$ & $-0.41 \%$ & $0.07 \%$ & $-0.53 \%$ & $0.13 \%$ & $-0.18 \%$ & $-0.21 \%$ \\
\hline & - & - & {$[0.189]$} & {$[0.106]$} & {$[0.021]$} & {$[0.354]$} & {$[0.225]$} & {$[0.549]$} & {$[0.149]$} & {$[0.148]$} & {$[0.828]$} & [0.427] \\
\hline \multicolumn{13}{|c|}{ Panel E. Forecasts based on macroeconomic \& commodity specific variables, factor valuation spreads and factor exposure spreads } \\
\hline Models\Commodities & S\&PGSCI & AVG & High Mom & $\begin{array}{l}\text { Low } \\
\text { Basis }\end{array}$ & $\begin{array}{c}\text { High } \\
\text { Basis-Mom } \\
\end{array}$ & High HP & High Value & $\begin{array}{c}\text { L/S } \\
\text { Mom } \\
\end{array}$ & $\begin{array}{l}\mathbf{L} / \mathbf{S} \\
\text { Basis } \\
\end{array}$ & $\begin{array}{c}\text { L/S } \\
\text { Basis-Mom } \\
\end{array}$ & L/S HP & $\begin{array}{c}\text { L/S } \\
\text { Value }\end{array}$ \\
\hline \multirow[t]{2}{*}{ Historical Avg. } & - & - & - & - & - & - & - & - & - & - & - & - \\
\hline & - & - & - & - & - & - & - & - & - & - & - & - \\
\hline \multirow[t]{2}{*}{ Avg. Pooled } & - & - & $-0.02 \%$ & $0.47 \%$ & $0.87 \%$ & $0.67 \%$ & $-0.14 \%$ & $0.24 \%$ & $0.01 \%$ & $0.42 \%$ & $1.23 \%$ & $0.10 \%$ \\
\hline & - & - & {$[0.897]$} & {$[0.257]$} & {$[0.095]$} & {$[0.118]$} & {$[0.806]$} & {$[0.275]$} & {$[0.671]$} & {$[0.033]$} & {$[0.039]$} & {$[0.577]$} \\
\hline \multirow[t]{2}{*}{ Diffusion Index } & - & - & $-0.01 \%$ & $-1.00 \%$ & $1.01 \%$ & $0.19 \%$ & $-1.03 \%$ & $-0.23 \%$ & $-4.33 \%$ & $-0.89 \%$ & $0.39 \%$ & $-1.50 \%$ \\
\hline & - & - & [0.329] & {$[0.268]$} & {$[0.093]$} & {$[0.105]$} & {$[0.541]$} & {$[0.137]$} & [0.899] & {$[0.209]$} & {$[0.103]$} & {$[0.167]$} \\
\hline \multirow[t]{2}{*}{ Multiple Regression } & - & - & $-13.98 \%$ & $-18.05 \%$ & $-9.50 \%$ & $-10.64 \%$ & $-11.46 \%$ & $-10.39 \%$ & $-16.23 \%$ & $-9.90 \%$ & $-18.77 \%$ & $-13.10 \%$ \\
\hline & - & - & {$[0.321]$} & {$[0.336]$} & {$[0.355]$} & {$[0.630]$} & {$[0.708]$} & {$[0.848]$} & {$[0.241]$} & {$[0.246]$} & {$[0.281]$} & {$[0.784]$} \\
\hline
\end{tabular}


Table IA8. The Relation Between Commodity Variance and Next Month Commodity Return, Variance and Sharpe ratio

This Table present the results from a univariate regression of the variance of the commodity portfolio on its one month lagged variance (Panel A), from a univariate regression of the commodity portfolio return on its one month lagged variance (Panel B) and from a univariate regression of the commodity portfolio Sharpe ratio (SR) on its one month lagged variance (Panel C). The Sharpe Ratio in a month is defined as the ratio of the average portfolio return over the volatility of the portfolio based on daily observations in the month. For commodity portfolios we consider the commodity benchmarks average commodity factor (AVG) and the long-only and longshort (L/S) commodity factors of momentum (mom), basis, basis-momentum (basis-mom), hedging pressure (hp) and value. We use the logarithm of the variance. The sample period spans from January 1980 to August 2018. Int . denotes the intercept of the time series regression and $R_{\text {adj }}^{2}$ denotes the adjusted $R^{2}$ of the regression. Newey-

West (1987) t-statistics are in parenthesis.

\begin{tabular}{|c|c|c|c|c|c|c|c|c|c|c|c|}
\hline & AVG & $\begin{array}{l}\text { High } \\
\text { Mom } \\
\end{array}$ & $\begin{array}{c}\text { Low } \\
\text { Basis } \\
\end{array}$ & $\begin{array}{c}\text { High } \\
\text { Basis-Mom }\end{array}$ & $\begin{array}{c}\text { High } \\
\text { HP } \\
\end{array}$ & $\begin{array}{c}\text { High } \\
\text { Value } \\
\end{array}$ & $\begin{array}{c}\text { L/S } \\
\text { Mom } \\
\end{array}$ & $\begin{array}{c}\text { L/S } \\
\text { Basis } \\
\end{array}$ & $\begin{array}{c}\text { L/S } \\
\text { Basis-Mom } \\
\end{array}$ & $\begin{array}{l}\text { L/S } \\
\text { HP } \\
\end{array}$ & $\begin{array}{c}\text { L/S } \\
\text { Value } \\
\end{array}$ \\
\hline \multicolumn{12}{|c|}{ Panel A. Variance $_{t}($ Portfolio $)=$ Int + Beta $*$ Variance $_{t-1}($ Portfolio $)+$ error $_{t}$} \\
\hline Int. & -3.129 & -2.266 & -3.188 & -3.204 & -2.586 & -3.333 & -2.994 & -4.029 & -3.406 & -3.242 & -2.639 \\
\hline & $(-7.339)$ & $(-9.592)$ & $(-9.210)$ & $(-8.919)$ & $(-8.598)$ & $(-10.712)$ & $(-12.319)$ & $(-14.996)$ & $(-7.738)$ & $(-12.483)$ & $(-8.937)$ \\
\hline Beta & 0.556 & 0.648 & 0.519 & 0.521 & 0.601 & 0.495 & 0.506 & 0.378 & 0.527 & 0.494 & 0.568 \\
\hline & $(9.470)$ & (18.140) & $(10.291)$ & $(9.897)$ & (13.216) & (10.722) & (12.597) & $(9.188)$ & $(8.757)$ & $(12.360)$ & (11.689) \\
\hline$R_{\text {adj }}^{2}$ & $30.73 \%$ & $41.91 \%$ & $26.77 \%$ & $26.97 \%$ & $35.94 \%$ & $24.30 \%$ & $25.50 \%$ & $14.12 \%$ & $27.61 \%$ & $24.17 \%$ & $32.13 \%$ \\
\hline \multicolumn{12}{|c|}{ Panel B. Return $($ Portfolio $)=$ Int + Beta $*$ Variance $_{t-1}\left({\text { Portfolio })+ \text { error }_{t}}\right.$} \\
\hline Int. & -0.024 & -0.010 & -0.027 & -0.025 & -0.002 & -0.031 & -0.044 & 0.021 & 0.014 & 0.022 & -0.001 \\
\hline & $(-0.803)$ & $(-0.384)$ & $(-0.792)$ & $(-0.809)$ & $(-0.062)$ & $(-1.586)$ & $(-2.041)$ & $(0.768)$ & $(0.787)$ & $(0.812)$ & $(-0.027)$ \\
\hline Beta & -0.004 & -0.002 & -0.005 & -0.005 & -0.001 & -0.005 & -0.009 & 0.002 & 0.000 & 0.003 & -0.001 \\
\hline & $(-0.877)$ & $(-0.620)$ & $(-1.013)$ & $(-1.086)$ & $(-0.173)$ & $(-1.761)$ & $(-2.563)$ & $(0.435)$ & (0.169) & $(0.634)$ & $(-0.109)$ \\
\hline$R_{a d j}^{2}$ & $0.34 \%$ & $-0.07 \%$ & $0.36 \%$ & $0.34 \%$ & $-0.21 \%$ & $0.38 \%$ & $0.91 \%$ & $-0.16 \%$ & $-0.21 \%$ & $-0.11 \%$ & $-0.21 \%$ \\
\hline \multicolumn{12}{|c|}{ Panel C. $S R_{t}($ Portfolio $)=$ Int. + Beta $*$ Variance $_{t-1}($ Portfolio $)+$ error $_{t}$} \\
\hline Int. & 0.045 & 0.447 & -0.122 & -0.339 & 0.370 & -0.988 & -1.135 & 0.432 & -0.026 & 0.361 & -0.199 \\
\hline & $(0.075)$ & $(0.925)$ & $(-0.211)$ & $(-0.522)$ & $(0.647)$ & (2.018) & $(-2.390)$ & $(0.729)$ & $(-0.070)$ & $(0.587)$ & $(-0.361)$ \\
\hline \multirow[t]{2}{*}{ Beta } & --0.010 & 0.035 & -0.056 & -0.095 & 0.033 & -0.162 & -0.228 & 0.022 & -0.007 & 0.032 & -0.042 \\
\hline & $(-0.123)$ & $(0.460)$ & $(-0.660)$ & $(-0.996)$ & $(0.365)$ & $(-2.160)$ & $(-2.979)$ & $(0.240)$ & $(-0.144)$ & $(0.327)$ & $(-0.478)$ \\
\hline$R_{a d j}^{2}$ & $-0.21 \%$ & $-0.16 \%$ & $-0.11 \%$ & $0.07 \%$ & $-0.18 \%$ & $0.62 \%$ & $1.63 \%$ & $-0.20 \%$ & $-0.21 \%$ & $-0.19 \%$ & $-0.16 \%$ \\
\hline
\end{tabular}




\section{Table IA9. Return-forecast and Variance Managed for the AVG and Long-Short Commodity Portfolios}

This Table tabulates the results for the return-forecast and variance managed for the average commodity factor (AVG) and long-short commodity factor portfolios. In Panel A the return forecasts are based on commodity specific \& macroeconomic variables. In Panel B the return forecasts are based on the factor valuation spreads. In Panel C the return forecasts are based on the factor exposure spreads. In Panel D the return forecasts are based on commodity specific \& macroeconomic variables, factor valuation spreads and factor exposure spreads. $f^{\sigma^{2}}$ denotes the 1-month variance-managed commodity portfolio, whilst $f_{j}^{\sigma^{2}, r}$ stands for the combined return-forecast and 1-month variance-managed portfolio. $j=$ histavg stands for the historical average. $j=$ poolavg stands for the pooled average method; $j=D I$ stands for the diffusion index method and $j=M U L T$ stands for the multiple regression method. We consider the unmanaged AVG and the unmanaged commodity long/short (L/S) portfolios MOM (i.e. Momentum), BASIS (i.e. Basis), BASIS-MOM (i.e. Basis-Momentum), HP (i.e. Hedging Pressure) and Value (i.e. Value). The mean, standard deviation (SD), Sharpe Ratio (SR), alpha (against the multifactor model), standard error (se), Appraisal Ratio (alpha/se) and Certainty Equivalent Return (CER, assuming power utility and $\gamma=5$ ) are annualised. The last column denotes the p-value of the change of the CER between the passive commodity portfolio and the managed portfolio following Diebold and Mariano (1995) test. The forecast evaluation period spans January 1980 to August 2018. We generate forecasts using an expanding window approach with an initial time window of 10 years. We use Newey-West (1987) standard errors for the statistical significance of alpha.* denotes significance at $10 \%$ level, $* *$ denotes significance at $5 \%$ level and $* * *$ denotes significance at $1 \%$ level.

\begin{tabular}{|c|c|c|c|c|c|c|c|c|}
\hline \multicolumn{9}{|c|}{ Panel A. Predictor variables: commodity specific \& macroeconomic variables } \\
\hline & Mean & SD & SR & Alpha & se & Appraisal Ratio & CER & p-value $(\triangle C E R)$ \\
\hline$f \equiv A V G$ & $2.17 \%$ & $12.30 \%$ & 0.176 & - & - & - & $-1.85 \%$ & - \\
\hline$f^{\sigma^{2}}$ & $0.79 \%$ & $12.30 \%$ & 0.064 & $-0.18 \%$ & 0.088 & -0.020 & $-4.43 \%$ & 0.406 \\
\hline$f_{\text {histavg }}^{\sigma^{2}, r}$ & $-0.44 \%$ & $12.30 \%$ & -0.036 & $-1.65 \%$ & 0.084 & -0.198 & $-5.15 \%$ & 0.328 \\
\hline$f_{\text {poolavg }}^{\sigma^{2}, r}$ & $0.02 \%$ & $12.30 \%$ & 0.002 & $-1.34 \%$ & 0.085 & -0.157 & $-4.59 \%$ & 0.365 \\
\hline$f_{D I}^{\sigma^{2}, r}$ & $1.95 \%$ & $12.30 \%$ & 0.158 & $1.32 \%$ & 0.106 & 0.124 & $-1.73 \%$ & 0.837 \\
\hline$f_{M U L T}^{\sigma^{2}, r}$ & $0.36 \%$ & $12.30 \%$ & 0.029 & $-0.85 \%$ & 0.110 & -0.078 & $-4.28 \%$ & 0.429 \\
\hline$f \equiv L / S M O M$ & $12.11 \%$ & $19.81 \%$ & 0.611 & - & - & - & $2.30 \%$ & - \\
\hline$f^{\sigma^{2}}$ & $16.80 \%$ & $19.81 \%$ & $0.848 * *$ & $7.62 \% * * *$ & 0.120 & 0.634 & $8.42 \%$ & 0.000 \\
\hline$f_{\text {histavg }}^{\sigma^{2}, r}$ & $16.63 \%$ & $19.81 \%$ & $0.839 * *$ & $7.35 \% * * *$ & 0.116 & 0.634 & $8.10 \%$ & 0.001 \\
\hline$f_{\text {poolavg }}^{\sigma^{2}, r}$ & $16.65 \%$ & $19.81 \%$ & $0.840 * *$ & $6.97 \% * * *$ & 0.111 & 0.627 & $7.89 \%$ & 0.001 \\
\hline$f_{D I}^{\sigma^{2}, r}$ & $14.87 \%$ & $19.81 \%$ & $0.751 *$ & $5.59 \% * * *$ & 0.124 & 0.450 & $5.60 \%$ & 0.357 \\
\hline$f_{M U L T}^{\sigma^{2}, r}$ & $8.04 \%$ & $19.81 \%$ & 0.406 & $1.31 \%$ & 0.172 & 0.076 & $-5.75 \%$ & 0.312 \\
\hline$f \equiv L / S B A S I S$ & $12.09 \%$ & $15.51 \%$ & 0.780 & - & - & - & $6.23 \%$ & - \\
\hline$f^{\sigma^{2}}$ & $9.50 \%$ & $15.51 \%$ & 0.613 & $-0.37 \%$ & 0.084 & -0.044 & $3.39 \%$ & 0.191 \\
\hline$f_{\text {histavg }}^{\sigma^{2}, r}$ & $9.11 \%$ & $15.51 \%$ & 0.588 & $-0.72 \%$ & 0.087 & -0.084 & $3.12 \%$ & 0.162 \\
\hline$f_{\text {poolavg }}^{\sigma^{2}, r}$ & $9.04 \%$ & $15.51 \%$ & 0.583 & $-0.74 \%$ & 0.089 & -0.083 & $3.06 \%$ & 0.177 \\
\hline$f_{D I}^{\sigma^{2}, r}$ & $6.39 \%$ & $15.51 \%$ & 0.412 & $-2.89 \%$ & 0.104 & -0.277 & $-0.39 \%$ & 0.059 \\
\hline$f_{M U L T}^{\sigma^{2}, r}$ & $7.09 \%$ & $15.51 \%$ & 0.457 & $3.55 \%$ & 0.143 & 0.248 & $2.45 \%$ & 0.494 \\
\hline$f \equiv L / S B A S I S-M O M$ & $14.20 \%$ & $16.09 \%$ & 0.882 & - & - & - & $7.74 \%$ & - \\
\hline$f^{\sigma^{2}}$ & $10.91 \%$ & $16.09 \%$ & 0.678 & $2.49 \%$ & 0.125 & 0.198 & $5.77 \%$ & 0.766 \\
\hline$f_{\text {histavg }}^{\sigma^{2}, r}$ & $10.62 \%$ & $16.09 \%$ & 0.660 & $2.53 \%$ & 0.128 & 0.198 & $5.53 \%$ & 0.830 \\
\hline$f_{\text {poolavg }}^{\sigma^{2}, r}$ & $10.45 \%$ & $16.09 \%$ & 0.650 & $2.41 \%$ & 0.128 & 0.188 & $5.42 \%$ & 0.832 \\
\hline$f_{D I}^{\sigma^{2}, r}$ & $9.17 \%$ & $16.09 \%$ & 0.570 & $1.27 \%$ & 0.129 & 0.099 & $4.19 \%$ & 0.800 \\
\hline$f_{M U L T}^{\sigma^{2}, r}$ & $8.42 \%$ & $16.09 \%$ & 0.523 & $2.69 \%$ & 0.143 & 0.188 & $3.53 \%$ & 0.774 \\
\hline$f \equiv L / S H P$ & $7.20 \%$ & $16.44 \%$ & 0.438 & - & - & - & $0.56 \%$ & - \\
\hline$f^{\sigma^{2}}$ & $6.44 \%$ & $16.44 \%$ & 0.392 & $1.17 \%$ & 0.084 & 0.139 & $0.32 \%$ & 0.819 \\
\hline$f_{\text {histavg }}^{\sigma^{2}, r}$ & $4.72 \%$ & $16.44 \%$ & 0.287 & $-1.85 \%$ & 0.136 & -0.136 & $-2.56 \%$ & 0.218 \\
\hline$f_{\text {poolavg }}^{\sigma^{2}, r}$ & $7.33 \%$ & $16.44 \%$ & 0.446 & $1.09 \%$ & 0.125 & 0.087 & $0.80 \%$ & 0.988 \\
\hline$f_{D I}^{\sigma^{2}, r}$ & $5.49 \%$ & $16.44 \%$ & 0.334 & $1.31 \%$ & 0.149 & 0.088 & $-0.73 \%$ & 0.720 \\
\hline$f_{M U L T}^{\sigma^{2}, r}$ & $3.35 \%$ & $16.44 \%$ & 0.204 & $-0.67 \%$ & 0.155 & -0.043 & $-3.66 \%$ & 0.186 \\
\hline$f \equiv L / S V A L U E$ & $4.92 \%$ & $19.72 \%$ & 0.250 & - & - & - & $-4.87 \%$ & - \\
\hline$f^{\sigma^{2}}$ & $5.62 \%$ & $19.72 \%$ & 0.285 & $0.15 \%$ & 0.113 & 0.013 & $-3.87 \%$ & 0.721 \\
\hline$f_{\text {histavg }}^{\sigma^{2}, r}$ & $2.91 \%$ & $19.72 \%$ & 0.148 & $-2.44 \%$ & 0.137 & -0.177 & $-6.44 \%$ & 0.741 \\
\hline$f_{\text {poolavg }}^{\sigma^{2}, r}$ & $2.61 \%$ & $19.72 \%$ & 0.132 & $-3.11 \%$ & 0.152 & -0.205 & $-8.16 \%$ & 0.356 \\
\hline$f_{D I}^{\sigma^{2}, r}$ & $-2.09 \%$ & $19.72 \%$ & -0.106 & $-6.47 \%$ & 0.176 & -0.367 & $-13.20 \%$ & 0.105 \\
\hline$f_{M U L T}^{\sigma^{2}, r}$ & $0.14 \%$ & $19.72 \%$ & 0.007 & $-2.65 \%$ & 0.193 & -0.138 & $-14.46 \%$ & 0.293 \\
\hline
\end{tabular}


Table IA9. Return-forecast and Variance Managed for the AVG and Long-Short Commodity Portfolios (Cont'd)

\begin{tabular}{|c|c|c|c|c|c|c|c|c|}
\hline \multicolumn{9}{|c|}{ Panel B. Predictor variables: Factor Valuation Spreads } \\
\hline & Mean & SD & SR & alpha & se & $\begin{array}{c}\text { Appraisal } \\
\text { Ratio }\end{array}$ & CER & $\begin{array}{l}\text { p-value } \\
(\triangle C E R)\end{array}$ \\
\hline$f \equiv A V G$ & $2.17 \%$ & $12.30 \%$ & 0.176 & - & - & - & $-1.85 \%$ & - \\
\hline$f^{\sigma^{2}}$ & $0.79 \%$ & $12.30 \%$ & 0.064 & $-0.18 \%$ & 0.088 & -0.020 & $-4.43 \%$ & 0.406 \\
\hline$f_{\text {histavg }}^{\sigma^{2}, r}$ & $-0.44 \%$ & $12.30 \%$ & -0.036 & $-1.65 \%$ & 0.084 & -0.198 & $-5.15 \%$ & 0.328 \\
\hline$f_{\text {poolavg }}^{\sigma^{2}, r}$ & - & - & - & - & - & - & - & - \\
\hline$f_{D I}^{\sigma^{2}, r}$ & - & - & - & - & - & - & - & - \\
\hline$f_{M U L T}^{\sigma^{2}, r}$ & - & - & - & - & - & - & - & - \\
\hline$f \equiv L / S M O M$ & $12.11 \%$ & $19.81 \%$ & 0.611 & - & - & - & $2.30 \%$ & - \\
\hline$f^{\sigma^{2}}$ & $16.80 \%$ & $19.81 \%$ & $0.848 * *$ & $7.62 \% * * *$ & 0.120 & 0.634 & $8.42 \%$ & 0.000 \\
\hline $\mathrm{f}_{\text {histavg }}^{\sigma^{2}, \mathrm{r}}$ & $16.63 \%$ & $19.81 \%$ & $0.839^{* *}$ & $7.35 \% * * *$ & 0.116 & 0.634 & $8.10 \%$ & 0.001 \\
\hline$f_{\text {poolavg }}^{\sigma^{2}, r}$ & - & - & - & - & - & - & - & - \\
\hline$f_{D I}^{\sigma^{2}, r}$ & - & - & - & - & - & - & - & - \\
\hline$f_{M U L T}^{\sigma^{2}, r}$ & $17.32 \%$ & $19.81 \%$ & $0.874 * *$ & $8.07 \% * * *$ & 0.125 & 0.644 & $7.97 \%$ & 0.000 \\
\hline$f \equiv L / S B A S I S$ & $12.09 \%$ & $15.51 \%$ & 0.780 & - & - & - & $6.23 \%$ & - \\
\hline$f^{\sigma^{2}}$ & $9.50 \%$ & $15.51 \%$ & 0.613 & $-0.37 \%$ & 0.084 & -0.044 & $3.39 \%$ & 0.191 \\
\hline$f_{\text {histavg }}^{\sigma^{2}, r}$ & $9.11 \%$ & $15.51 \%$ & 0.588 & $-0.72 \%$ & 0.087 & -0.084 & $3.12 \%$ & 0.162 \\
\hline$f_{\text {poolavg }}^{\sigma^{2}, r}$ & - & - & - & - & - & - & - & - \\
\hline$f_{D I}^{\sigma^{2}, r}$ & - & - & - & - & - & - & - & - \\
\hline$f_{M U L T}^{\sigma^{2}, r}$ & $8.44 \%$ & $15.51 \%$ & 0.544 & $-0.94 \%$ & 0.089 & -0.106 & $2.27 \%$ & 0.109 \\
\hline$f \equiv L / S B A S I S-M O M$ & $14.20 \%$ & $16.09 \%$ & 0.882 & - & - & - & $7.74 \%$ & - \\
\hline$f^{\sigma^{2}}$ & $10.91 \%$ & $16.09 \%$ & 0.678 & $2.49 \%$ & 0.125 & 0.198 & $5.77 \%$ & 0.766 \\
\hline$f_{\text {histavg }}^{\sigma^{2}, r}$ & $10.62 \%$ & $16.09 \%$ & 0.660 & $2.53 \%$ & 0.128 & 0.198 & $5.53 \%$ & 0.830 \\
\hline$f_{\text {poolavg }}^{\sigma^{2}, r}$ & - & - & - & - & - & - & - & - \\
\hline$f_{D I}^{\sigma^{2}, r}$ & - & - & - & - & - & - & - & - \\
\hline$f_{M U L T}^{\sigma^{2}, r}$ & $11.04 \%$ & $16.09 \%$ & 0.686 & $1.69 \%$ & 0.118 & 0.143 & $5.51 \%$ & 0.903 \\
\hline$f \equiv L / S H P$ & $7.20 \%$ & $16.44 \%$ & 0.438 & - & - & - & $0.56 \%$ & - \\
\hline$f^{\sigma^{2}}$ & $6.44 \%$ & $16.44 \%$ & 0.392 & $1.17 \%$ & 0.084 & 0.139 & $0.32 \%$ & 0.819 \\
\hline$f_{\text {histavg }}^{\sigma^{2}, r}$ & $4.72 \%$ & $16.44 \%$ & 0.287 & $-1.85 \%$ & 0.136 & -0.136 & $-2.56 \%$ & 0.218 \\
\hline$f_{\text {poolavg }}^{\sigma^{2}, r}$ & - & - & - & - & - & - & - & - \\
\hline$f_{D I}^{\sigma^{2}, r}$ & - & - & - & - & - & - & - & - \\
\hline$f_{M U L T}^{\sigma^{2}, r}$ & $4.14 \%$ & $16.44 \%$ & 0.252 & $-0.40 \%$ & 0.140 & -0.028 & $-2.74 \%$ & 0.276 \\
\hline$f \equiv L / S V A L U E$ & $4.92 \%$ & $19.72 \%$ & 0.250 & - & - & - & $-4.87 \%$ & - \\
\hline$f^{\sigma^{2}}$ & $5.62 \%$ & $19.72 \%$ & 0.285 & $0.15 \%$ & 0.113 & 0.013 & $-3.87 \%$ & 0.721 \\
\hline$f_{\text {histavg }}^{\sigma^{2}, r}$ & $2.91 \%$ & $19.72 \%$ & 0.148 & $-2.44 \%$ & 0.137 & -0.177 & $-6.44 \%$ & 0.741 \\
\hline$f_{\text {poolavg }}^{\sigma^{2}, r}$ & - & - & - & - & - & - & - & - \\
\hline$f_{D I}^{\sigma^{2}, r}$ & - & - & - & - & - & - & - & - \\
\hline$f_{M U L T}^{\sigma^{2}, r}$ & $1.57 \%$ & $19.72 \%$ & 0.079 & $2.48 \%$ & 0.194 & 0.128 & $-7.88 \%$ & 0.554 \\
\hline
\end{tabular}




\begin{tabular}{|c|c|c|c|c|c|c|c|c|}
\hline \multicolumn{9}{|c|}{$\begin{array}{c}\text { Table IA9. Return-forecast and Variance Managed for the AVG and Long-Short Commod } \\
\text { Panel C. Predictor variables: Factor Exposure Spreads }\end{array}$} \\
\hline & Mean & SD & SR & alpha & se & $\begin{array}{l}\text { Appraisal } \\
\text { Ratio }\end{array}$ & CER & $\begin{array}{l}\text { p-value } \\
(\triangle C E R)\end{array}$ \\
\hline$f \equiv A V G$ & $2.17 \%$ & $12.30 \%$ & 0.176 & - & - & - & $-1.85 \%$ & - \\
\hline$f^{\sigma^{2}}$ & $0.79 \%$ & $12.30 \%$ & 0.064 & $-0.18 \%$ & 0.088 & -0.020 & $-4.43 \%$ & 0.406 \\
\hline$f_{\text {histavg }}^{\sigma^{2}, r}$ & $-0.44 \%$ & $12.30 \%$ & -0.036 & $-1.65 \%$ & 0.084 & -0.198 & $-5.15 \%$ & 0.328 \\
\hline$f_{\text {poolavg }}^{\sigma^{2}, r}$ & - & - & - & - & - & - & - & - \\
\hline$f_{D I}^{\sigma^{2}, r}$ & - & - & - & - & - & - & - & - \\
\hline$f_{M U L T}^{\sigma^{2}, r}$ & - & - & - & - & - & - & - & - \\
\hline$f \equiv L / S M O M$ & $12.11 \%$ & $19.81 \%$ & 0.611 & - & - & - & $2.30 \%$ & - \\
\hline$f^{\sigma^{2}}$ & $16.80 \%$ & $19.81 \%$ & $0.848 * *$ & $7.62 \%$ *** & 0.120 & 0.634 & $8.42 \%$ & 0.000 \\
\hline $\mathrm{f}_{\text {histavg }}^{\sigma^{2}, \mathrm{r}}$ & $16.63 \%$ & $19.81 \%$ & $0.839 * *$ & $7.35 \% * * *$ & 0.116 & 0.634 & $8.10 \%$ & 0.001 \\
\hline$f_{\text {poolavg }}^{\sigma^{2}, r}$ & - & - & - & - & - & - & - & - \\
\hline$f_{D I}^{\sigma^{2}, r}$ & - & - & - & - & - & - & - & - \\
\hline$f_{M U L T}^{\sigma^{2}, r}$ & $16.51 \%$ & $19.81 \%$ & $0.833 * *$ & $7.03 \% * * *$ & 0.112 & 0.628 & $7.79 \%$ & 0.016 \\
\hline$f \equiv L / S B A S I S$ & $12.09 \%$ & $15.51 \%$ & 0.780 & - & - & - & $6.23 \%$ & - \\
\hline$f^{\sigma^{2}}$ & $9.50 \%$ & $15.51 \%$ & 0.613 & $-0.37 \%$ & 0.084 & -0.044 & $3.39 \%$ & 0.191 \\
\hline$f_{\text {histavg }}^{\sigma^{2}, r}$ & $9.11 \%$ & $15.51 \%$ & 0.588 & $-0.72 \%$ & 0.087 & -0.084 & $3.12 \%$ & 0.162 \\
\hline$f_{\text {poolavg }}^{\sigma^{2}, r}$ & - & - & - & - & - & - & - & - \\
\hline$f_{D I}^{\sigma^{2}, r}$ & - & - & - & - & - & - & - & - \\
\hline$f_{M U L T}^{\sigma^{2}, r}$ & $8.32 \%$ & $15.51 \%$ & 0.536 & $-0.23 \%$ & 0.106 & -0.022 & $2.76 \%$ & 0.237 \\
\hline$f \equiv L / S B A S I S-M O M$ & $14.20 \%$ & $16.09 \%$ & 0.882 & - & - & - & $7.74 \%$ & - \\
\hline$f^{\sigma^{2}}$ & $10.91 \%$ & $16.09 \%$ & 0.678 & $2.49 \%$ & 0.125 & 0.198 & $5.77 \%$ & 0.766 \\
\hline$f_{\text {histavg }}^{\sigma^{2}, r}$ & $10.62 \%$ & $16.09 \%$ & 0.660 & $2.53 \%$ & 0.128 & 0.198 & $5.53 \%$ & 0.830 \\
\hline$f_{\text {poolavg }}^{\sigma^{2}, r}$ & - & - & - & - & - & - & - & - \\
\hline$f_{D I}^{\sigma^{2}, r}$ & - & - & - & - & - & - & - & - \\
\hline$f_{M U L T}^{\sigma^{2}, r}$ & $9.58 \%$ & $16.09 \%$ & 0.595 & $1.70 \%$ & 0.131 & 0.130 & $4.64 \%$ & 0.879 \\
\hline$f \equiv L / S H P$ & $7.20 \%$ & $16.44 \%$ & 0.438 & - & - & - & $0.56 \%$ & - \\
\hline$f^{\sigma^{2}}$ & $6.44 \%$ & $16.44 \%$ & 0.392 & $1.17 \%$ & 0.084 & 0.139 & $0.32 \%$ & 0.819 \\
\hline$f_{\text {histavg }}^{\sigma^{2}, r}$ & $4.72 \%$ & $16.44 \%$ & 0.287 & $-1.85 \%$ & 0.136 & -0.136 & $-2.56 \%$ & 0.218 \\
\hline$f_{\text {poolavg }}^{\sigma^{2}, r}$ & - & - & - & - & - & - & - & - \\
\hline$f_{D I}^{\sigma^{2}, r}$ & - & - & - & - & - & - & - & - \\
\hline$f_{M U L T}^{\sigma^{2}, r}$ & $3.80 \%$ & $16.44 \%$ & 0.231 & $-2.40 \%$ & 0.154 & -0.156 & $-2.96 \%$ & 0.288 \\
\hline$f \equiv L / S V A L U E$ & $4.92 \%$ & $19.72 \%$ & 0.250 & - & - & - & $-4.87 \%$ & - \\
\hline$f^{\sigma^{2}}$ & $5.62 \%$ & $19.72 \%$ & 0.285 & $0.15 \%$ & 0.113 & 0.013 & $-3.87 \%$ & 0.721 \\
\hline$f_{\text {histavg }}^{\sigma^{2}, r}$ & $2.91 \%$ & $19.72 \%$ & 0.148 & $-2.44 \%$ & 0.137 & -0.177 & $-6.44 \%$ & 0.741 \\
\hline$f_{\text {poolavg }}^{\sigma^{2}, r}$ & - & - & - & - & - & - & - & - \\
\hline$f_{D I}^{\sigma^{2}, r}$ & - & - & - & - & - & - & - & - \\
\hline$f_{M U L T}^{\sigma^{2}, r}$ & $1.57 \%$ & $19.72 \%$ & 0.079 & $2.48 \%$ & 0.194 & 0.128 & $-7.88 \%$ & 0.554 \\
\hline
\end{tabular}


Table IA9. Return-forecast and Variance Managed for the AVG and Long-Short Commodity Portfolios (Cont'd) Panel D. Predictor variables: commodity specific \& macroeconomic variables, factor valuation spreads and factor exposure spreads

\begin{tabular}{|c|c|c|c|c|c|c|c|c|}
\hline & Mean & SD & SR & Alpha & se & $\begin{array}{c}\text { Appraisal } \\
\text { Ratio } \\
\end{array}$ & $C E R$ & $\begin{array}{l}\text { p-value } \\
(\triangle C E R)\end{array}$ \\
\hline$f \equiv A V G$ & $2.17 \%$ & $12.30 \%$ & 0.176 & - & - & - & $-1.85 \%$ & - \\
\hline$f^{\sigma^{2}}$ & $0.79 \%$ & $12.30 \%$ & 0.064 & $-0.18 \%$ & 0.088 & -0.020 & $-4.43 \%$ & 0.406 \\
\hline$f_{\text {histavg }}^{\sigma^{2}, r}$ & $-0.44 \%$ & $12.30 \%$ & -0.036 & $-1.65 \%$ & 0.084 & -0.198 & $-5.15 \%$ & 0.328 \\
\hline$f_{\text {poolavg }}^{\sigma^{2}, r}$ & - & - & - & - & - & - & - & - \\
\hline$f_{D I}^{\sigma^{2}, r}$ & - & - & - & - & - & - & - & - \\
\hline$f_{M U L T}^{\sigma^{2}, r}$ & - & - & - & - & - & - & - & - \\
\hline$f \equiv L / S M O M$ & $12.11 \%$ & $19.81 \%$ & 0.611 & - & - & - & $2.30 \%$ & - \\
\hline$f^{\sigma^{2}}$ & $16.80 \%$ & $19.81 \%$ & $0.848 * *$ & $7.62 \% * * *$ & 0.120 & 0.634 & $8.42 \%$ & 0.000 \\
\hline $\mathrm{f}_{\text {histavg }}^{\sigma^{2}, \mathrm{r}}$ & $16.63 \%$ & $19.81 \%$ & $0.839^{* *}$ & $7.35 \% * * *$ & 0.116 & 0.634 & $8.10 \%$ & 0.001 \\
\hline$f_{\text {poolavg }}^{\sigma^{2}, r}$ & $16.72 \%$ & $19.81 \%$ & $0.844 * *$ & $7.06 \% * * *$ & 0.112 & 0.632 & $8.01 \%$ & 0.001 \\
\hline$f_{D I}^{\sigma^{2}, r}$ & $14.98 \%$ & $19.81 \%$ & $0.756^{*}$ & $5.31 \% * * *$ & 0.112 & 0.453 & $5.56 \%$ & 0.434 \\
\hline$f_{M U L T}^{\sigma^{2}, r}$ & $10.48 \%$ & $19.81 \%$ & 0.529 & $3.30 \% *$ & 0.172 & 0.192 & $-0.72 \%$ & 0.386 \\
\hline$f \equiv L / S B A S I S$ & $12.09 \%$ & $15.51 \%$ & 0.780 & - & - & - & $6.23 \%$ & - \\
\hline$f^{\sigma^{2}}$ & $9.50 \%$ & $15.51 \%$ & 0.613 & $-0.37 \%$ & 0.084 & -0.044 & $3.39 \%$ & 0.191 \\
\hline$f_{\text {histavg }}^{\sigma^{2}, r}$ & $9.11 \%$ & $15.51 \%$ & 0.588 & $-0.72 \%$ & 0.087 & -0.084 & $3.12 \%$ & 0.162 \\
\hline$f_{\text {poolavg }}^{\sigma^{2}, r}$ & $9.01 \%$ & $15.51 \%$ & 0.583 & $-0.73 \%$ & 0.088 & -0.082 & $3.06 \%$ & 0.179 \\
\hline$f_{D I}^{\sigma^{2}, r}$ & $5.51 \%$ & $15.51 \%$ & 0.355 & $-2.91 \%$ & 0.111 & -0.262 & $-1.58 \%$ & 0.778 \\
\hline$f_{M U L T}^{\sigma^{2}, r}$ & $7.63 \%$ & $15.51 \%$ & 0.492 & $3.85 \%$ & 0.0143 & 0.270 & $3.10 \%$ & 0.700 \\
\hline$f \equiv L / S B A S I S-M O M$ & $14.20 \%$ & $16.09 \%$ & 0.882 & - & - & - & $7.74 \%$ & - \\
\hline$f^{\sigma^{2}}$ & $10.91 \%$ & $16.09 \%$ & 0.678 & $2.49 \%$ & 0.125 & 0.198 & $5.77 \%$ & 0.766 \\
\hline$f_{\text {histavg }}^{\sigma^{2}, r}$ & $10.62 \%$ & $16.09 \%$ & 0.660 & $2.53 \%$ & 0.128 & 0.198 & $5.53 \%$ & 0.830 \\
\hline$f_{\text {poolavg }}^{\sigma^{2}, r}$ & $10.47 \%$ & $16.09 \%$ & 0.650 & $2.33 \%$ & 0.128 & 0.183 & $5.42 \%$ & 0.832 \\
\hline$f_{D I}^{\sigma^{2}, r}$ & $8.67 \%$ & $16.09 \%$ & 0.539 & $1.05 \%$ & 0.131 & 0.081 & $3.83 \%$ & 0.737 \\
\hline$f_{M U L T}^{\sigma^{2}, r}$ & $8.14 \%$ & $16.09 \%$ & 0.506 & $1.11 \%$ & 0.136 & 0.081 & $2.70 \%$ & 0.297 \\
\hline$f \equiv L / S H P$ & $7.20 \%$ & $16.44 \%$ & 0.438 & - & - & - & $0.56 \%$ & - \\
\hline$f^{\sigma^{2}}$ & $6.44 \%$ & $16.44 \%$ & 0.392 & $1.17 \%$ & 0.084 & 0.139 & $0.32 \%$ & 0.819 \\
\hline$f_{\text {histavg }}^{\sigma^{2}, r}$ & $4.72 \%$ & $16.44 \%$ & 0.287 & $-1.85 \%$ & 0.136 & -0.136 & $-2.56 \%$ & 0.218 \\
\hline$f_{\text {poolavg }}^{\sigma^{2}, r}$ & $7.19 \%$ & $16.44 \%$ & 0.437 & $0.80 \%$ & 0.126 & 0.064 & $0.55 \%$ & 0.851 \\
\hline$f_{D I}^{\sigma^{2}, r}$ & $5.54 \%$ & $16.44 \%$ & 0.337 & $1.31 \%$ & 0.146 & 0.090 & $-0.80 \%$ & 0.635 \\
\hline$f_{M U L T}^{\sigma^{2}, r}$ & $2.14 \%$ & $16.44 \%$ & 0.130 & $-1.94 \%$ & 0.159 & -0.122 & $-9.95 \%$ & 0.307 \\
\hline$f \equiv L / S V A L U E$ & $4.92 \%$ & $19.72 \%$ & 0.250 & - & - & - & $-4.87 \%$ & - \\
\hline$f^{\sigma^{2}}$ & $5.62 \%$ & $19.72 \%$ & 0.285 & $0.15 \%$ & 0.113 & 0.013 & $-3.87 \%$ & 0.721 \\
\hline$f_{\text {histavg }}^{\sigma^{2}, r}$ & $2.91 \%$ & $19.72 \%$ & 0.148 & $-2.44 \%$ & 0.137 & -0.177 & $-6.44 \%$ & 0.741 \\
\hline$f_{\text {poolavg }}^{\sigma^{2}, r}$ & $2.91 \%$ & $19.72 \%$ & 0.147 & $-2.87 \%$ & 0.149 & -0.193 & $-8.06 \%$ & 0.362 \\
\hline$f_{D I}^{\sigma^{2}, r}$ & $-1.46 \%$ & $19.72 \%$ & -0.074 & $-6.03 \%$ & 0.181 & -0.334 & $-11.62 \%$ & 0.146 \\
\hline$f_{M U L T}^{\sigma^{2}, r}$ & $-0.08 \%$ & $19.72 \%$ & -0.004 & $-2.16 \%$ & 0.194 & -0.111 & $-12.67 \%$ & 0.216 \\
\hline
\end{tabular}




\section{Table IA10. Return-forecast and Variance Managed for the Long-Only Commodity Factor Portfolios}

This Table tabulates the results for the return-forecast and variance managed for the long-only commodity factor portfolios. In Panel A the return forecasts are based on commodity specific \& macroeconomic variables. In Panel B the return forecasts are based on the factor valuation spreads. In Panel C the return forecasts are based on factor exposure spreads. In Panel D the return forecasts are based on commodity specific \& macroeconomic variable, factor valuation spreads and factor exposure spreads. $f^{\sigma^{2}}$ denotes the 1-month variance-managed commodity portfolio, whilst $f_{j}^{\sigma^{2}, r}$ stands for the combined return-forecast and 1-month variance-managed portfolio. $j=$ histavg stands for the historical average. $j=$ poolavg stands for the pooled average method; $j=D I$ stands for the diffusion index method and $j=M U L T$ stands for the multiple regression method. We consider the unmanaged commodity long-only portfolios MOM (i.e. Momentum), BASIS (i.e. Basis), BASIS-MOM (i.e. Basis-Momentum), HP (i.e. Hedging Pressure) and Value (i.e. Value). The mean, standard deviation (SD), Sharpe Ratio (SR), alpha (against the multifactor model), standard error (se), Appraisal Ratio (alpha/se) and Certainty Equivalent Return (CER, assuming power utility and $\gamma=5$ ) are annualised. The last column denotes the p-value of the change of the CER between the passive commodity portfolio and the managed portfolio following Diebold and Mariano (1995) test. The forecast evaluation period spans January 1980 to August 2018. We generate forecasts using an expanding window approach with an initial time window of 10 years. We use Newey-West (1987) standard errors for the statistical significance of alpha.* denotes significance at $10 \%$ level, $* *$ denotes significance at $5 \%$ level and $* * *$ denotes significance at $1 \%$ level

\begin{tabular}{|c|c|c|c|c|c|c|c|c|}
\hline \multicolumn{9}{|c|}{ Panel A. Predictor variables: $\mathrm{c}$} \\
\hline & Mean & SD & SR & Alpha & se & $\begin{array}{c}\text { Appraisal } \\
\text { Ratio } \\
\end{array}$ & $C E R$ & $\begin{array}{l}\text { p-value } \\
(\Delta C E R)\end{array}$ \\
\hline$f \equiv H i g h M O M$ & $8.44 \%$ & $18.50 \%$ & 0.456 & - & - & - & $-0.98 \%$ & - \\
\hline$f^{\sigma^{2}}$ & $7.98 \%$ & $18.50 \%$ & 0.431 & $1.60 \%$ & 0.132 & 0.121 & $-2.90 \%$ & 0.524 \\
\hline$f_{\text {histavg }}^{\sigma^{2}, r}$ & $7.28 \%$ & $18.50 \%$ & 0.393 & $0.71 \%$ & 0.127 & 0.056 & $-2.60 \%$ & 0.669 \\
\hline$f_{\text {poolavg }}^{\sigma^{2}, r}$ & $7.45 \%$ & $18.50 \%$ & 0.403 & $0.68 \%$ & 0.125 & 0.054 & $-2.14 \%$ & 0.778 \\
\hline$f_{D I}^{\sigma^{2}, r}$ & $7.70 \%$ & $18.50 \%$ & 0.416 & $1.16 \%$ & 0.129 & 0.090 & $-1.53 \%$ & 0.960 \\
\hline$f_{M U L T}^{\sigma^{2}, r}$ & $5.34 \%$ & $18.50 \%$ & 0.289 & $-0.43 \%$ & 0.148 & -0.029 & $-4.13 \%$ & 0.547 \\
\hline$f \equiv \operatorname{Low} B A S I S$ & $8.35 \%$ & $15.52 \%$ & 0.538 & - & - & - & $2.01 \%$ & - \\
\hline$f^{\sigma^{2}}$ & $10.20 \%$ & $15.52 \%$ & 0.658 & $2.61 \% *$ & 0.089 & 0.293 & $4.44 \%$ & 0.351 \\
\hline$f_{\text {histavg }}^{\sigma^{2}, r}$ & $9.09 \%$ & $15.52 \%$ & 0.586 & $1.28 \%$ & 0.091 & 0.141 & $3.09 \%$ & 0.693 \\
\hline$f_{\text {poolavg }}^{\sigma^{2}, r}$ & $9.17 \%$ & $15.52 \%$ & 0.591 & $1.36 \%$ & 0.090 & 0.151 & $3.28 \%$ & 0.603 \\
\hline$f_{D I}^{\sigma^{2}, r}$ & $8.52 \%$ & $15.52 \%$ & 0.549 & $1.62 \%$ & 0.111 & 0.145 & $2.10 \%$ & 0.825 \\
\hline$f_{M U L T}^{\sigma^{2}, r}$ & $6.29 \%$ & $15.52 \%$ & 0.405 & $1.96 \%$ & 0.135 & 0.145 & $0.32 \%$ & 0.764 \\
\hline$f \equiv H i g h B A S I S-M O M$ & $10.20 \%$ & $15.58 \%$ & 0.655 & - & - & - & $4.31 \%$ & - \\
\hline$f^{\sigma^{2}}$ & $10.56 \%$ & $15.58 \%$ & 0.678 & $2.11 \%$ & 0.098 & 0.214 & $5.67 \%$ & 0.341 \\
\hline$f_{\text {histavg }}^{\sigma^{2}, r}$ & $9.67 \%$ & $15.58 \%$ & 0.621 & $1.02 \%$ & 0.098 & 0.104 & $4.56 \%$ & 0.706 \\
\hline$f_{\text {poolavg }}^{\sigma^{2}, r}$ & $9.67 \%$ & $15.58 \%$ & 0.621 & $1.06 \%$ & 0.100 & 0.106 & $4.52 \%$ & 0.766 \\
\hline$f_{D I}^{\sigma^{2}, r}$ & $9.10 \%$ & $15.58 \%$ & 0.584 & $1.10 \%$ & 0.114 & 0.097 & $3.79 \%$ & 0.876 \\
\hline$\underline{f_{M U L T}^{\sigma^{2}, r}}$ & $8.36 \%$ & $15.58 \%$ & 0.537 & $1.47 \%$ & 0.119 & 0.124 & $2.55 \%$ & 0.546 \\
\hline$f \equiv H i g h H P$ & $5.01 \%$ & $16.61 \%$ & 0.302 & - & - & - & $-2.07 \%$ & - \\
\hline$f^{\sigma^{2}}$ & $4.74 \%$ & $16.61 \%$ & 0.285 & $1.16 \%$ & 0.101 & 0.115 & $-2.08 \%$ & 0.900 \\
\hline$f_{\text {histavg }}^{\sigma^{2}, r}$ & $3.52 \%$ & $16.61 \%$ & 0.212 & $-0.27 \%$ & 0.095 & -0.029 & $-3.45 \%$ & 0.653 \\
\hline$f_{\text {poolavg }}^{\sigma^{2}, r}$ & $5.23 \%$ & $16.61 \%$ & 0.315 & $1.62 \%$ & 0.099 & 0.165 & $-1.50 \%$ & 0.696 \\
\hline$f_{D I}^{\sigma^{2}, r}$ & $7.32 \%$ & $16.61 \%$ & 0.441 & $5.68 \%$ & 0.134 & 0.424 & $0.96 \%$ & 0.230 \\
\hline$f_{M U L T}^{\sigma^{2}, r}$ & $5.97 \%$ & $16.61 \%$ & 0.359 & $2.94 \%$ & 0.133 & 0.221 & $-0.81 \%$ & 0.687 \\
\hline$f \equiv H i g h V A L U E$ & $3.86 \%$ & $14.89 \%$ & 0.260 & - & - & - & $-1.64 \%$ & - \\
\hline$f^{\sigma^{2}}$ & $5.83 \%$ & $14.89 \%$ & 0.391 & $2.41 \% *$ & 0.081 & $29.67 \%$ & $0.45 \%$ & 0.213 \\
\hline$f_{\text {histavg }}^{\sigma^{2}, r}$ & $4.63 \%$ & $14.89 \%$ & 0.311 & $1.26 \%$ & 0.080 & 0.156 & $-0.82 \%$ & 0.657 \\
\hline$f_{p o o l a v g}^{\sigma^{2}, r}$ & $4.82 \%$ & $14.89 \%$ & 0.324 & $1.48 \%$ & 0.085 & 0.174 & $-0.54 \%$ & 0.454 \\
\hline$f_{D I}^{\sigma^{2}, r}$ & $5.42 \%$ & $14.89 \%$ & 0.364 & $2.74 \% *$ & 0.116 & 0.236 & $0.11 \%$ & 0.478 \\
\hline$f_{M U L T}^{\sigma^{2}, r}$ & $3.52 \%$ & $14.89 \%$ & 0.236 & $1.68 \%$ & 0.128 & 0.132 & $-1.64 \%$ & 0.909 \\
\hline
\end{tabular}




\begin{tabular}{|c|c|c|c|c|c|c|c|c|}
\hline \multicolumn{9}{|c|}{$\begin{array}{l}\text { Table IA10. Return-forecast and Variance Managed for the Long-Only Commodity Po } \\
\text { Panel B. Predictor variables: Factor Valuation Spreads }\end{array}$} \\
\hline & Mean & SD & SR & Alpha & se & $\begin{array}{l}\text { Appraisal } \\
\text { Ratio }\end{array}$ & CER & $\begin{array}{l}\text { p-value } \\
(\triangle C E R) \\
\end{array}$ \\
\hline$f \equiv \operatorname{High} M O M$ & $8.44 \%$ & $18.50 \%$ & 0.456 & - & - & - & $-0.98 \%$ & - \\
\hline$f^{\sigma^{2}}$ & $7.98 \%$ & $18.50 \%$ & 0.431 & $1.60 \%$ & 0.132 & 0.121 & $-2.90 \%$ & 0.524 \\
\hline$f_{\text {histavg }}^{\sigma^{2}, r}$ & $7.28 \%$ & $18.50 \%$ & 0.393 & $0.71 \%$ & 0.127 & 0.056 & $-2.60 \%$ & 0.669 \\
\hline$f_{\text {poolavg }}^{\sigma^{2}, r}$ & - & - & - & - & - & - & - & - \\
\hline$f_{D I}^{\sigma^{2}, r}$ & - & - & - & - & - & - & - & - \\
\hline$f_{M U L T}^{\sigma^{2}, r}$ & $7.24 \%$ & $18.50 \%$ & 0.391 & $0.68 \%$ & 0.129 & 0.052 & $-2.42 \%$ & 0.742 \\
\hline$f \equiv$ Low BASIS & $8.35 \%$ & $15.52 \%$ & 0.538 & - & - & - & $2.01 \%$ & - \\
\hline$f^{\sigma^{2}}$ & $10.20 \%$ & $15.52 \%$ & 0.658 & $2.61 \% *$ & 0.089 & 0.293 & $4.44 \%$ & 0.351 \\
\hline$f_{\text {histavg }}^{\sigma^{2}, r}$ & $9.09 \%$ & $15.52 \%$ & 0.586 & $1.28 \%$ & 0.091 & 0.141 & $3.09 \%$ & 0.693 \\
\hline$f_{\text {poolavg }}^{\sigma^{2}, r}$ & - & - & - & - & - & - & - & - \\
\hline$f_{D I}^{\sigma^{2}, r}$ & - & - & - & - & - & - & - & - \\
\hline$f_{M U L T}^{\sigma^{2}, r}$ & $7.83 \%$ & $15.52 \%$ & 0.505 & $0.36 \%$ & 0.102 & 0.035 & $1.15 \%$ & 0.644 \\
\hline$f \equiv H i g h B A S I S-M O M$ & $10.20 \%$ & $15.58 \%$ & 0.655 & - & - & - & $4.31 \%$ & - \\
\hline$f^{\sigma^{2}}$ & $10.56 \%$ & $15.58 \%$ & 0.678 & $2.11 \%$ & 0.098 & 0.214 & $5.67 \%$ & 0.341 \\
\hline$f_{\text {histavg }}^{\sigma^{2}, r}$ & $9.67 \%$ & $15.58 \%$ & 0.621 & $1.02 \%$ & 0.098 & 0.104 & $4.56 \%$ & 0.706 \\
\hline$f_{\text {poolavg }}^{\sigma^{2}, r}$ & - & - & - & - & - & - & - & - \\
\hline$f_{D I}^{\sigma^{2}, r}$ & - & - & - & - & - & - & - & - \\
\hline$f_{M U L T}^{\sigma^{2}, r}$ & $8.79 \%$ & $15.58 \%$ & 0.564 & $0.45 \%$ & 0.112 & 0.040 & $4.84 \%$ & 0.274 \\
\hline$f \equiv H i g h H P$ & $5.01 \%$ & $16.61 \%$ & 0.302 & - & - & - & $-2.07 \%$ & - \\
\hline$f^{\sigma^{2}}$ & $4.74 \%$ & $16.61 \%$ & 0.285 & $1.16 \%$ & 0.101 & 0.115 & $-2.08 \%$ & 0.900 \\
\hline$f_{\text {histavg }}^{\sigma^{2}, r}$ & $3.52 \%$ & $16.61 \%$ & 0.212 & $-0.27 \%$ & 0.095 & -0.029 & $-3.45 \%$ & 0.653 \\
\hline$f_{\text {poolavg }}^{\sigma^{2}, r}$ & - & - & - & - & - & - & - & - \\
\hline$f_{D I}^{\sigma^{2}, r}$ & - & - & - & - & - & - & - & - \\
\hline$f_{M U L T}^{\sigma^{2}, r}$ & $3.65 \%$ & $16.61 \%$ & 0.220 & $0.38 \%$ & 0.100 & 0.038 & $-3.01 \%$ & 0.907 \\
\hline$f \equiv H i g h \quad V A L U E$ & $3.86 \%$ & $14.89 \%$ & 0.260 & - & - & - & $-1.64 \%$ & - \\
\hline$f^{\sigma^{2}}$ & $5.83 \%$ & $14.89 \%$ & 0.391 & $2.41 \% *$ & 0.081 & $29.67 \%$ & $0.45 \%$ & 0.213 \\
\hline$f_{\text {histavg }}^{\sigma^{2}, r}$ & $4.63 \%$ & $14.89 \%$ & 0.311 & $1.26 \%$ & 0.080 & 0.156 & $-0.82 \%$ & 0.657 \\
\hline$f_{\text {poolavg }}^{\sigma^{2}, r}$ & - & - & - & - & - & - & - & - \\
\hline$f_{D I}^{\sigma^{2}, r}$ & - & - & - & - & - & - & - & - \\
\hline$f_{M U L T}^{\sigma^{2}, r}$ & $4.34 \%$ & $14.89 \%$ & 0.292 & $1.14 \%$ & 0.087 & 0.131 & $-1.11 \%$ & 0.834 \\
\hline
\end{tabular}




\begin{tabular}{|c|c|c|c|c|c|c|c|c|}
\hline \multicolumn{9}{|c|}{$\begin{array}{c}\text { Table IA10. Return-forecast and Variance Managed for the Long-Only Commodity Po } \\
\text { Panel C. Predictor variables: Factor Exposure Spreads }\end{array}$} \\
\hline & Mean & SD & SR & Alpha & se & $\begin{array}{c}\text { Appraisal } \\
\text { Ratio }\end{array}$ & CER & $\begin{array}{l}\text { p-value } \\
(\triangle C E R)\end{array}$ \\
\hline$f \equiv$ High MOM & $8.44 \%$ & $18.50 \%$ & 0.456 & - & - & - & $-0.98 \%$ & - \\
\hline$f^{\sigma^{2}}$ & $7.98 \%$ & $18.50 \%$ & 0.431 & $1.60 \%$ & 0.132 & 0.121 & $-2.90 \%$ & 0.524 \\
\hline$f_{\text {histavg }}^{\sigma^{2}, r}$ & $7.28 \%$ & $18.50 \%$ & 0.393 & $0.71 \%$ & 0.127 & 0.056 & $-2.60 \%$ & 0.669 \\
\hline$f_{\text {poolavg }}^{\sigma^{2}, r}$ & - & - & - & - & - & - & - & - \\
\hline$f_{D I}^{\sigma^{2}, r}$ & - & - & - & - & - & - & - & - \\
\hline$f_{M U L T}^{\sigma^{2}, r}$ & $6.95 \%$ & $18.50 \%$ & 0.376 & $0.49 \%$ & 0.129 & 0.038 & $-2.91 \%$ & 0.659 \\
\hline$f \equiv$ Low BASIS & $8.35 \%$ & $15.52 \%$ & 0.538 & - & - & - & $2.01 \%$ & - \\
\hline$f^{\sigma^{2}}$ & $10.20 \%$ & $15.52 \%$ & 0.658 & $2.61 \% *$ & 0.089 & 0.293 & $4.44 \%$ & 0.351 \\
\hline$f_{\text {histavg }}^{\sigma^{2}, r}$ & $9.09 \%$ & $15.52 \%$ & 0.586 & $1.28 \%$ & 0.091 & 0.141 & $3.09 \%$ & 0.693 \\
\hline$f_{\text {poolavg }}^{\sigma^{2}, r}$ & - & - & - & - & - & - & - & - \\
\hline$f_{D I}^{\sigma^{2}, r}$ & - & - & - & - & - & - & - & - \\
\hline$f_{M U L T}^{\sigma^{2}, r}$ & $8.28 \%$ & $15.52 \%$ & 0.534 & $1.16 \%$ & 0.110 & 0.106 & $2.43 \%$ & 0.882 \\
\hline$f \equiv \operatorname{High} B A S I S-M O M$ & $10.20 \%$ & $15.58 \%$ & 0.655 & - & - & - & $4.31 \%$ & - \\
\hline$f^{\sigma^{2}}$ & $10.56 \%$ & $15.58 \%$ & 0.678 & $2.11 \%$ & 0.098 & 0.214 & $5.67 \%$ & 0.341 \\
\hline$f_{\text {histavg }}^{\sigma^{2}, r}$ & $9.67 \%$ & $15.58 \%$ & 0.621 & $1.02 \%$ & 0.098 & 0.104 & $4.56 \%$ & 0.706 \\
\hline$f_{\text {poolavg }}^{\sigma^{2}, r}$ & - & - & - & - & - & - & - & - \\
\hline$f_{D I}^{\sigma^{2}, r}$ & - & - & - & - & - & - & - & - \\
\hline$f_{M U L T}^{\sigma^{2}, r}$ & $9.78 \%$ & $15.58 \%$ & 0.628 & $1.27 \%$ & 0.102 & 0.124 & $4.35 \%$ & 0.986 \\
\hline$f \equiv H i g h H P$ & $5.01 \%$ & $16.61 \%$ & 0.302 & - & - & - & $-2.07 \%$ & - \\
\hline$f^{\sigma^{2}}$ & $4.74 \%$ & $16.61 \%$ & 0.285 & $1.16 \%$ & 0.101 & 0.115 & $-2.08 \%$ & 0.900 \\
\hline$f_{\text {histavg }}^{\sigma^{2}, r}$ & $3.52 \%$ & $16.61 \%$ & 0.212 & $-0.27 \%$ & 0.095 & -0.029 & $-3.45 \%$ & 0.653 \\
\hline$f_{\text {poolavg }}^{\sigma^{2}, r}$ & - & - & - & - & - & - & - & - \\
\hline$f_{D I}^{\sigma^{2}, r}$ & - & - & - & - & - & - & - & - \\
\hline$f_{M U L T}^{\sigma^{2}, r}$ & $2.81 \%$ & $16.61 \%$ & 0.169 & $-0.35 \%$ & 0.106 & -0.033 & $-3.94 \%$ & 0.646 \\
\hline$f \equiv$ High $V A L U E$ & $3.86 \%$ & $14.89 \%$ & 0.260 & - & - & - & $-1.64 \%$ & - \\
\hline$f^{\sigma^{2}}$ & $5.83 \%$ & $14.89 \%$ & 0.391 & $2.41 \% *$ & 0.081 & $29.67 \%$ & $0.45 \%$ & 0.213 \\
\hline$f_{\text {histavg }}^{\sigma^{2}, r}$ & $4.63 \%$ & $14.89 \%$ & 0.311 & $1.26 \%$ & 0.080 & 0.156 & $-0.82 \%$ & 0.657 \\
\hline$f_{\text {poolavg }}^{\sigma^{2}, r}$ & - & - & - & - & - & - & - & - \\
\hline$f_{D I}^{\sigma^{2}, r}$ & - & - & - & - & - & - & - & - \\
\hline$f_{M U L T}^{\sigma^{2}, r}$ & $4.34 \%$ & $14.89 \%$ & 0.292 & $1.14 \%$ & 0.087 & 0.131 & $-1.11 \%$ & 0.834 \\
\hline
\end{tabular}


Table IA10. Return-forecast and Variance Managed for the Long-Only Commodity Portfolios (Cont'd)

Panel D. Predictor variables: commodity specific \& macroeconomic variables, factor valuation spreads and factor

\begin{tabular}{|c|c|c|c|c|c|c|c|c|}
\hline & Mean & SD & SR & Alpha & se & $\begin{array}{c}\text { Appraisal } \\
\text { Ratio }\end{array}$ & CER & $\begin{array}{l}\text { p-value } \\
(\triangle C E R)\end{array}$ \\
\hline$f \equiv \operatorname{High} M O M$ & $8.44 \%$ & $18.50 \%$ & 0.456 & - & - & - & $-0.98 \%$ & - \\
\hline$f^{\sigma^{2}}$ & $7.98 \%$ & $18.50 \%$ & 0.431 & $1.60 \%$ & 0.132 & 0.121 & $-2.90 \%$ & 0.524 \\
\hline$f_{\text {histavg }}^{\sigma^{2}, r}$ & $7.28 \%$ & $18.50 \%$ & 0.393 & $0.71 \%$ & 0.127 & 0.056 & $-2.60 \%$ & 0.669 \\
\hline$f_{\text {poolavg }}^{\sigma^{2}, r}$ & $7.42 \%$ & $18.50 \%$ & 0.401 & $0.67 \%$ & 0.125 & 0.053 & $-2.19 \%$ & 0.771 \\
\hline$f_{D I}^{\sigma^{2}, r}$ & $7.83 \%$ & $18.50 \%$ & 0.423 & $1.40 \%$ & 0.128 & 0.109 & $-1.42 \%$ & 0.970 \\
\hline$f_{M U L T}^{\sigma^{2}, r}$ & $6.00 \%$ & $18.50 \%$ & 0.324 & $0.50 \%$ & 0.153 & 0.033 & $-3.65 \%$ & 0.628 \\
\hline$f \equiv$ Low BASIS & $8.35 \%$ & $15.52 \%$ & 0.538 & - & - & - & $2.01 \%$ & - \\
\hline$f^{\sigma^{2}}$ & $10.20 \%$ & $15.52 \%$ & 0.658 & $2.61 \% *$ & 0.089 & 0.293 & $4.44 \%$ & 0.351 \\
\hline$f_{\text {histavg }}^{\sigma^{2}, r}$ & $9.09 \%$ & $15.52 \%$ & 0.586 & $1.28 \%$ & 0.091 & 0.141 & $3.09 \%$ & 0.693 \\
\hline$f_{\text {poolavg }}^{\sigma^{2}, r}$ & $9.15 \%$ & $15.52 \%$ & 0.590 & $1.31 \%$ & 0.095 & 0.144 & $3.22 \%$ & 0.655 \\
\hline$f_{D I}^{\sigma^{2}, r}$ & $8.29 \%$ & $15.52 \%$ & 0.535 & $1.87 \%$ & 0.120 & 0.156 & $1.74 \%$ & 0.743 \\
\hline$f_{M U L T}^{\sigma^{2}, r}$ & $5.78 \%$ & $15.52 \%$ & 0.373 & $1.63 \%$ & 0.137 & 0.119 & $-0.30 \%$ & 0.649 \\
\hline$f \equiv \operatorname{High} B A S I S-M O M$ & $10.20 \%$ & $15.58 \%$ & 0.655 & - & - & - & $4.31 \%$ & - \\
\hline$f^{\sigma^{2}}$ & $10.56 \%$ & $15.58 \%$ & 0.678 & $2.11 \%$ & 0.098 & 0.214 & $5.67 \%$ & 0.341 \\
\hline$f_{\text {histavg }}^{\sigma^{2}, r}$ & $9.67 \%$ & $15.58 \%$ & 0.621 & $1.02 \%$ & 0.098 & 0.104 & $4.56 \%$ & 0.706 \\
\hline$f_{\text {poolavg }}^{\sigma^{2}, r}$ & $9.67 \%$ & $15.58 \%$ & 0.621 & $1.03 \%$ & 0.100 & 0.103 & $4.61 \%$ & 0.696 \\
\hline$f_{D I}^{\sigma^{2}, r}$ & $9.35 \%$ & $15.58 \%$ & 0.600 & $1.55 \%$ & 0.117 & 0.132 & $4.36 \%$ & 0.810 \\
\hline$f_{M U L T}^{\sigma^{2}, r}$ & $7.55 \%$ & $15.58 \%$ & 0.485 & $0.32 \%$ & 0.123 & 0.026 & $2.38 \%$ & 0.670 \\
\hline$f \equiv H i g h H P$ & $5.01 \%$ & $16.61 \%$ & 0.302 & - & - & - & $-2.07 \%$ & - \\
\hline$f^{\sigma^{2}}$ & $4.74 \%$ & $16.61 \%$ & 0.285 & $1.16 \%$ & 0.101 & 0.115 & $-2.08 \%$ & 0.900 \\
\hline$f_{\text {histavg }}^{\sigma^{2}, r}$ & $3.52 \%$ & $16.61 \%$ & 0.212 & $-0.27 \%$ & 0.095 & -0.029 & $-3.45 \%$ & 0.653 \\
\hline$f_{\text {poolavg }}^{\sigma^{2}, r}$ & $5.02 \%$ & $16.61 \%$ & 0.302 & $1.44 \%$ & 0.098 & 0.147 & $-.171 \%$ & 0.745 \\
\hline$f_{D I}^{\sigma^{2}, r}$ & $6.91 \%$ & $16.61 \%$ & 0.416 & $5.28 \%$ & 0.131 & 0.405 & $0.54 \%$ & 0.268 \\
\hline$f_{M U L T}^{\sigma^{2}, r}$ & $3.85 \%$ & $16.61 \%$ & 0.232 & $0.95 \%$ & 0.138 & 0.069 & $-3.44 \%$ & 0.588 \\
\hline$f \equiv H i g h \quad V A L U E$ & $3.86 \%$ & $14.89 \%$ & 0.260 & - & - & - & $-1.64 \%$ & - \\
\hline$f^{\sigma^{2}}$ & $5.83 \%$ & $14.89 \%$ & 0.391 & $2.41 \% *$ & 0.081 & $29.67 \%$ & $0.45 \%$ & 0.213 \\
\hline$f_{\text {histavg }}^{\sigma^{2}, r}$ & $4.63 \%$ & $14.89 \%$ & 0.311 & $1.26 \%$ & 0.080 & 0.156 & $-0.82 \%$ & 0.657 \\
\hline$f_{\text {poolavg }}^{\sigma^{2}, r}$ & $4.79 \%$ & $14.89 \%$ & 0.322 & $1.46 \%$ & 0.085 & 0.172 & $-0.56 \%$ & 0.466 \\
\hline$f_{D I}^{\sigma^{2}, r}$ & $5.37 \%$ & $14.89 \%$ & 0.361 & $2.55 \%$ & 0.113 & 0.225 & $0.03 \%$ & 0.480 \\
\hline$f_{M U L T}^{\sigma^{2}, r}$ & $3.46 \%$ & $14.89 \%$ & 0.232 & $1.69 \%$ & 0.132 & 0.128 & $-1.66 \%$ & 0.918 \\
\hline
\end{tabular}

